\title{
WestVirginiaUniversity
}

THE RESEARCH REPOSITORY @ WVU

Graduate Theses, Dissertations, and Problem Reports

2015

\section{Spirituality, Help-seeking Attitude, and Black Women: A Qualitative Study}

Pamela LaShe Jackson

Follow this and additional works at: https://researchrepository.wvu.edu/etd

\section{Recommended Citation}

Jackson, Pamela LaShe, "Spirituality, Help-seeking Attitude, and Black Women: A Qualitative Study" (2015). Graduate Theses, Dissertations, and Problem Reports. 5868.

https://researchrepository.wvu.edu/etd/5868

This Dissertation is protected by copyright and/or related rights. It has been brought to you by the The Research Repository @ WVU with permission from the rights-holder(s). You are free to use this Dissertation in any way that is permitted by the copyright and related rights legislation that applies to your use. For other uses you must obtain permission from the rights-holder(s) directly, unless additional rights are indicated by a Creative Commons license in the record and/ or on the work itself. This Dissertation has been accepted for inclusion in WVU Graduate Theses, Dissertations, and Problem Reports collection by an authorized administrator of The Research Repository @ WVU.

For more information, please contact researchrepository@mail.wvu.edu. 
Spirituality, Help-seeking Attitude, and Black Women: A Qualitative Study

Pamela LaShé Jackson

\begin{abstract}
Dissertation submitted to the College of Education and Human Services at West Virginia University in partial fulfillment of the requirements for the degree of
\end{abstract}

Doctor of Philosophy/
in
Counseling Psychology

James W. Bartee, Ph. D., Chair Jeffrey Daniels, Ph. D.

Christine Schimmel, Ed. D. Charline Barnes-Rowland, Ed. D. Christina Wilson, Ph.D.

Department of Counseling, Rehabilitation Counseling, and Counseling Psychology

\author{
Morgantown, West Virginia \\ 2015
}

Keywords: Black Women; Therapy; Spirituality; Help-seeking Attitude; Interpretative Phenomenological Analysis Copyright 2015 Pamela L. Jackson 


\section{ABSTRACT \\ Spirituality, Help-seeking Attitude, and Black Women: A Qualitative Study}

\section{Pamela L. Jackson}

A semi-structured interview was used to survey help-seeking attitude via questions about spirituality, therapy, and the connections between the two. Interpretative Phenomenological Analysis (IPA) was used to provide a framework for understanding how these factors potentially effect professional help-seeking attitudes in Black women and the role spirituality plays in developing help-seeking attitudes and the potential effect on professional psychological help. Ten interviews were conducted with Black women who lived or went to church in Akron, Ohio. Data from nine study participants were used and seven super-ordinate themes were found. The themes identified were as follows: 1) awareness and access; 2) God is enough; 3) informal therapy; 4) relationships; 5) spirituality; 6); therapy as a resource; and 7) upbringing. The findings suggested spirituality has a major impact on help-seeking attitude, the development of help-seeking attitude, and potentially help-seeking behavior. Additionally, the significance of spirituality was evident in how participants discussed other themes, suggesting spirituality was intricately woven throughout the lived experience of the women. These findings are significant for clinicians who work with Black women who endorse spirituality as important in their lives and who uses spirituality as a psychological resource. The results provided a reference point for discussion and exploration about how spiritual factor are used in stressful times; and, whether or not the client has supplemented therapeutic approaches with spirituality. This is important as it could allow therapist to understand the efficacy of the strategies used with Black women or if those strategies, unbeknownst to the therapist, were being supplemented with elements of 
spirituality. Several questions surfaced based on the findings that may provide a foundation for future studies. Recommendations were made for moving this line of inquiry forward. 


\section{TABLE OF CONTENTS}

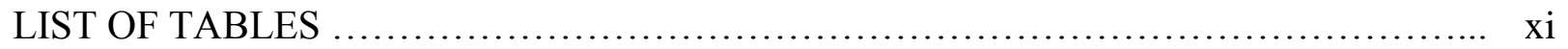

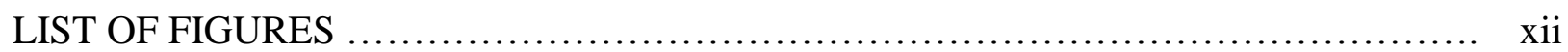

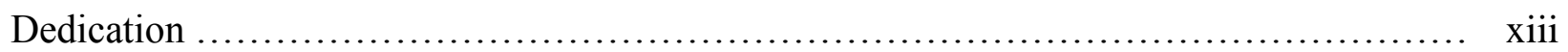

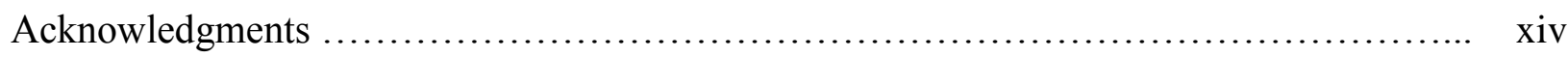

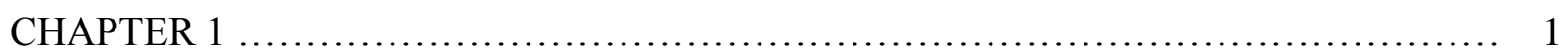

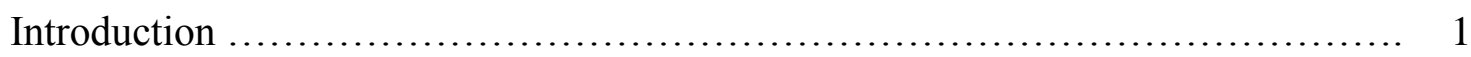

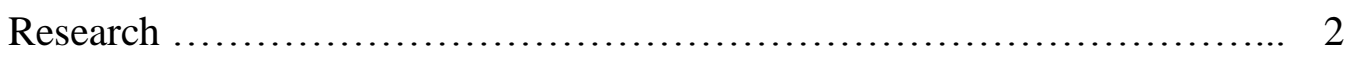

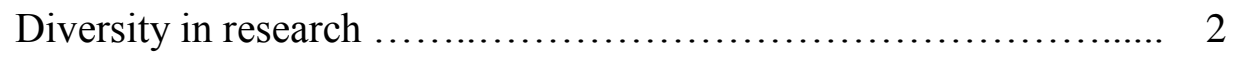

Research guidelines ..................................... 4

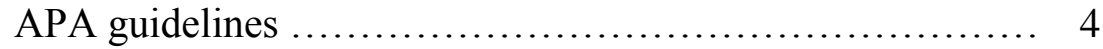

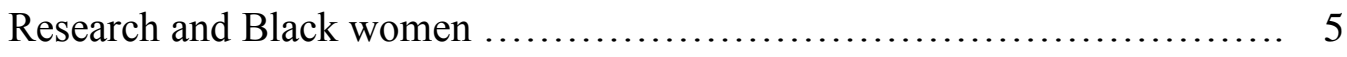

Mental health in the Black community $\ldots \ldots \ldots \ldots \ldots \ldots \ldots \ldots \ldots \ldots \ldots \ldots, 6$

Obstacles to seeking mental health services ................... 6

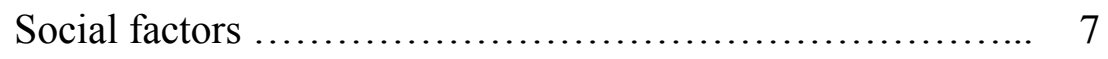

Treatment factors $\ldots \ldots \ldots \ldots \ldots \ldots \ldots \ldots \ldots \ldots \ldots \ldots \ldots \ldots, 8$

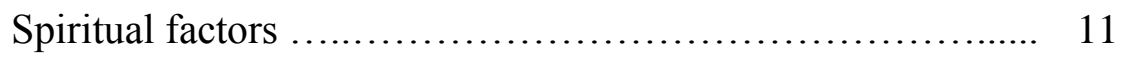

Diversity in the profession of psychology $\ldots \ldots \ldots \ldots \ldots \ldots \ldots \ldots \ldots \ldots \ldots \ldots, 11$

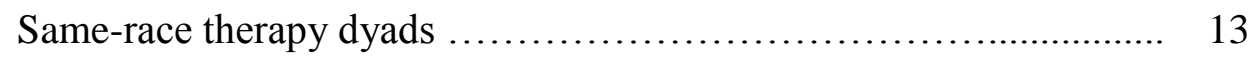

Mental health service utilization ..................................... 14

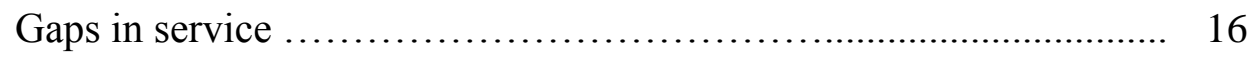

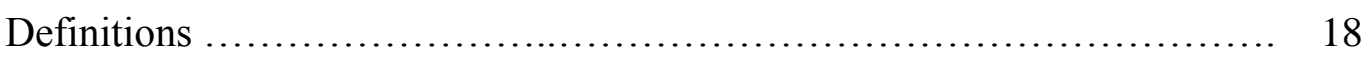

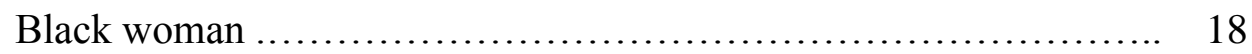


Help-seeking................................................... 18

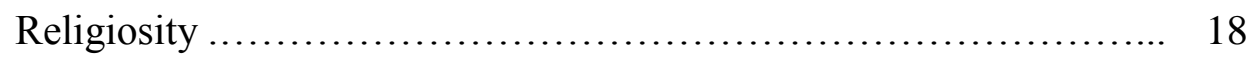

Spirituality ................................................. 18

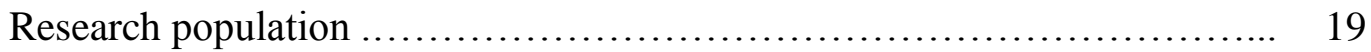

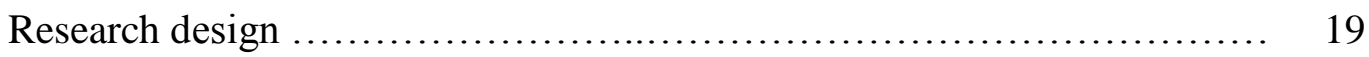

Research questions ................................................. 19

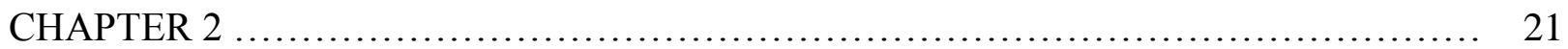

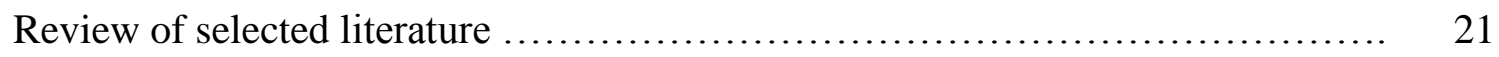

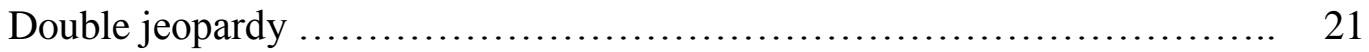

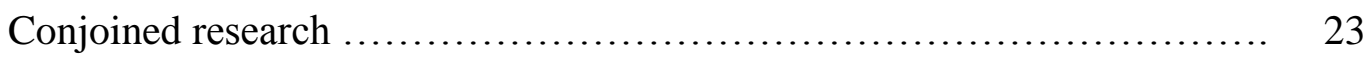

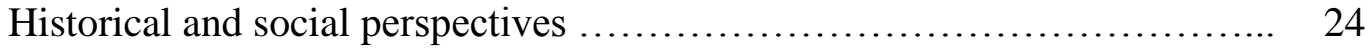

Black women and strength ................................... 24

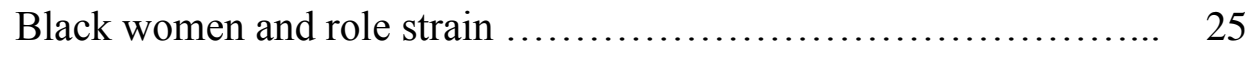

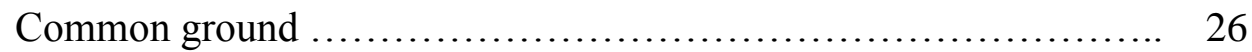

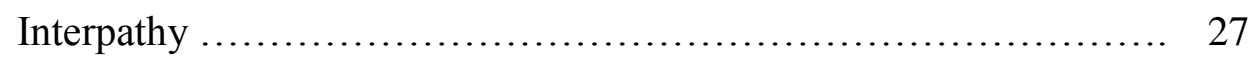

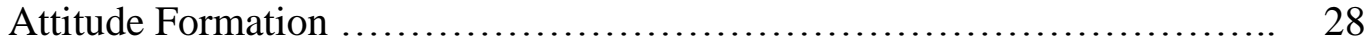

Definition .................................................... 28

Attitude research ................................................ 29

Schools of thought in attitude research .................... 30

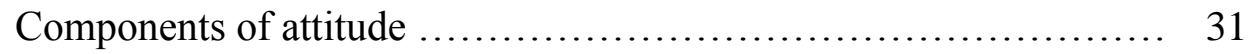

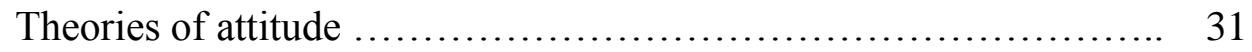

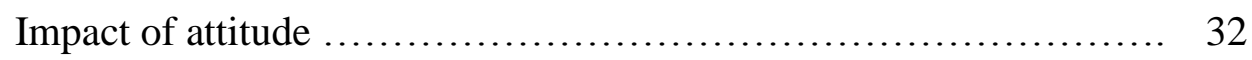

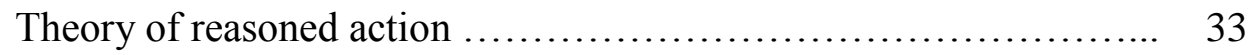




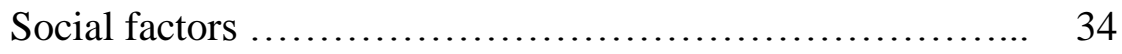

Personal factors ...................................... 34

Causal relationships ...................................... 35

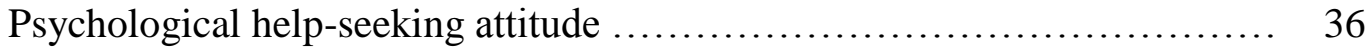

Help seeking ................................................ 37

Definition ...................................................... 39

Implications for current study $\ldots \ldots \ldots \ldots \ldots \ldots \ldots \ldots \ldots \ldots \ldots, 40$

Help-seeking attitudes and people of color .......................... 40

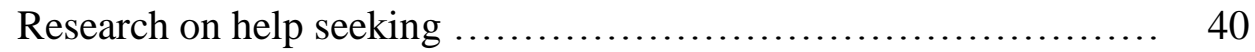

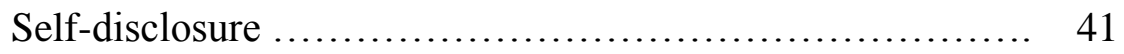

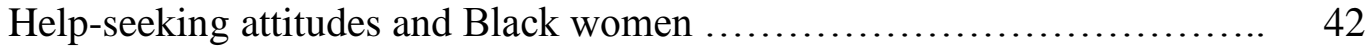

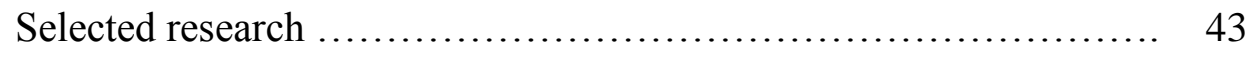

Methods .............................................. 44

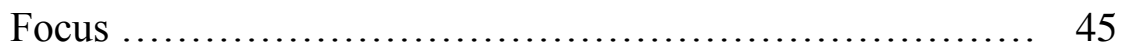

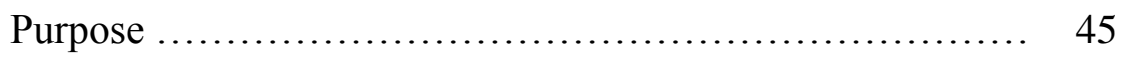

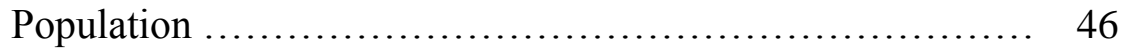

Results ................................................. 46

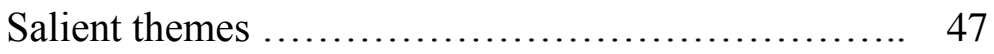

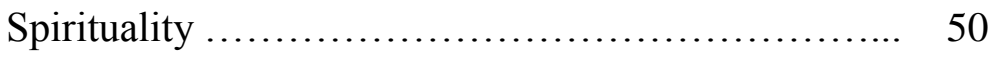

Research connections ................................. 51

Summation ................................................. 52

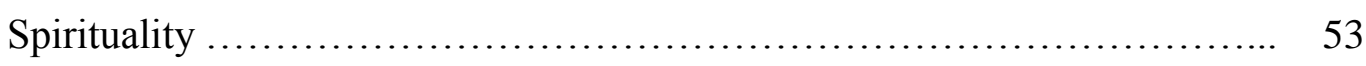

Overview ...................................................... 53 


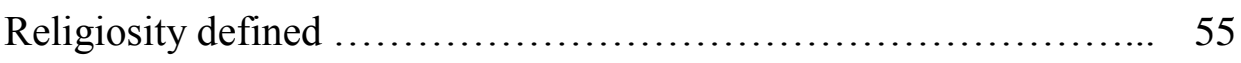

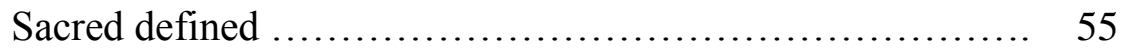

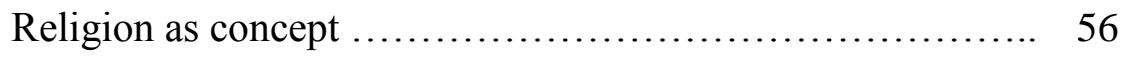

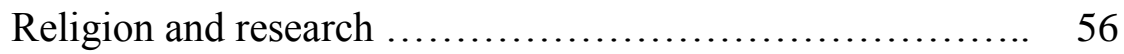

Extrinsic religion .............................. 57

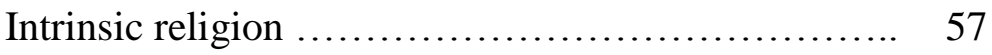

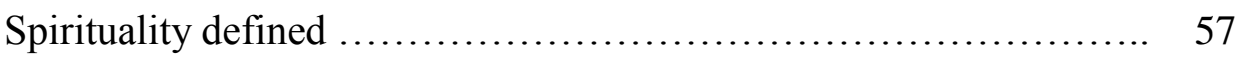

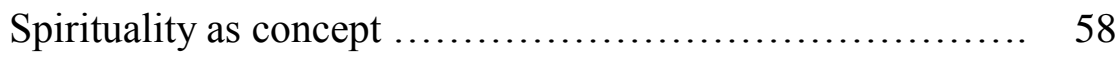

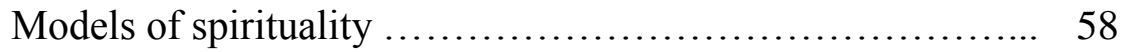

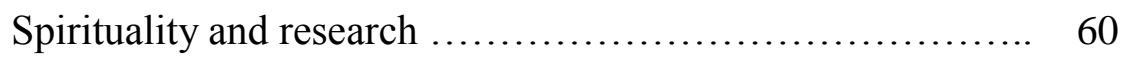

Cultural factors in research ........................ 61

Spirituality and mental health ...................... 61

Spirituality and Black women .................... 62

Role of the Black church .......................... 62

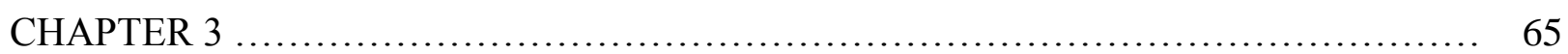

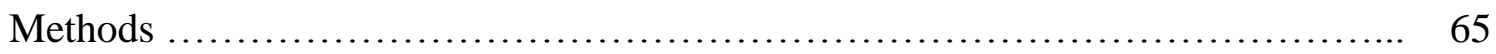

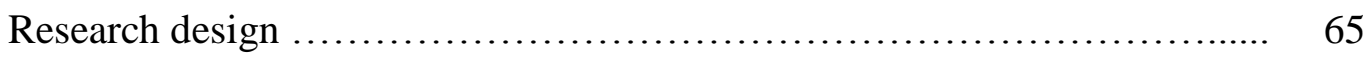

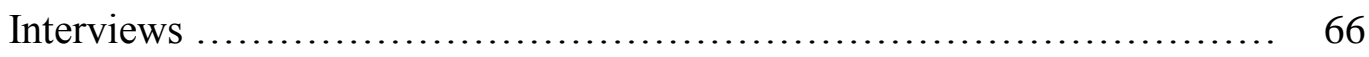

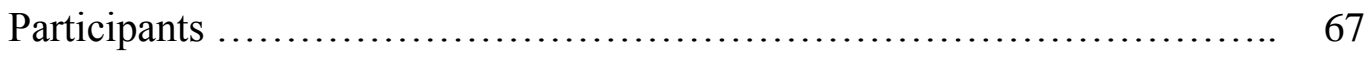

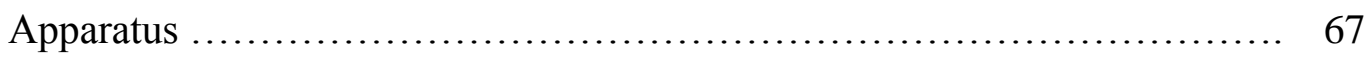

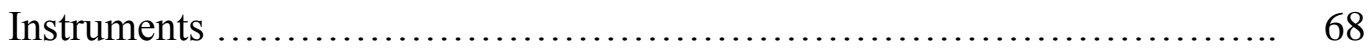

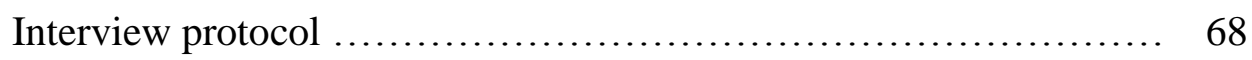

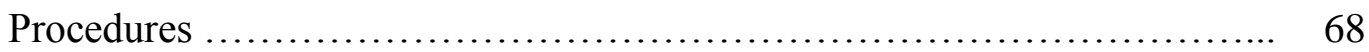




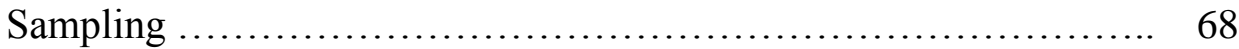

Participant interview ...................................... 71

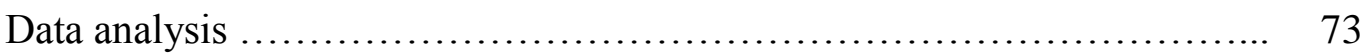

Transcript analysis ............................................ 74

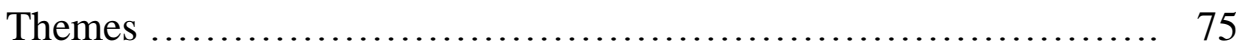

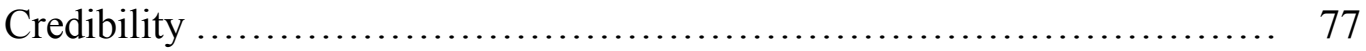

Trustworthiness ....................................................... 78

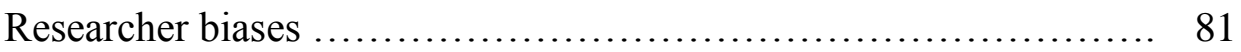

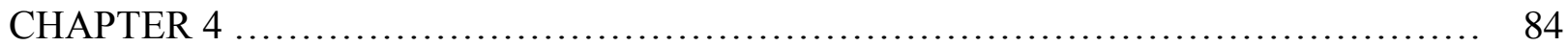

Results ........................................................................... 84

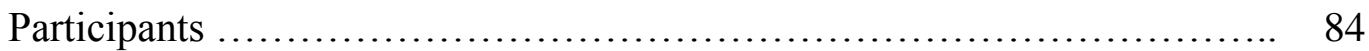

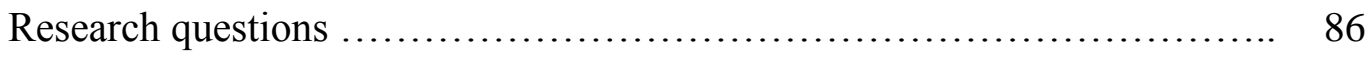

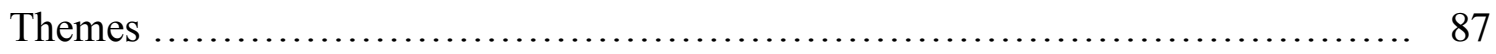

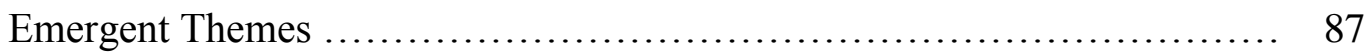

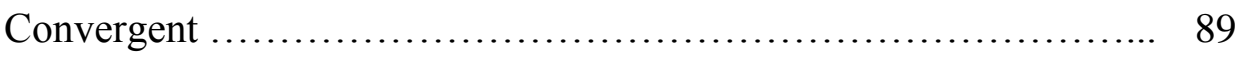

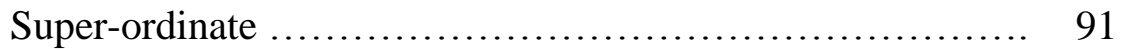

Awareness and access .............................. 93

Upbringing .................................... 100

Spirituality .................................... 105

God is enough ................................. 109

Therapy as resource $\ldots \ldots \ldots \ldots \ldots \ldots \ldots \ldots \ldots \ldots \ldots, 110$

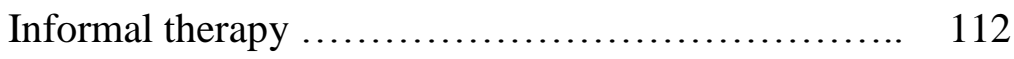

Relationships ................................... 117 


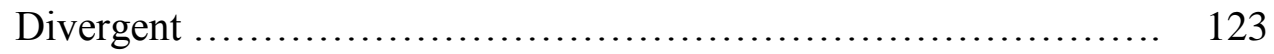

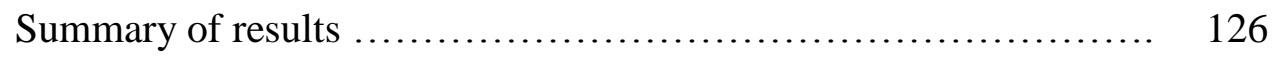

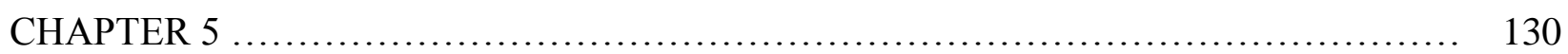

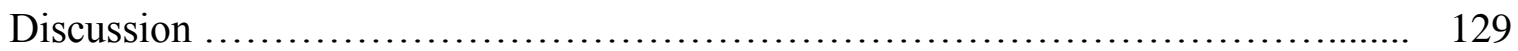

Results ...................................................... 129

Beliefs and thoughts about seeking professional psychological services

The role of spirituality in shaping help-seeking attitudes in Black women

Limitations and strengths of the study ................................ 138

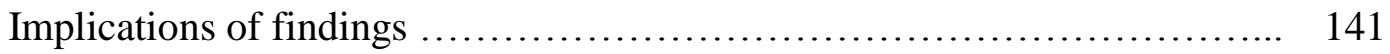

Clinical recommendations ............................................. 146

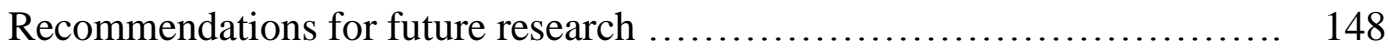

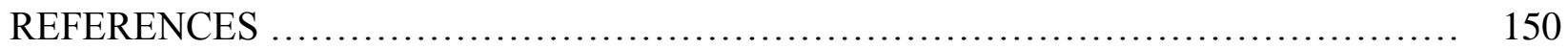

APPENDICES [....................................................................... 168

Appendix A: Interview Protocol ............................................. 169

Appendix B: Letter of Recruitment ....................................... 170

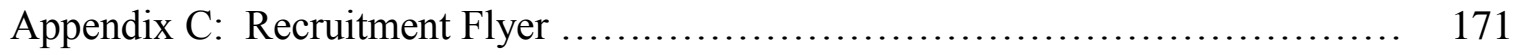

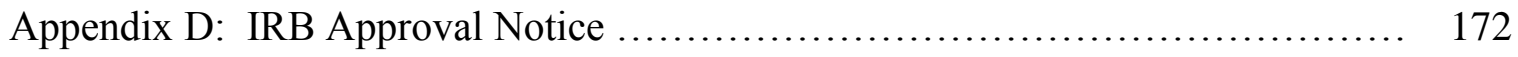

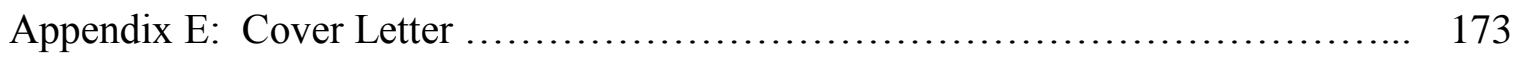

Appendix F: Demographic Questionnaire ................................. 176

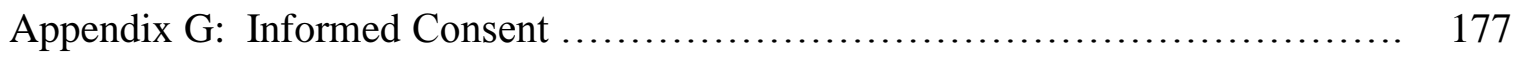

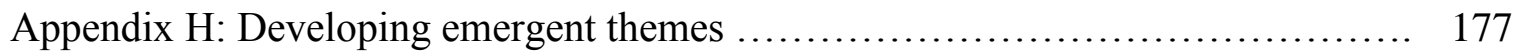




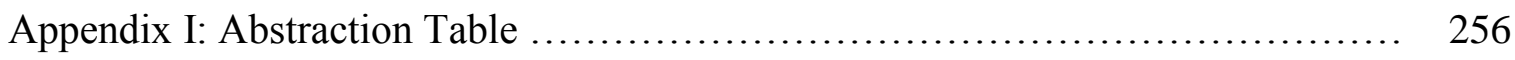




\section{LIST OF TABLES}

Page

Table 1. Utilization of Clergy vs. Traditional Mental Health Services .................. 64

Table 2. Demographic Features …............................................. 85

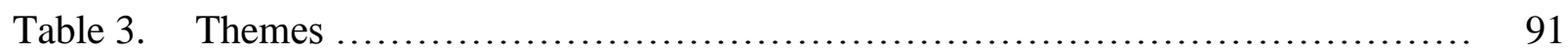

Table 4. Recurrent Themes ................................................... 92 


\section{LIST OF FIGURES}

Page

Figure 1. Factors impacting help-seeking attitudes in racial/ethnic populations ......... 41

Figure 2. The Koenig Spirituality Model $\ldots \ldots \ldots \ldots \ldots \ldots \ldots \ldots \ldots \ldots \ldots \ldots \ldots \ldots \ldots . . \ldots 0$

Figure 3. The Holmes, Hardin/Hill, and Pargament Spirituality Model .............. 60

Figure 4. The Allport/Kahoe Spirituality Model $\ldots \ldots \ldots \ldots \ldots \ldots \ldots \ldots \ldots \ldots \ldots \ldots \ldots \ldots . \quad 60$ 


\section{DEDICATION}

To the One I love; Whom without, I would cease to be... 


\section{ACKNOWLEDGMENT}

Betty L. Dixon Bennett

James W. Bartee, Ph.D.

Bishop F. Josephus (Joey) Johnson

Juanita K. Martin, Ph.D.

Suzette Speight, Ph. D

Kardia, Charis, Timios

Family and Friends

The Faith Community

The Participants and Black Women Everywhere

Those above, I thank with all of my heart for your love, support, encouragement, and belief in my ability to accomplish this task and move into what God has ordained. For YOU all, I am eternally grateful... 


\section{CHAPTER 1}

\section{Introduction}

In this study, I hope to show that African-American women underutilize needed mental health services due to a number of social, historical, and psychological concerns. The reasons for this have not received adequate study in the past, as the literature review will demonstrate. It is my intention to add to our understanding and knowledge regarding why Black women may avoid seeking and receiving psychological help.

In 2002, the American Psychological Association (APA) released Guidelines on Multicultural Education, Training, Research, Practice, and Organizational Change for Psychologist. "A number of academics have voiced concerns about the cultural limitations of psychological research in the United States" (APA, 2002) implying a need for change in psychological research practices. APA states "although scholars began to heed the call for culturally diverse samples in research, many research samples continue to be predominantly White and middle class with people of color underrepresented in these samples" (APA, 2002). While the historical challenges endured by those in America of African descent is a difficult and often painful conversation, it is essential in understanding the evolution of Black women's emerging roles as heads of households.

The U.S. Department of Commerce Economics and Statistics Administration Bureau of the Census (2013) provided documents and briefs on "findings from Census 2000, current demographic surveys, and the 1997 Economic Census... Prior to November 1996, the Census Briefs were called the Statistical Briefs" which highlighted information the Census Bureau considered relevant. Statistical Brief Black Americans: A Profile, the U.S. Department of 
Commerce Economics and Statistics Administration Bureau of the Census (1993) are a part of these documents.

In Statistical Brief Black Americans: A Profile, the U.S. Department of Commerce Economics and Statistics Administration Bureau of the Census (1993) states from 1970-1980 single family households led by Black women increased from $28 \%$ to $40 \%$. In the 2002 Black Population in the United States study, $43 \%$ of single-parent households were headed by Black women (U.S. Department of Commerce Economics and Statistics Administration Bureau of the Census, 2003). Most recently, the U.S. Department of Commerce Economics and Statistics Administration Bureau of the Census (2012) identified that approximately $50 \%$ of Black children live with their biological mothers. The trend of Black families being led, disproportionately, by Black women continues to rise. Although it has been well over a decade since the APA (2002) called for increased diversity within psychological research, as will be shown, there remains a dearth of studies focused on communities of color in America as compared to White American culture.

\section{Research.}

Diversity in research. Most research studies have consistently investigated from Eurocentric and White American perspectives, suggesting a bent toward these perspectives in the development of psychological theories (Alderfer, 1994; APA, 2002; Dana, 2002; Howitt \& Owusu-Bempah, 1994; Sue, 1999). Furthermore, when research from Eurocentric perspectives are treated as psychological absolutes in considering people of varying race and ethnicities, the distinctions between different groups of people are lost (Owusu-Bempah, 1994). The assumption that theories and principles apply across humanity is misleading. This distortion is even more prominent when research is conducted with specific populations then related to other populations 
without adequate support to substantiate the application. Yet, as this trend continues, it seems to decrease the opportunity to survey subtle difference among ethnic and racial populations and between Black women and men and American Whites. Additionally, variation in life experiences or cultural contexts among and within the groups studied is not accessed. It seems natural to explore the experiences of African Americans as a means to provide insight and understanding of the experiences of this population, and particularly, Black women.

To further complicate matters, West (1995), who cited Bell, Bland, Houston, and Jones, (1983), Green (1985), and Thomas and Sillen (1972) implied negative stereotypes of diverse populations are, at times, incorporated into therapy and research. Perceived stereotypes can then go on to shape how research is carried out (Guthrie, 1988). This becomes problematic in scientific research. Especially, if the components of a research study are skewed before the investigation begins. Partiality in research and service administration (Dana, 2002) impacts availability of services, quality of assessment, and clinical diagnoses for people of color. It is considered bias when psychological services are applied in ways that assume African Americans experience and respond to life stressors in ways that are similar to Whites (Dana, 2002). Again, this assertion contributes to bias in therapy by conducted European Americans among people of color (Dana, 2002).

Awareness of restrictive research practices and prejudices may affect how psychological services are conceptualized and utilized by racial and ethnic groups. This awareness may decrease positive development of help-seeking attitudes. While the lack of research on helpseeking attitude of people of color is expected, it may also explain the underutilization of services by underrepresented populations, including those studied here. This claim advocates for a variety of strategies to be implemented to ensure diversity in therapeutic practices and research. 
Research guidelines. Conducting research without guidelines to help shape the research process, including how research is written, is dangerous given it lends itself to creating "otherness" and possibly a "them versus us" attitude (Olesen, 2000) while, maintaining a flawed view of non-White populations. 'Othering' or otherness speaks to the oppressive practices, definitions, and marginalized identities that can be produced by research (Denzin \& Lincoln, 2005; Olesen, 2000; Van Den Tillaart, Kurtz, \& Cash, 2009). Olesen (2000) proposes the power wielded by the researcher can be misused; especially, since the responsibility of how these encounters are constructed primarily lay with the researcher.

Guiding principles specific to diverse populations limits the generalizability across race and ethnicity in research. This premise can potentially reduce the concerns reported by Logan (2007). Logan (2007) asserted that sociocultural structures and practices in the United States shape mental health and mental illness experienced by Blacks. Mental health is defined "as a stable internal state of mind" and mental illness as "all diagnosable mental disorders or health conditions that are characterized by alterations in thinking, mood, or behaviors associated with distress and/or impaired functioning" (Logan, 2007, p. 43). Therefore, if research guidelines are matched to the population being studied, the role of sociocultural factors and the impact of oppressive practices can be lessened.

APA research guidelines. The American Psychological Association (2002) offers guidelines that facilitate consideration of race and ethnicity in research. The Multicultural Guidelines (APA, 2002) provides leadership in examining these concerns. The focus of the Multicultural Guidelines (APA, 2002) lends credibility to conducting research that focuses on Black women. The goals of the Multicultural Guidelines (APA, 2002) provide psychologist with several things: 
" (a) the rationale and needs for addressing multiculturalism and diversity in education, training, research, practice, and organizational change; (b) basic information, relevant terminology, current empirical research from psychology and related disciplines, and other data that support the proposed guidelines and underscore their importance; (c) references to enhance on-going education, training, research, practice, and organizational change methodologies; and (d) paradigms that broaden the purview of psychology as a profession" (p. 1)

These goals are found to be specific to this study. These goals along with the statistical information gathered by the Census Bureau (U.S. Department of Commerce Economics and Statistics Administration Bureau of the Census, 1993, 2003, 2012) provide further credence for conducting research that focuses on Black women.

Research and Black women. To further support this claim, a general search of "research on Black women" was conducted using Academic Search Complete, which is a part of EBSCO Industries (2012). Academic Search Complete is widely used by researchers and is consistent in meeting scholarly requirements for psychological research (EBSCO Industries, 2012). The search yielded 5,767 peer-reviewed articles (EBSCO Industries, 2012). The search was then refined by subject and "Blacks" was selected. This yielded 821 articles (EBSCO Industries, 2012). After which, "human females" was selected and 241 articles were found (EBSCO Industries, 2012). Only one hundred and thirty-five or $2 \%$ of the articles appeared to focus solely on "research on Black women" (EBSCO Industries, 2012). This is significant, as there are over 15 million Black women in the United States (U.S. Department of Commerce Economics and Statistics Administration Bureau of the Census, 2012) and it affirms that the need for increased research on underrepresented populations, specifically with Black women, is a valid research 
agenda. The Academic Search Complete (EBSCO Industries, 2012) data suggest that little has been done to address this need by the scientific community.

The fact that $50 \%$ of Black families are being headed by Black women (U.S. Department of Commerce Economics and Statistics Administration Bureau of the Census, 2012) strengthens the case for this research study and other studies that examine and/or explore the needs of Black women. More importantly, the implications of this type of study can be far-reaching. Consider the following; research on Black women may assist researchers in developing more in-depth understanding of the experiences of Black women and how those experiences potentially impact the lives of Black children, families, and communities. Understanding emotional experiences potentiates treatment protocols specific to a particular population; especially those populations that do not fit neatly into gender and/or racial and ethnic categories. It would seem that such an approach would align with APA's Multicultural Guidelines (APA, 2002) while facilitating treatment, encouraging persistence in treatment, and ultimately, psychological health. Yet, there is still much to be done regarding mental health in the Black community, including examining social, treatment, and spiritual factors, that in theory, impact service utilization.

\section{Mental health in the Black community.}

Obstacles to seeking mental health services. Historically, mental health issues have been inadequately addressed in the Black community (Gibson \& Denby, 2007). Gibson and Denby (2007) contended that "the information about the treatment of African Americans in the mental health system is parsimonious at best" (p. 9). A variety of reasons are present which seem to hinder the discussion of mental health in the Black community. Social (Blue \& Griffith, 2001; Logan, 2007), treatment (Logan, 2007), and spiritual factors (Blue \& Griffith, 2001; Gibson \& 
Denby, 2007) have been identified as probable obstacles to seeking mental health services for African Americans.

Social factors. Logan (2007) wrote, "given the unique niche that people of African descent occupy in the history of the United States and contemporary American society, it is critically important that the mental health needs of African Americans be discussed within this broad historical context" (p. 39). Logan (2007) went on to say, "despite laudable history of African-American survival, growth, and high degree of mental health, the long shadow of two centuries of enslavement continues, in some form, to haunt the mind and spirit of all African Americans" (p. 39). Moreover, the emotional scarring attributable to the experience of slavery is experienced transgenerationally (Dana, 2002, p. 4).

Social factors apparently bled into service quality and utilization as well. According to Dana (2002) who cited Leong, Wagner, and Tata (1995) the services available in community mental health systems were often "inadequate and underutilized because of financial, institutional, and cultural barriers" (p. 4). Additionally, Blue and Griffith (2001) suggest the stigma associated with mental health services may be primary in ensuring discussions about mental health do not take place within the Black community.

Logan (2007) asserted that limited references have been made to the mental health experiences of Blacks. She states "prevailing ideologies and social policies that guided the mental health treatment of African Americans from the earliest recorded history still influence treatment of African Americans today" (Logan, 2007, p. 40). The impact of "sociocultural and structural forces on the mind, body, and spirit" of Blacks is not hard to imagine (Logan, 2007, p. 42) and it is easy to understand some of the intercultural interactions, especially with regard to mental health experiences. These dynamics underscore the belief that "sociocultural structures 
and practices" are integral in the "level and quality of mental health and illness experienced by African Americans" (Logan, 2007, p. 42).

Exploring these points may aid researchers in understanding Black women as a population of scholarly interest. Furthermore, "the belief that sociocultural structures and practices in this country play a significant role in level and quality of mental health and illness experienced by African Americans" is evidenced by the "growing number of families and children that are at risk for debilitating effects of mental health related problems" (Logan, 2007, p. 42). While the impact of social factors is important, treatment received by African Americans in mental health institutions is also noteworthy.

Treatment factors. Social factors also seem to have impacted mental health treatment of enslaved Africans. Logan (2007) implied that diagnostic system during slavery was unfair. She described enslaved Africans being diagnosed without consideration of "the impact of enslavement and ongoing oppression on the mental health of people of African descent (Logan, 2007, p. 42). For example, drapetomania, as identified Dr. Samuel A Cartwright during the $19^{\text {th }}$ century, was considered "a disease causing the slaves to run away" (Logan, 2007, p. 41; Ocampo, 2008). It was assumed that "accepting the conditions of enslavement" was a sign of sanity, and "fleeing slavery” was considered insanity (Ocampo, 2008, p. 158).

Szasz (1971) pointed out in his article The Sane Slave: An historical note on the use of medical diagnosis as justificatory rhetoric that symptoms of drapetomania, such as "sulkiness" and "dissatisfaction" "when displayed by whites" were "viewed as the normal expressions of unhappiness with one's lot in life" (Szasz, 1971, p. 235). He went on to state that drapetomania morphed into depression at the end of slavery when the usefulness of drapetomania waned 
(Szasz, 1971). These declarations support Logan's (2007) assertion that sociocultural factors and practices negatively affect mental health experiences of African Americans.

To view diagnosis without cultural context is errant. But, such practices seemed to influence diagnostic criteria and how diagnosing was implemented (Szasz, 1971). Szasz (1971) purported "the current criteria of mental health and mental illness" is based upon "the acceptance of the social roles imposed upon us by birth, fate, law, or our superiors in life or their rejection" (Szasz, 1971, p. 235). It appears that past instances of African Americans seeking support for mental health concerns resulted in misuse of the diagnostic system. This seemingly produced cultural mistrust in mental health services (Logan, 2007; Whaley, 2001a, 2001b), particularly across racial lines (Whaley, 2001b).

According to Whaley (2004) Blacks are often over-diagnosed with severe mental illness, such as schizophrenia, or admitted to psychiatric hospitals more frequently than White Americans. The rationale for diagnostic bias is identified as either clinician bias or cultural bias (Whaley, 2004). Whaley (2004) defined clinician bias as "the lack of adherence to diagnostic criteria during psychiatric evaluations" and cultural bias as "ethnic/racial differences in symptom expression being overlooked or misinterpreted by diagnosticians" (p. 169).

Furthermore, "it is important to recognize that ascertainment of symptoms and placing them in their cultural context reflects separate aspects of a dynamic process in psychiatric diagnoses" hence "a clinician can identify a behavior as a psychiatric symptom with or without placing it in the cultural context" (Whaley, 2004, p. 169). Therefore, "strict adherence to diagnostic criteria is necessary but may not be sufficient to address bias in psychiatric evaluations" (Whaley, 2004, p. 169). So, acknowledging both forms of bias and ensuring accurate diagnosis becomes important in working with African Americans. 
Whaley (2004) postulated cultural mistrust, experienced via bias, cultural or clinician, impacts service utilization, he also reported "cultural mistrust is associated with such varied psychological, social, and behavioral variables [as] ... interracial attitudes, racism reaction... self-concept, and help seeking for mental health problems" (p. 171; Whaley, 2001a, 2001b). Whaley's (2001a, 2001b, 2004) research confirms the impact of treatment factors on help seeking.

Sohler and Bromet (2003) on the other hand suggested this is not the case. They stated "there was no evidence that the hypothesized racial bias influenced clinical diagnoses in this first admission sample of patients with psychotic disorders" (p. 468). Sohler and Bromet (2003) addressed clinical and cultural bias through additional confirmatory analyses by using the symptom data provided by the patient's significant others. Justification of the results was provided by reports of family members. Sohler and Bromet (2003) declared, that patients' family members "should be less likely to be racially biased than reports from either hospital clinicians or researchers" (p. 468).

In addition, Sohler and Bromet (2003) affirmed that, "while there was no evidence to support our hypotheses regarding racial bias in the assignment of schizophrenia and affective disorders, black patients were more often discharged without a definitive diagnosis than white patients" (p. 468), acknowledging their uncertainty in interpreting the way diagnosing is done in patients of color (Sohler \& Bromet, 2003). They determined the reason the discharge pattern with Blacks may be related to clinicians having a better understanding of the influence of race on psychiatric diagnoses (Sohler \& Bromet, 2003). Furthermore, Sohler and Bromet (2003) intimated "this diagnostic pattern might have treatment implications for black patients; it will be 
important for future research to evaluate differences in treatment patterns for patients diagnosed with schizophrenia vs. psychosis NOS at first hospitalization" (p. 468).

Spiritual factors. There is limited literature on the impact of spiritual factors when discussing mental health services. The idea that mental health concerns "were topics more closely aligned with the majority culture" and Blacks viewed themselves as "God-fearing people" who relied solely on God (Gibson \& Denby, 2007, p. 4) seems to promote maintaining the status quo regarding the open discussion of mental health among Blacks. Dana (2002) postulated, "more comfortable, credible, and relevant services were found in churches... or from community people" (p. 4). It is not hard to imagine why Blacks may have felt unsafe sharing mental health concerns with professionals, in light of the above social and treatment factors. Yet, without research that focuses on this area or that concentrates on Black women in particular, the expectation of fully understanding of the experiences of Black women and the role of spirituality in pursuing professional psychological help, may be futile.

\section{Diversity in the profession of psychology.}

Carkhuff and Pierce (1967) suggested same race and ethnic therapy dyads increase the depth of self-exploration. Taking into consideration Black women, this would suggest an increased need for Black women psychologists. However, Daniel (2009) found fewer Black women in tenured faculty positions within the discipline of psychology compared to their White counterparts. Daniel (2009) also reported that the potential for role models and mentors diminishes for Black students, thereby, potentially impacting recruitment and retention efforts of Black students in the profession of psychology. While the recruitment of Black women in the field may change the treatment dynamic for Black women, the underrepresentation of Black women psychologist, especially in American universities, does not help. 
Historically, scholarly activities by Black psychologist have not been well supported by White research scientists in the field. Guthrie (1998), who focused his research on psychological scholarship from the 1870 s, reported, "the white academic community was indifferent to the remarks of Black academic scholars" (p. 108); especially, when their opinions regarding flawed research were expressed. He noted "a sense of helplessness prevailed among Black academicians whose voices of dissent were simply ignored and made little or no impact on the white research community" (Guthrie, 1998, p. 108). Daniel's (2009) claims, although a decade later, are similar to those made by Guthrie in 1998.

Several studies have examined the issue of lack of diversity in the field of psychology (see, Chandler, 2011; Hammond \& Yung, 1993; Moradi \& Neimeyer, 2005). Chandler (2011) and Hammond and Yung (1993) focused their research on recruitment and retention strategies of Black students and faculty within school psychology, and the recruitment and retention of Students of Color at schools of professional psychology, respectively. Moradi and Neimeyer (2005) examined faculty diversity in academia. Within counseling psychology, a "clear and consistent increase from approximately $7 \%$ (in 1981-1982) to 26\% (in 2001-2003)" (p. 662) was evident. Moradi and Neimeyer (2005) asserted that although "representation of racial-ethnic minority faculty across counseling psychology programs (26\%) far surpasses that of doctoral-level faculty in departments of psychology... at the same time the present data suggest that counseling psychology programs, collectively, have not yet achieved the aspiration set forth by Ponterotto et al. (1995) to have 30\% or more racial-ethnic minority representation among faculty in academic training programs" (p. 662). 
Although, the tide may be changing in the profession, via more balanced recruiting and hiring strategies in American universities, the current status remains problematic.

In theory, the infusion of Black women psychologists, not only creates greater opportunities for Black women to work with clinicians whose background and life experiences may be similar, it may also serve to make room for Black women to experience interpathy. Interpathy is the "cognitive and affective entry" into the "client's world of experience, which allows the therapist to envision and to experience a different epistemology and feel its commensurate effective impact" (Augsburger, 1993, p. 131). Interpathy increases the effectiveness and deepens empathic encounters within same race and gender dynamics and crosscultural counseling experiences (Augsburger, 1993). The tenets of interpathy seem to align well with Carkhuff and Pierce's (1967) contention that same-race therapy dyads allow for expanded therapeutic encounters between client and clinician. This may further aid the deepening of the therapeutic relationship between Black clients and therapists. While an infusion of Black women psychologist is suggestive of moving Black women towards greater health; this is not without challenges or consideration of the therapy needs of this population.

Same-race therapy dyads. Although same-race and ethnic therapeutic dyads may deepen the therapeutic relationship (Carkhuff \& Pierce, 1967) or allow Black clients to experience interpathy, few studies have been done on Black-on-Black therapy dyads (Blue \& Griffith, 2001) and most "do not address the diverse aspects of the therapeutic process that might affect therapeutic outcome" (Sanders, Thompson, \& Alexander, 2006, p. 100). Those studies that do address factors that influence the therapeutic process "suggest the need to explore the impact of these issues on perceptions of actual therapy (Sanders Thompson, \& Alexander, 2006, p. 100). For example, one challenge found in ethnically similar dyads is when clinicians are viewed as 
inferior to White clinicians in their expertise or psychological knowledge by clients of the same race and ethnicity (Farsimadan, Draghi-Lorenz, \& Ellis, 2007). Additionally, clinicians of Color may not be considered trustworthy by clients of Color compared to their White counterparts (Farsimadan, Draghi-Lorenz, \& Ellis, 2007).

It is important to note that racial attitudes in the Black community run along a continuum which may also affect Black-on-Black therapy dyads (Blue \& Griffith, 2001). Additionally, negative attitudes held by Black clinicians can undermine the therapeutic alliance and work done with Black clients, proposing the therapeutic process be conceptualized as a cross-cultural experience regardless of race (Blue \& Griffith, 2001). In light of the factors that may negatively impact Black-on-Black therapy dyads, the idea remains that within Black-on-Black therapy dyads, "some shared identity element...will allow the patient to be understood implicitly by the therapist and obviate the tedious work of telling their personal story" (Blue \& Griffith, 2001, p. 147).

\section{Mental health service utilization.}

The President's Commission on Mental Health Report (1978) henceforth known as the Report, provides a starting place to better understand access to and utilization of mental health services. Kushner and Sher (1991) concluded that the Report substantiated the need to explore factors that impact access and utilization of mental health services. Furthermore, Kushner and Sher (1991) cited statics from the Report suggesting " $12 \%$ of the American population was in need of mental health services at any given time, but only $3 \%$ sought out and made use of available treatments" (p. 196). The Therapy in America survey, also cited by Kushner and Sher (1991) found "almost one-third (30\%) of all Americans appear to have needed mental health treatment at some point within the past two years" (p. 196). 
Although these reports document the underutilization of mental health care services, it seems as if little has been done to address the discontinuity between need and the provision of mental health care services. Current research suggests this trend continues for a variety of reasons, such as pejorative attitudes regarding seeking therapy, the causes of mental illness, and, negative propaganda circulated in the Black community that distorts the mental health system (Dixon \& Vaz, 2005). Moreover "social strains that perpetuate the belief that they [Blacks] must be strong and never ask for help or admit needs" (Dixon \& Vaz, 2005, p. 170) and the Black church or spirituality (Harley, 2005) also play a role in the underutilization of mental health services. Additionally, Harley (2005) purported "for African Americans the belief in faith as the ultimate resolution to many problems serves as a contradiction to seeking mental health services" (p. 195). Additional explanations regarding the underutilization of mental health services by Black and other racial and ethnic populations can be found in Dixon and Vaz (2005), Morrell and Metzl (2006), and the Surgeon General's Report (1999).

The National Survey on Drug Use and Health: Mental Health (Substance Abuse and Mental Health Services Administration, 2012) reported 19.6\% of the U.S. population 18 or older received a diagnosable mental illness and approximately $13 \%$ of individuals 18 or older utilized mental health services during 2011. The Survey also recorded 7.6\% of Blacks, 18 and older, as using mental health services in 2011 (Substance Abuse and Mental Health Services Administration, 2012). While the need for mental health services increases, access to services by people of color decreases.

The reasons for decreased use of mental health services are vast. Kushner and Sher (1991) alluded to the lack of accessibility to mental health services as a major factor in only twothirds of Americans receiving services. Although, Kushner and Sher (1991) were not specific 
regarding why one-third of Americans in need of psychological services did not obtain services, their article implied intrapersonal and interpersonal challenges, experienced by some when seeking professional psychological help, might hinder seeking psychological services. For example, in their discussion of treatment fearfulness, Kushner and Sher (1989) defined it as arising from "aversive expectations about seeking and consumption of mental health services... that the specific content of the fears are most likely multifaceted, culturally influenced, and, in some cases, idiosyncratic" (p. 251). They went on to report potential sources of treatment fearfulness as, fear of embarrassment, change, stigma, and treatment stereotype (Kushner \& Sher, 1991) that may impact pursuit of services.

The National Survey on Drug Use and Health: Mental Health (Substance Abuse and Mental Health Services Administration, 2012) identified several additional reasons why Americans in need of psychological services were not receiving them. These included, limited financial resources, insufficient insurance or being underinsured, limited knowledge of where to seek treatment, stigma, and concerns about confidentiality (Substance Abuse and Mental Health Services Administration, 2012). If the results from the above surveys and reports are correct, then many factors affect the pursuit of psychological services for Americans (Sher \& Kushner, 1991; Substance Abuse and Mental Health Services Administration, 2012). Although the survey results do not address issues specific to people of color, they hint that barriers to mental health services may have lasting repercussions. More research, specific to non-White populations, is important in an effort to reduce or eliminate barriers between racial and ethnic groups and accessing and utilizing therapy.

Gaps in service. Addressing the gaps that exist in current research literature might prove fruitful in providing a better understanding of how Blacks view mental health services, think 
about mental health services, and pursue professional psychological help. Prior research is consistent in identifying barriers to seeking mental health services. Barriers identified by previous studies are, economic disparities (Dixon \& Vaz, 2005; Surgeon General's Report, 1999), self-concealment (Cepeda-Benito \& Short, 1998; Wallace \& Constantine, 2005), selfdisclosure (Kahn, Achter, \& Shambaugh, 2001; Morrell \& Metzl, 2006), stigma (Ang, Lim, Tan, \& Yau, 2004; Morrell \& Metzl, 2006), and failure to provide culturally relevant treatment modalities (Atkinson, Jennings, \& Liongson, 1990; Wallace \& Constantine, 2005). The identified factors all influence seeking psychological services. Research that focuses on addressing these and other barriers to mental health services may increase understanding of how to address these concerns. While, additional research on the viewpoints of ethnic populations about mental health services may encourage the implementation of cultural and contextual sensitivity within the scientific community and among service providers. This study endeavors to do just that.

Identifying gaps in service utilization is important and provides a foundation for this study. I concentrated on spirituality, understanding of therapy, and the connection between the spirituality and therapy as a way to look at help-seeking attitude in Black women. To facilitate the exploration of help-seeking attitude and the effect of spirituality on this population, background definitions are provided. Discussions about study limitations, the research population, and the research design addresses two things; 1) a continuation of research studies inclusive of people of color and designed to examine concerns in their respective communities; and 2) extending models of research beyond White American and Eurocentric perspectives. 


\section{Definitions.}

The terms defined here are provided to aid in understanding the complexity of helpseeking attitudes of Black women and offer transparency vis-à-vis the research process.

Black woman. Black woman is defined as a woman of African descent. This definition includes a woman of mixed race and/or ethnicity who self-identifies as Black or African American. Black and African American is used interchangeably throughout the study.

Help seeking. The definition of help seeking, as expressed by Fischer and Turner (1970), are used. Fischer and Turner (1970) defined help-seeking attitude as "one's tendency to seek or to resist professional aid during a personal crisis or following prolonged psychological discomfort" (p. 79).

Religiosity. Religiosity is defined as engagement in an organized system of beliefs, practices, and rituals. Religiosity aligns with and supports Allport's (1950) tenets of extrinsic religious orientation. Although the definition of religiosity transcends faiths, religiosity is viewed within the context of Christianity. Non-Christian faiths were not considered for this study.

Spirituality. Spirituality is defined as a search for the sacred. Spirituality involves the activation of faith or religious beliefs being actively lived out in the individual's life. It also includes, transcendent experiences which are specific, contextual, and within the individual's ascribed faith. Spirituality is aligned with and supports Allport's (1950) tenets of intrinsic religious orientation. Although the definition of spirituality transcends faiths, spirituality is viewed within the context of Christianity. Non-Christian faiths were not considered for this study. 


\section{Research population.}

Research participants were at least 18 years of age or older, who self-identified as Black women. The participants attend Christian churches and/or live in in Akron, Ohio and selfidentified as members of the Christian faith. This population was chosen, because church attendance suggests elements of religiosity and/or spirituality may be present, suggesting experiences with spirituality. Furthermore, Akron was chosen due to researcher proximity and convenience. As stated above, non-Christian faiths were excluded from this study. No other exclusionary criteria were applied.

\section{Research design.}

This study used an interpretative qualitative approach and a semi-structured interview format was employed. Exploration of the methodology, including, but not limited to, the research design, limitations, and data analysis are discussed in Chapter 3.

\section{Research questions.}

While there is sufficient research on help-seeking attitudes and ethnic populations (Diala et al., 2000; Haynes, 2010; Kushner \& Sher, 1991; Masuda et al. 2009; Narrow et al., 2000; Sue et al., 1991) research that includes help-seeking attitudes and spirituality is nearly non-existent. A variety of factors, including spirituality, may influence the development of help-seeking attitudes in Black women. Research in this area is warranted to understand help-seeking attitudes of this population and the role spirituality plays in attitude development.

To date, "the needs of African-American women are not documented, nor have their experiences regarding psychotherapeutic process been fully recorded "(Watkins, 2000, p. 3). The same can be said of the influence of spirituality on help-seeking attitudes of African American women. Delving into this area of research, potentially enhances understanding of the influence of 
spirituality on help-seeking attitudes of Black women. The following questions are posed to determine the role of spirituality in contributing to the help-seeking attitudes of African American women:

1. What do Black women believe or think about seeking professional psychological services?

2. What role does spirituality play in shaping the help-seeking attitudes of Black women? 


\section{CHAPTER 2}

\section{Review of Selected Literature}

Chisholm (1996) and Heath (2006) identified a deficiency in research literature on Black women in mainstream scientific journals. This is also seen in publications dedicated to research on African Americans (Robinson, 1983). The research deficit is particularly noticeable in the area of mental health (Heath, 2006). For example, I conducted a search using Electronic Journal Center (OhioLINK, 2013), which is a database that houses electronic journals in partnership with colleges and universities in Ohio. I searched the Journal of Black Psychology from 1988 to 2013. A keyword search, which focuses specifically on the term entered, was used. The search yielded three articles on Black women and mental health. With over 1200 articles on 'Black People' found in the social sciences category of the Electronic Journal Center dated from 1969-2013 (OhioLINK, 2013), three articles on Black women and mental health constitutes meager findings. Such small numbers in this area of research produce challenges in conducting scientific investigations on specific topics such as the current study.

This dissertation project examined the interaction between spirituality and help-seeking attitudes by examining thoughts on spirituality and help-seeking attitudes. The aim of the literature review is to provide sufficient background into the experiences of Black women with the expectation that exploring some of the cultural and contextual actualities of Black women aids readers in understanding the complexity of help-seeking attitude development within this population.

\section{Double jeopardy.}

In 2006, Heath asserted that Black women may experience a type of double jeopardy in mental health research and life. She suggested that Black women are often placed into gender, 
class, or ethnicity and race categories (Heath, 2006; Mitchell, 2004) without regard to the role each play in mental health. Heath (2006) stated, "mental health research seldom provides little, if any, value to mental health issues specific to Black women" (p. 163). Furthermore, because "Black men and women share common experiences, the effects of racial and gender stereotyping become unique to Black women's mental well-being” (Heath, 2006, p. 163).

Thomas (2004) claimed experiences of Black women are intersectional and therefore cannot be adequately explained with isolated emphasis on either gender or race"' (p. 287). The assertion that Black women's experiences are interconnected and that gender and race play a role in how those experiences are described, is also supported by Mitchell (2004). Thus, "understanding the social and cultural factors that influence Black women's life experiences is essential to understanding the context in which the realities of Black women's mental health is shaped" (Heath, 2006, p. 162; Mitchell, 2004); this idea is principal for this study. Chisholm's (1996) original hypothesis that "the African-American woman, as a double minority, knows the limitations imposed on her by normative societal prescriptions of femaleness" (p. 162) supports this assertion. Although these limitations are clear to Black women; they seemingly are not understood by African American men or White women.

Without cultural knowledge or understanding of how a group of people arrives at a mental status, where every aspect of their existence is credible, we are lost to perceiving their realities with vision that is skewed. Although African American women find themselves in a unique position and it could be surmised that some of these limitations are also evident in gender, as well as, race and ethnicity (Heath, 2006) it becomes even more important to study Black women. Singular studies on African American women will hopefully indicate that concerns specific to this population will not be relegated to blackness or femaleness when both 
are important in the historical, social, and emotional construction of Black women and the lives they lead (Chisholm, 1996).

\section{Conjoined research.}

Black men and Black women are often grouped together in research on African Americans with the results conjoined (Chisholm, 1996; Heath, 2006; Thomas, 2004). Thomas (2004) reported "the void in studying the lives of Black women within their own uniqueness calls for a repositioning of scholarship in the field of psychology in ways that make it more contextually responsive to the lived experiences of this population” (p. 288). In other words, concerns specific to Black women and other Women of Color may be subsumed into the worlds of American White women, who deal more so with gender victimization (Comas-Diaz, 1994) and/or Black men who are constrained by racial victimization (Mitchell, 2004). In citing Brown (2003), Mitchell (2004) suggested African American women are rendered "vulnerable to the concurrent effects of racism and sexism in ways that no other race and gender subgroup of the US population suffer" (Mitchell, 2004, p. 10). The potential for such research practices to increase the negation of experiences specific to Black women (Mitchell, 2004) and other persons of color is great.

Although there are shared realities among gender and race and ethnicity, "membership in an ethnic minority qualitatively alters the parameters in which she [the African American woman] is allowed to function (Chisholm, 1996, p. 162). Chisholm (1996) described this as subjecting Black women to "the worst of both worlds" (p. 163). The acknowledgment that Black men and Black women go through life challenges differently due to a power differential based on gender (Chisholm, 1996) is lacking. Mitchell (2004) concurred. She stated, "as targets of both racial and gender stigma, they [African American women] therefore are at 'triple jeopardy'." 
They must not only contend [with] the individual effects of racism and sexism and the discrimination emanating from the two in isolation, yet they are also required to navigate the sequelae of interactional effects as well” (Mitchell, 2004, p. 9).

Such factors strengthen the case for scientific research that focuses primarily on Black women. While the importance of exploring themes salient to Black women is recognized, the plausibility of fully accomplishing this in this study is slim and beyond the scope of this research project. I have selected to review literature relevant to the research questions at hand. Although, the current study is a subset of a wider body of knowledge germane to the experiences of Black women in America, research encompassing the historical and social perspectives of this population will be explored to provide understanding regarding how help-seeking attitudes and spirituality intersect in the lives African American women.

\section{Historical and social perspectives.}

Black women and strength. Historically, themes of strength and role strain have been a part of the experiences of African American women (Chisholm, 1996). Others comment on the 'strength" of Black women "as a positive character or asset that has contributed to resilience and fortitude" (Woods-Giscombe, 2008, p. 22) among African American women (Harley, 2005). Woods-Giscombe (2008) suggested the idea of strength may encourage the pursuit of an unachievable role of superwoman. Harley (2005) cited Poussaint and Alexander (2000), who also viewed 'strength' as having extraordinary staying power in spite of social, historical, and psychological concerns. Harley (2005) proposed a more accurate depiction is suggestive of Blacks developing "the strength to suffer, struggle, survive, and succeed" (p. 191) in the face of challenging life experiences. 
As cited by Beauboeuf-Lafontant (2005), Morgan (1999) in her feminist approach to understanding the experiences of Black women articulated strength in this way; "she gave up a willingness to assuage everyone around her by hiding her own distress and desires under the guise of "strength"” (Beauboeuf-Lafontant, 2005, p. 107). Morgan (1999) seems to suggest that strength is a mask worn by African American women that allows distress and desire to go unaddressed, and maybe even, unacknowledged (Beauboeuf-Lafontant, 2005). Although perhaps not fully understood, this research implies the idea that 'strength' is potentially detrimental to Black women and may influence their views of and attitudes about seeking mental health services (Harley, 2005).

Black women and role strain. Role strain for African American women can be both severe and long-lasting. As seen in the various reports by the Census Bureau Black women primarily function in the role of primary caretaker of Black children (U.S. Department of Commerce Economics and Statistics Administration Bureau of the Census, 1993, 2003, 2012). Heath (2006) defined role strain as operating in a role and taking on the responsibilities of woman and/or motherhood that are not based in reality, while juggling jobs and ensuring safety and provision for their families. She described role strain in terms of the matriarchal role of Black women (Heath, 2006). Heath (2006) went on to suggest that "some Black women are viewed as the backbone of the family and stereotyped as possessing the strong matriarchal role... [and] in many cases, they are considered the glue that holds everything in the community, church, and family together" (p. 163; Watkins, 2000). This implies that some Black women have no outside support and that a portion of Black women are doing it all on their own. That would mean no family, community, church, state, or any other type of sustenance is being provided to help these women sustain themselves and their families. 
bell hooks [spelling in original] (1981) asserted that being a matriarch, often used interchangeably with strong Black woman, "implies the existence of a social order in which women exercise social and political power, a state that in no way resembles the conditions of Black women or all women in American society" (p. 72). In turn, suggesting that Black women transcend difficulties encountered in life, is inaccurate and portends this population possess superhuman characteristics in the face of historical traumas (Heath, 2006).

Heath (2006) went on to propose role strain may negatively impact how help-seeking attitudes are shaped in Black women. The emotional toll experienced by role strain is believed to affect African American women psychologically (Chisholm, 1996). In light of the research reviewed here, it can be concluded that the cultivation of psychological help-seeking attitudes in Black women may to be related to self-perceptions that are often distorted and attached to real and/or perceived roles and responsibilities undertaken by this population.

Common ground. Moreover, the American Psychological Association's Guidelines for Psychological Practice with Girls and Women, reports that individuals from "diverse ethnicities, social classes, sexual orientations, and life experiences have encountered dramatic and complex changes...[in] care giving roles, and personal relationships" (APA, 2002, p. 949). For women of color, such changes have seemingly and negatively increased life stressors, affected health, and, at times, resulted in "systematic denial of resources" (APA, 2002, p. 959). It is no wonder that such experiences can potentially thwart the wellbeing of Black women and impact their experiences in therapy (Chisholm, 1996).

The common ground found between women of diverse ethnic and cultural backgrounds is clear. These shared factors often expose women of color to experiences in society without full benefits of either maleness or Whiteness (Chisholm, 1996). Chisholm (1996) believes that 
challenging harmful self-perceptions may come about with the affirmation of experiences that potentially shapes the identity of Black women negatively. It stands to reason that creating a space for self-discovery within the context of the therapeutic working alliance may prove beneficial for women seeking to understand themselves better (Chisholm, 1996).

Interpathy. Augsburger (1993) suggested doing this from a cross-cultural perspective or engaging an interpathic approach (interpathy), as found in pastoral psychotherapy, may be valuable in working cross-culturally. It may also be necessary in working with racial and ethnic groups. Augsburger (1993) continued by inferring intracultural, intercultural, and transcultural conflicts exist but, may not be acknowledged when working cross-culturally. This hints that resolution to conflicts within, between, and beyond cultural parameters may be needed in order to address some of the more negative elements of historical and social experiences (Augsburger, 1993) like racism, oppression, and slavery, mainly endured by people of color.

The reliance of contextual congruence, multicontextual clarity, and supracultural relevancy, all components of interpathy, are integral in cultural therapeutic exchanges (Augsburger, 1993). For African American women, exploring weightier historical and social concerns, in ways that acknowledge and validate their unique experiences, may decrease the negative impacts these experiences have on developing healthy emotionality. Interpathy, in many ways, is a step toward understanding the self-perceptions of Black women, from an 'in her shoes' perspective. Interpathy also models emotional, cognitive, and behavioral practices (Augsburger, 1993) that potentially assist Black women in changing harmful self-perceptions and finding healthier ways to view themselves.

Black women developing healthy self-concepts may be inherent in understanding the impact both 'strength' and role strain appear to have on Black women and psychological help- 
seeking attitudes. Exploration of how attitudes are developed, in particular, help-seeking attitudes, may shed light on the help seeking process of many African American women. This, in turn, may lead to deeper understanding of a very complex issue; thereby, finding alternate ways to address the issues of Black women.

\section{Attitude formation.}

The attitude formation literature is extensive. This section will discuss some of the existing literature on attitude formation related to this study, such as the conceptualization of attitude development versus theories of attitude development. This will include definitions, research, and a synopsis of components and theories of attitude development. Additionally, the impact of attitudes will be briefly examined, while the Theory of Reasoned Action (TRA) will be explored as a way to understand attitude formation. A brief overview of the social and personal factors of intention and causal relationships within TRA will also be provided. The section will conclude with a discussion on attitude formation, in particular, help-seeking attitudes and the effect of spirituality on developing attitudes about seeking professional psychological support.

Definition. The construct of attitude is difficult to define. Hundreds of definitions exist with little consensus (Albarracín, Johnson, Zanna, \& Tarcan Kumkale, 2005; Doob, 1947). "Consequently, reaching definitions that satisfy all...is as difficult as it is indispensable" (Albarracín et al., 2005, p. 4). Albarracín et al. (2005) implied a comprehensive definition would include conceptualizing attitudes as memories, judgments, and beliefs. They asserted "attitudes can be distinguished from affective reactions in that affective reactions are not necessarily tied to a particular entity" (Albarracín et al., 2005, p. 5) whereas; attitude appears to be suggesting a connection between attitude and a specific construct, person, or thing. 
It may be viewed as customary to connect feelings to how something is evaluated. However, this may not always be the case for attitudes. Albarracín and colleagues (2005) propose attitudes are "reserved for evaluative tendencies, which can be inferred from and have an influence on beliefs, affect, and overt behavior" (p. 5). The connection of affect, beliefs, and behaviors to attitude indicates these factors may be more than just components of the same construct; but, that each factor has a distinct role and impact on attitude formation.

Although there is currently no agreement regarding the definition of attitude, Fishbein and Ajzen (1975) proposed consensus is both plausible and problematic for researchers. They offered a singular definition of attitude that is both conceptually and theoretically implausible (Fishbein \& Ajzen, 1975). Because the existing research on attitudes is broad, containing both theory and conceptualization, finding a singular definition that adequately defines theory and concept is doubtful. Furthermore, it may not be possible to measure attitudes theoretically and conceptually within a single model (Fishbein \& Ajzen, 1975). Fishbein and Ajzen (1975) state “conceptual definitions will be most useful when they provide an adequate basis for the development of measurement procedures without trying to elaborate on the theoretical meaning of the concept" (p. 6). In other words, definitions of attitude are beneficial when the researcher addresses either the conceptual or theoretical component of attitudes, instead of trying to define both. For this study, attitude is defined as "implicit, drive-producing response considered socially significant in the individual's society" (p. 136). For the purpose of this study, attitude will be defined "a psychological tendency that is expressed by evaluating a particular entity with some degree of favor or disfavor” (Albarracín, Johnson, Zanna, \& Tarcan Kumkale 2005, p. 4).

Attitude research. Preliminary research on attitudes suggests that the evaluative component of attitude as an "object stimulus" (Diestel, 1971, p. 18) is measurable. Doob (1947) 
viewed attitude as "implicit, drive-producing response considered socially significant in the individual's society" (p. 136). Both Diestel (1971) and Doob (1947) proposed a learning component to attitude. Doob (1947) and Fishbein and Ajzen (1975) believed attitude is "learned, implicit anticipatory response" that acts as an "unobservable response to an object that occurs prior to, or in the absence of, any overt response" (Fishbein \& Ajzen, 1975, p. 24; Doob, 1947). In other words, although we can see behavioral responses to an object, we can't see attitude, making it more difficult to measure. Fishbein and Ajzen (1975) referred to attitude as “a person's location on a bipolar evaluative or affective dimension with respect to some object, action, or event" (p. 216).

As mentioned prior, attitude is defined as "a psychological tendency that is expressed by evaluating a particular entity with some degree of favor or disfavor" (Albarracín et al., 2005, p. 4). The definition is broad enough to incorporate cognitive, affective, and behavioral domains without diminishing the individual and collective impact these features have on attitude formation. The definition also includes components salient to the research of Diestel (1971) in that the meaning includes measurability factors and Doob (1947) and Fishbein and Ajzen (1975) in that the explanation hints at learned responses that elicits the evaluation of an object stimulus.

Schools of thought in attitude research. Attitude research suggests two main schools of thought regarding attitude: formation and origin, and change and resistance (Prislin \& Crano, 2008). Albarracín et al., (2005) looked at how attitude is "represented in memory, and translated into cognitions, motivations, and actions" (p. 3). They considered these components vitally important in understanding attitude formation (Albarracín et al., 2005). Additionally, several theories exist regarding how attitude is formed and what it measures. Some researchers suggest attitude formation evolves out of evaluative conditioning or learning (Olson \& Kendrick, 2008; 
Prislin \& Crano, 2008; Walther \& Langer, 2008). Evaluative conditioning implies we come to like or dislike something based on associations developed after repeated exposure to a stimulus (Walther \& Langer, 2008). Other researchers suggest the reduction of cognitive dissonance plays a role in attitude formation (Walls, 1999), and that by monitoring past behaviors and responses toward something we can understand how attitude develops (Olson \& Kendrick, 2008).

Components of attitude. Fishbein and Ajzen (1975) put forward three basic features of attitude. They proposed, "attitude is learned, that it predisposes action, and that such actions are consistently favorable or unfavorable toward the object" (Fishbein \& Ajzen, 1975, p. 6). This premise is also supported by Albarracín et al. (2005), who cited Eagly and Chaiken's (1993) definition of attitude. According to Albarracín and colleagues (2005), Eagly and Chaiken’s description supports ideas first introduced by Fishbein and Ajzen (1975). The connection between the definitions of attitude is, at its core, attitude and attitude formation contain an evaluative component that can be measured (Albarracín et al., 2005; Diestel, 1971; Fishbein and Ajzen, 1975; Prislin \& Crano, 2008).

Theories of attitude. Three prominent attitude theories are provided by Walls (1999) who focused on Festinger's work in 1957; Olson and Kendrick (2008) who expand Darryl J. Bem's research in 1972; and Fishbein's original research conducted in 1967 (Ajzen \& Fishbein, 1980). Walls (1999) stated as people try to reduce the unpleasantness of cognitive dissonance "they try to fit their ideas, beliefs, or thoughts together to make a meaningful whole and devalue or disregard the sore point or misfitting information" (p. 267). Olson and Kendrick (2008) reported that attitude could be inferred by paying attention to how an individual has responded to an object in the past. Lastly, Fishbein's model of attitude formation was "refined, developed, and tested" in 1980 (Ajzen \& Fishbein, 1980, p. 5). Fishbein viewed attitude development from the 
perspective of concept, while Ajzen and Fishbein (1980) focused on understanding the mechanics of attitude development. For a more complete compilation of theories on attitude formation see Albarracín et al., (2005) and Crano and Prislin (2008).

Impact of attitude. Diestel (1971) stated, “by knowing one's attitudes toward an object it is assumed that one's behavior toward that object may be predicted" (p. 3). In other words, being aware of how we evaluate certain experiences may assist in calculating responses to the stimulus over time. Although Diestel's (1971) assertion is noteworthy, current research suggests that attitudes are more complex. Yet, Diestel's (1971) statement could be useful; especially regarding the underutilization of mental health services by so many people, in that it may appear reasonable to suggest that understanding help-seeking attitudes and spirituality equals the ability to predict if Black women will or will not pursue professional psychological help. Or, at least it can provide a context in which to understand help-seeking behavior in this population.

Fishbein and Ajzen (1975) contended attitude is representative of positive or negative feelings toward stimulus objects. This claim adds depth to Diestel's (1971) statement, which appears one-dimensional. As beliefs are developed about the object, an attitude is "automatically and simultaneously" acquired about the object (Fishbein \& Ajzen, 1975, p. 216). Fishbein and Ajzen (1975) went on to report the belief that is linked to a trait and the evaluation of that trait is based upon the attitude developed by the individual. Their viewpoint takes into consideration not just awareness, but evaluation of that awareness.

To further compound the understanding of attitude formation, determinants of attitude formation are also associated with life experiences (Fishbein \& Ajzen, 1975). The salience, strength, and importance of beliefs that are held by an individual about those experiences become a part of attitude formation (Fishbein \& Ajzen, 1975). Salience suggests beliefs that are 
placed higher in the hierarchy of beliefs about a particular object as the basis of attitude (Fishbein \& Ajzen, 1975). The consistency and strength of the belief is contingent upon where the belief is located or ranked in the order of the beliefs (Fishbein \& Ajzen, 1975). For example, a belief ranked first in order suggests that the belief has greater strength. Importance of beliefs, or how one values a belief, also impacts how attitude is formed. Still, this does not suggest that order is necessarily congruent with salience and/or strength of beliefs (Fishbein \& Ajzen, 1975). It does, however, reveal the complexity of attitude development and suggest that a framework in which to view attitude formation is vital.

Theory of reasoned action. Ajzen and Fishbein (1980) claimed individuals take a rational and systematic approach, using available information, to determine their behavior. This approach is counter to the idea of the automaticity of behavior, and used to predict and understand behavior (Ajzen \& Fishbein, 1980). Although, the aim of this study is not to predict psychological help-seeking behavior of Black women, the importance in understanding this factor is recognized. TRA provides an appropriate frame in which to examine psychological help-seeking attitudes of African American women. Therefore, this study will use Theory of Reasoned Action (TRA) to provide necessary structure to explore attitude development in Black women; not as a means to simplify attitude formation in this population, but to examine one of many factors that potentially shape attitude about psychological help seeking. The factor studied will be spirituality.

TRA denotes intentionality to act "as the immediate determinant of action" (Ajzen \& Fishbein, 1980, p. 5), suggesting individuals "will usually act in accordance with his or her intention" (Ajzen \& Fishbein, 1980, p. 5). Jaccard and Blanton (2005) support these ideas. TRA proposes identifying the determinants of intention as essential in understanding behavior. This 
includes both personal and social factors (Ajzen \& Fishbein, 1980). The positive or negative evaluation of performing the behavior is personal and called "attitude toward the behavior" (Ajzen \& Fishbein, 1980, p. 6). While “the beliefs that underlie a person's attitude toward the behavior are termed behavioral belief' (Ajzen \& Fishbein, 1980, p. 7).

The TRA focuses on attitude towards behaviors as opposed to "objects, people, or institutions" and/or attempting to explain behavior (Ajzen \& Fishbein, 1980, p. 8). Ajzen and Fishbein (1980) recognized the confluence of these factors, yet did not consider them an integral part of their theory. In identifying objects, people, or institutions as 'external variables', they conveyed "an external variable will have an effect on behavior only to the extent that it influences the determinants of that behavior" (Ajzen \& Fishbein, 1980, p. 9). Social and personal factors, which are discussed below, can shape attitude and impact behavior, or, at the least illuminate intention behind the behavior. Stigma, for example, can be viewed in this way. It has both social and personal importance and potentially changes the behavioral response to seeking psychological help.

Social factors. The social aspect of intention is consistent with how individuals perceive and/or experience societal pressures to engage in certain behavior (Ajzen \& Fishbein, 1980). When individuals believe a behavior is socially appropriate, and others agree with the behavior, they are more likely to engage in that behavior. According Ajzen and Fishbein (1980) and Jaccard and Blanton (2005) this knowledge, in concert with life experiences, salience, strength, importance, and the hierarchy of belief constructs, as well as, intention, predict behavior and facilitate attitudinal understanding.

Personal factors. Ajzen and Fishbein (2005) also recognized the importance of "cultural, personal and situational factors" (p. 194) that influence behavior. Gender, race and ethnicity, 
personality styles, and individualistic and collectivistic orientations all impact how beliefs and attitudes are developed (Ajzen \& Fishbein, 2005). Additionally, physical environments, values and prejudices, and access to information also weigh in (Ajzen \& Fishbein, 2005). According to Ajzen and Fishbein (1980) all of these factors impact attitude, belief, intention, and behavior.

It is clear that both social and personal factors impact intention in ways that are not fully understood. Although the relationship between social and personal factors and belief is complex, understanding the relationship dynamic between these factors may increase understanding of attitude formation within the Theory of Reasoned Action. For this study, this is important when considering the complexity of the contextual and cultural reality of others. Furthermore, any theory that considers the historical, social, and psychological experiences of people, in particular Black women, is worth further exploration; including their relationship to each other and attitude formation.

Causal relationships. Jaccard and Blanton (2005) purported several causal relationships (direct, indirect, spurious, unanalyzed, and moderated) can be found in TRA. They suggested direct causal relationship is defined as $\mathrm{X}$ causes $\mathrm{Y}$. Indirect causal relationships suggest $\mathrm{X}$ influences Y through Z; while, spurious causal relationships suggest a relationship between $\mathrm{X}$ and $Y$, because of Z. Jaccard and Blanton (2005) also discussed the implications of an unanalyzed causal relationship. They reported $\mathrm{X}$ and $\mathrm{Y}$ are related through an indeterminate source, and a moderated causal relationship proposes the relationship between $\mathrm{X}$ and $\mathrm{Y}$ is controlled by Z (Jaccard \& Blanton, 2005).

If the factors from this study are plugged into the above equations, the picture becomes a little clearer and helps the reader understand the function of TRA in the study. For example, in a direct causal relationship, $\mathrm{X}$ (gender or ethnicity) has a direct and indirect impact on $\mathrm{Y}$ 
(behavioral and normative beliefs). Gender or ethnicity underlies behavioral and normative beliefs, which influences Z (attitude toward behavior or subjective norm). This can be seen through direct and indirect relationships. This interaction ultimately impacts behavioral intention, which is closely aligned with attitudes. The interaction between gender or ethnicity, beliefs, and attitudes toward certain behaviors is further complicated because a relationship between gender and ethnicity, although unanalyzed, is assumed. Furthermore, behavioral intention, which has been found to predict behavior is mediated by the addition of environmental constraints (Ajzen \& Fishbein, 1980; Jaccard \& Blanton, 2005) and other social and personal factors.

\section{Psychological help-seeking attitude}

Because help-seeking attitude and spirituality are separate entities, importance is placed on the conjoined constructs and the role they play in understanding Black women's attitude about therapy. Albarracín et al., (2005) and Fishbein and Ajzen (1975) assigned great significance to an entity or experience, known characteristics, and the cognitive processes that occur prior to or simultaneously with an event. What is central in understanding attitude is the impact of the formed attitude on behavior (Albarracín et al., 2005; Prislin \& Crano, 2008; Fishbein \& Ajzen, 1975).

It can be inferred that this is also true for psychological help-seeking attitude. Therefore, paying attention to experiences, traits, and thoughts prior to or during a discussion about psychological help seeking with Black women becomes vital to understanding how attitude is formed. It may also be important to examine the relationship between religiosity and spirituality. A relationship that is assumed without analysis does not account for the impact spirituality may have on help-seeking attitude development and behavior, particularly in Black women. 
Unwittingly, Ajzen and Fishbein (1980, 2005), Jaccard and Blanton (2005), and other researchers of attitude development, seem to support the premise of this study. Their research showcases the complexity of attitude development and the issues underlying attitude formation (Ajzen \& Fishbein, 1980, 2005; Jaccard \& Blanton, 2005). Coupled with the lack of research on the intersection between Black women, spirituality, and psychological help seeking, the research of Ajzen and Fishbein $(1980,2005)$ and Jaccard and Blanton (2005) is suggestive of the need for further exploration of these factors.

This study attempts to do just that. By providing an overview of help-seeking attitude, help seeking in racial and ethnic populations with an emphasis on Black women, in addition to selected literature on spirituality, and the mental health of African American women, an opportunity to explore the research questions is presented.

Help seeking. There is an abundance of literature on help seeking that can be divided into two major categories: behavior and attitude. Although the theoretical perspectives differ among researchers, the focus of this study is on help-seeking attitude with the understanding that attitude influences behavior, as demonstrated in the section on attitude formation. Fischer and Turner (1969) were first in studying the construct of help-seeking attitude. Their rationale for research in this area was to develop a scale that would measure help-seeking attitude to better understand factors that shape whether or not an individual would pursue professional psychological help (Fischer \& Turner, 1969). The research goal was to identify "attitudes and personality domains" that potentially affect professional psychological help seeking (Fischer \& Turner, 1970, p. 79).

Subsequent to their initial study, studies on a help-seeking attitude covered a range of topics to aid in understanding the factors that potentially impact psychological help seeking 
(Fischer \& Turner, 1970). Fischer and Cohen (1972) and Zedlow and Greenberg (1979) carried out two additional studies on help-seeking attitude. Fischer and Cohen (1972) looked at help seeking and demographic correlates (social class, educational level, religion, and college major). They sampled both male and female secondary (high school) and post-secondary students from Connecticut, New York City, and Washington D.C. (Fischer \& Cohen, 1972). Fischer and Cohen (1972) found a positive correlation between educational levels and help-seeking attitude. The study implies that more education increased the likelihood of seeking professional psychological help (Fischer \& Cohen, 1972). The results also indicate that religious/cultural factors impact help-seeking attitude. For example, Jewish participants were more inclined to seek psychological services than Protestant and Catholic participants (Fischer \& Cohen, 1972). The impact of religion on help-seeking attitude held irrespective of social class (Fischer \& Cohen, 1972). This was also true for those students majoring in social sciences as opposed to those majoring in applied fields, like nursing (Fischer \& Cohen, 1972). Social science majors seemed to take a liberal stance regarding social attitudes, compared to the more conservative posture of those students who majored in applied fields.

Zeldow and Greenberg (1979) studied help-seeking attitude and gender identity. They focused on liberal versus conservative attitudes toward women, and counseling experience. Their sample consisted of male and female university students, who were paid to participate in the study. The results showed a positive correlation between liberal attitudes toward women and help-seeking attitude, in both sexes, while the effect of prior counseling experience only revealed a marginally significant effect (Zeldow \& Greenberg, 1979). Zeldow and Greenberg (1979) suggested the results on counseling experience be interpreted with caution. They identified that a small and/or unrepresentative sample size potentially limited the opportunity to explore the 
interaction between prior counseling experiences and help-seeking attitude of liberal and conservative participants (Zeldow \& Greenberg, 1979).

These studies are significant for a number of reasons. First, they used the Attitudes Toward Seeking Professional Psychological Help (ATSPPH) scale (Fischer \& Turner, 1970). Second, Fischer and Cohen (1972) and Zeldow and Greenberg (1979) suggested the factors that influence psychological help-seeking attitude might be more complex than originally anticipated. In a series of studies that follow Fischer and Turner's (1969) initial study, researchers suggested the characteristics measured in the studies appear grounded in attitudes and social constructs which are steeped in cultural, personal, and situational factors (Ajzen \& Fishbein, 1980, 2005; Fishbein \& Ajzen, 1975). In examining the samples of Fischer and Turner's (1970) study, this becomes clear. Their participants included college students, adolescents, women and men recruited from university and community samples. The participants were from urban and suburban environments. The heterogeneity of the sample implies diversity factors are potentially endless, thus making it nearly impossible to determine which factors impact psychological help seeking, and the roles religion, gender, and culture play in help seeking. How those traits impact help-seeking attitude development remains to be seen. What is clear is that further research on cultural, personal, and situational factors surrounding help-seeking attitude may be warranted. It is my hope that this project will add to the body of knowledge on help-seeking attitude as the impact of spirituality, as it relates to African American women, is explored.

Definition. Help seeking, as defined by Gourash (1978) offers some understanding of the initial steps taken to address psychological distress. Gourash (1978) defined help seeking as "any communication about a problem or troublesome event which is directed toward obtaining support, advice or assistance in times of distress" (p. 414). Based upon this definition, the act of 
seeking help appears connected to intrapersonal processes governed by an individual's viewpoint, personality domain, or attitude about how to acquire help.

Fischer and Turner (1970) investigated the construct of help-seeking attitude to better understand the process of acquiring support for psychological factors. They sought to study the factors that impact seeking psychological help and to develop a scale that measures them (Fischer \& Turner, 1970). Accordingly, Fischer and Turner (1970) defined help-seeking attitude as "one's tendency to seek or to resist professional aid during a personal crisis or following prolonged psychological discomfort" (p. 79). Although other definitions exist, the consistent use of Fischer and Turner's (1970) definition (e.g., Fischer \& Farina, 1995; Townes, Chavez-Korell, \& Cunningham, 2009) necessitates its use for this study.

Implications for current study. Self-concealment, cultural mistrust, economic disparities, development of social networks, availability and access to mental health care, and the relevancy of treatment modalities for racial and ethnic populations are all important in understanding the development of help-seeking attitudes and behaviors. While different scales offer unique perspectives about help seeking and are useful in a variety of contexts, ATSPPH and Short Form scales are consistently used in help-seeking attitude research. For the purpose of the study, the spirit of ATSPPH was used to formulate of the interview protocol.

\section{Help-seeking attitudes and people of color.}

Research on help seeking. Research on mental health in people of color is growing. Current research identifies several important factors related to help seeking. Dixon and Vaz (2005) suggested that the current mental health system is ill equipped to address the mental health needs of racial and ethnic populations. Economic disparities (Dixon \& Vaz, 2005; Surgeon General's Report, 1999); self-concealment (Cepeda-Benito \& Short, 1989); failure to 
provide culturally relevant treatment modalities (Atkinson, Jennings, \& Liongson, 1990; Wallace \& Constantine, 2005); cultural mistrust (Cooper-Patrick, Gallo, Powe, Steinwachs, Eaton, \& Ford, 1999; Mitchell, 2004; Nickerson, Helms, \& Terrell, 1994; Townes, Chavez-Korell, \& Cunningham, 2009); social networks (Golding \& Wells, 1990; Wallace \& Constantine, 2005); stigma (Ang, Lim, Tan, \& Yau, 2004; Morrell \& Metzl, 2006); and availability and access to mental health care (Alvidrez, 1999; Davey \& Watson, 2008) have been cited as features that influence the pursuit of mental health resources for these populations.

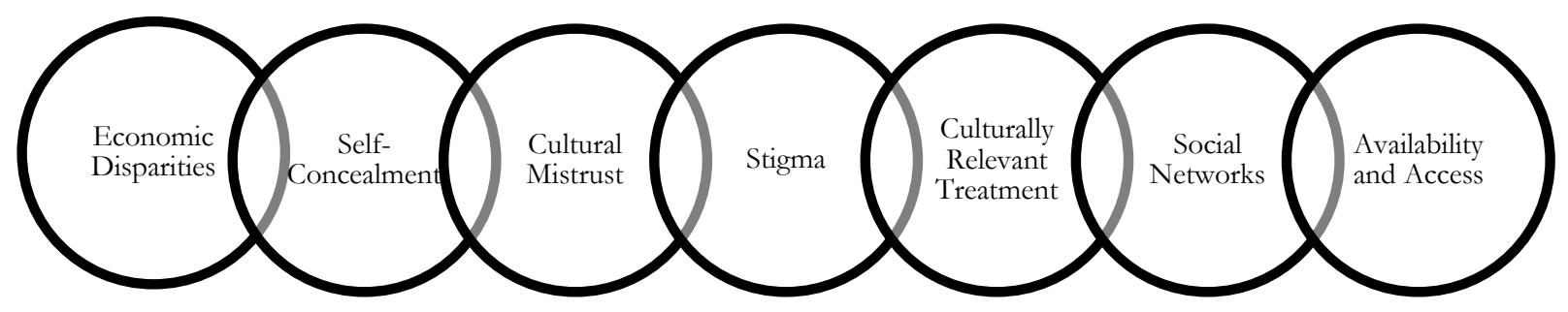

Figure 1 (Factors impacting help-seeking attitudes of racial/ethnic populations)

Figure 1 highlights several areas of potential exploration to better understand help-seeking attitude of non-White populations. It is clear that all of these factors are important, but only selfdisclosure and the therapeutic relationship will be examined further. These two factors assist with understanding important details about some African American women and whether or not to pursue therapy.

Self-disclosure. While the above research highlights the varying factors that impact pursuit of professional psychological services, it seems clear that the choice to pursue psychological services may also be shaped by a variety of historical, social, and psychological experiences specific to people of color. For example, Morrell and Metzl (2006) identified selfdisclosure as impeding the pursuit of therapy for many non-Whites. Furthermore, the willingness to share intimate details surrounding emotional struggles may hinder many racial and ethnic 
populations from pursuing and persisting in the use of available mental health resources. This was also captured by the research conducted by Kahn, Achter, and Shambaugh (2001). Kahn et al., (2001) also reported that some racial and ethnic group members may be more comfortable sharing with family, friends, and members of the clergy, rather than with mental health professionals.

While it can be surmised that the preference to not self-disclose obstructs seeking professional psychological help this may not always be the case. Carkhuff and Pierce (1967) suggested racial and ethnic populations, particularly Black women, may display an increased willingness to self-disclose in same-race therapy dyads during the initial clinical interview. Maki (1999) also acknowledged greater identification and increased potential for connection within same-race dyads. This proposes increased comfort levels in sharing intimate information within same-race dyads, at least initially (Carkhuff \& Pierce, 1967). Maki (1999) states "it is the sharing of dynamics related to being an ethnic minority that produced the increase in identification range and intensity" (p. 68). As discussed earlier, this is problematic with the limited number of Blacks who enter the profession of psychology.

\section{Help-seeking attitudes and Black women.}

Fischer and Turner's (1970) psychological help-seeking attitudes definition is critical in aiding future research projects on help-seeking attitude in people of color, and specifically Black women. Their focus on clarification of attitude and personality domains suggests the importance of understanding interpersonal processes surrounding help-seeking attitude (Fischer \& Turner, 1970). While emphasis in these areas may help to capture the lived experience of Black women, it also hints that different types of exploration may be needed to understand the development of help-seeking attitude in African American women. In turn, studying help-seeking attitude in this 
population may prove insightful regarding the interpersonal processes of the women who participate in the study. Furthermore, examining help-seeking attitude may reveal how helpseeking attitude is formed in Black women and the role of spirituality in developing this attitude.

Selected research. The paucity of literature on the help-seeking attitude of racial and ethnic populations, particularly Black women, makes conducting research in this area a challenging task. Whereas several studies were found on help-seeking attitude of racial and ethnic populations, only three identified African American women and help-seeking attitude as a primary focus. Those studies were conducted by Mitchell (2004), Sisley et al., (2011), and Watkins (2000).

The selected research emphasized other factors adjunctive to help-seeking attitude. For example, Mitchell's (2004) research examined factors that impact service utilization; while Watkins' (2000) explored spirituality in her study, and Sisley et al., (2011) looked at helpseeking behavior specific to Black women of Caribbean heritage in the United Kingdom (UK). Although behavior was the primary focus of the Sisley, Hutton, Goodbody, and Brown (2011) study, attitude and behavior are closely aligned (Fishbein \& Ajzen, 1975). Additionally, many of the study participants provided interesting insights into their help-seeking attitude, which is valuable in providing context for the present study. The methodology, focus, purpose, population, and the results of each study are briefly discussed below.

Notably, two of the studies used qualitative methodologies to explore help-seeking behavior in Black women (Mitchell, 2004; Sisley et al., 2011). Sisley et al., (2011) used Interpretative Phenomenological Analysis or IPA; Mitchell (2004), on the other hand, used constant-comparative method for their analyses. IPA, which is the approach used to analyze data for the current study, is discussed extensively in the methods chapter. 
Methods. Constant-comparative method, developed by Glaser and Strauss in 1967, requires the raw data be organized into conceptual categories out of which major themes are constructed (Mitchell, 2004). The conceptual categories contain specific and significant experiences found in the data. This information was coded into concepts, and then categorized into groups. The process continued until saturation of the concepts was reached. Saturation suggests Mitchell (2004) could 'predict' participants' responses to the interview questions. The analysis process was collaborative in that participants were sent copies of the transcribed interview to make corrections, additions, and clarifications (Mitchell, 2004). Both studies utilized semi-structured interview formats.

Watkins' (2000) research methodology was quantitative. She included the AfricanAmerican Woman Survey, which was designed by the author specifically for the study (Watkins, 2000). The Survey was intended to measure behavior, experience, attitude, belief, and needs of African American women related to psychotherapy (Watkins, 2000). The Fischer Attitude Scale (1970) (FAS) or Attitude Toward Seeking Professional Psychological Help scale (ATSPPH) was also used, in conjunction with two other standardized assessments. The Index of Core Spiritual Experiences (INSPIRIT) (Kass, Friedman, Leserman, Zuttermiester, \& Benson, 1991), which focuses on determining "the degree to which one has beliefs and experiences of a higher power" and that "measures one's relation to that power and identifies transpersonal experiences" (Watkins, 2000, p. 53) and the expanded version of Internal, Powerful Other, \& Chance Locus of Control (Rotter, 1966) or IPC developed by Levenson in 1972, were used. Watkins (2000) reported the IPC was set up to "ascertain if a person believes he or she is in control (Internal) or is controlled by external forces (External)" (p. 54). 
Focus. The major connectors of the studies were Black women, help-seeking attitude, and coping strategies (Mitchell, 2004; Sisley et al., 2011; Watkins, 2000). Mitchell's (2004) research proposed that before help-seeking behavior and service utilization could be measured, African American women must first consider therapy as an option. She identified several helpseeking behaviors as a coping strategy (Mitchell, 2004). Watkins' (2000) research; however, centered on exploring the needs of Black women. She reportedly, examined needs that had not been identified or described in prior research on Black women. Watkins (2000) endeavored to explore "attitudes, beliefs, spiritual influences, ideas, and needs, along with help-seeking behaviors" (p. 9) of African American women. While the study conducted by Sisley and colleagues (2011) also stressed psychological help-seeking behavior, they sought to "explore individual explanatory models of experiences of distress, coping and help-seeking choices" (Sisley et al., 2011, p. 392).

Purpose. While some commonality of the studies is recognized, the purposes were decidedly different for each study. By examining factors that encouraged and impeded seeking therapy, Mitchell (2004) in her abstract cited the research rationale as "identify[ing] issues pertinent to African American women and their attitudes toward counseling and/or therapy as they affect patterns of mental health care utilization". Mitchell (2004) approached her study qualitatively to demonstrate the value in asking questions of 'why' and 'how' and 'what is it like' to understand individual experiences.

Through their study, Sisley et al. (2011) sought to "explore individual explanatory models of experiences of distress, coping and help-seeking choices" (p. 392). Their intent was to identify women under-utilizing mental health services with the goal of "improving [the] cultural relevance of services" used by Black women in the UK (Sisley et al., 2011, p. 392). Watkins 
(2000), on the other hand, highlighted the use of transpersonal psychology with African American women, which makes her study unique. She implied that transpersonal psychology provides an opportunity to address "questions of value, meaning, purpose, and spirit" while taking into consideration the "familial, social, ecological, global, and cosmic contexts" that shape the experiences of this population (Watkins, 2000, p. 5). Also expressed in Watkins' (2000) study is the assertion that transpersonal psychology adds the "dimension of spirituality to the understanding of human experience" (p. 5). This becomes important because spirituality has been identified as one of the support systems utilized by African American women (Harris, 1992; Mattis, 2000; Mitchell, 2004; Schiele, 2000; Sisley, Hutton, Goodbody, \& Brown, 2011) and is a major component of the current study.

Population. Although diverse, all three studies sampled Black women. Mitchell (2004) interviewed eight women, located on the east coast of the United States, who were between the ages of 25-55 and of various socioeconomic statuses. Sisley, Hutton, Goodbody, and Brown (2011) sampled seven women, between the ages of 30 and 50, who resided in the UK, and who self-identified as African Caribbean. Watkins' (2000) sample consisted of 241 African American women, between the ages of 18 and 71, from across the continental United States. The socioeconomic status of the women in the Sisley et al., (2011) and Watkins' (2000) study was not recorded.

Results. Watkins (2000) found that participants preferred to use informal support systems (e.g., mother and friends) to address mental health concerns and held a relatively positive attitude toward seeking professional psychological help; yet, participants were less likely to utilize mental health services immediately. Sisley et al., (2011) reported their study participants also 
identified various ways of managing distress, as well as, concerns about accessing mental health services that are tailored specifically to Black women.

Mitchell (2004), in contrast, found that study participants did not readily endorse use of psychological services, but favored alternate resources to address psychological distress. Although the endorsement of mental health services distinguishes Mitchell's (2004) study from Sisley and colleagues (2011) and Watkins (2000), the behaviors are similar. Mitchell (2004) identified other behaviors preferable to seeking professional psychological help for her study participants. Those behaviors included connecting with family and friends, engaging coworkers, talking to clergy, and attending church (Mitchell, 2004), which are also highlighted by Watkins' (2000) and Sisley et al. (2011). Furthermore, Mitchell's (2004) research highlights the significant role church plays in the emotional well-being of Black women. This is also evident in Watkins (2000) study, but did not emerge in the research of Sisley et al., (2011).

Finally, Mitchell (2004) drew several conclusions in her study that might be important to note. Mitchell (2004) supported the idea that how mental health issues are conceptualized in White American women is most likely improbable for working with Black women in treatment settings. She also stated the mental health community would do well to develop stronger ties to the Black church as a means of reaching and assisting African American women in need of services (Mitchell, 2004).

Salient themes. The results yielded significant themes shared by the researchers. The analysis conducted by Sisley et al., (2011) yielded 23 subthemes, which were clustered into five super-ordinate themes. The super-ordinate themes are as follows: explanations of distress, experiences of distress, managing distress, social and cultural influences, and seeking help. Many of the subthemes were self-explanatory. There were a few, however, that appear unclear. For 
example it is hard to determine what 'generations' found in the super-ordinate theme of social and cultural influences, means without providing a deeper contextual reference. The authors noted 'generations' referred to the ability of past generations to handle greater emotional distress (Sisley et al., 2011).

Watkins (2000) discussed seven 'causal' factors that impinge upon Black women seeking therapy. The first reported causal factor was stereotypes or the view of African Americans in stereotypic roles. She reported this perspective as suggestive of an inner strength that almost forbids the acknowledgement of pain, fear, and vulnerabilities (Watkins, 2000). This idea was captured by Mitchell's (2004) research as well. Watkins (2000) and others (Dana, 2002; Fischer \& Turner, 1970; Mitchell, 2004; Sisley, Hutton, Goodbody, \& Brown, 2011) also identified mistrust of the health system, monetary cost, accessibility, and the lack of African American therapist, as contributing to limited interaction with mental health providers and help-seeking behaviors. Furthermore, she suggests causal factors include the impact of internalized racism and the negative influence of stereotypes within the profession of psychology (Watkins, 2000).

Mitchell (2004) found several categories dominant in participant responses. One response, "it doesn't work" seems to indicate participants were fearful of not being able to obtain relief from mental and/or emotional suffering (Mitchell, 2004, p. 75). Secondarily, therapy was "viewed as a last resort" and the idea that the participant would receive "no more than I can bear" which implies the participant would rely on God to move through challenging situations (Mitchell, 2004, p. 75) was also documented. Other themes included "my way works fine" indicating increased self-efficacy to address psychological distress, and "community perceptions" which, proposed therapy as inconsistent with African American cultural norms (Mitchell, 2004, p. 75). The themes captured a "range of definitions, thoughts, and feelings held 
by African American women relative to mental health care in general and in relation to themselves" (Mitchell, 2004, p. 75). It would seem that participant responses clarify motivators and detractors for using mental health services (Mitchell, 2004).

Many of the themes found in the studies are consistent with known obstructions to seeking therapy identified by Fischer and Turner (1969). For example, Fischer and Turner (1970) proposed recognition of personal need for professional psychological help; tolerance of stigma associated with psychiatric help; interpersonal openness regarding one's problem; and confidence in the mental health professional as factors impinging upon seeking professional psychological help. Watkins' (2000) study yielded positive results in recognition of need for service and ability to withstand stigma associated with going to therapy. But, interpersonal openness or a willingness to share emotional concerns and trust in the mental health system was significantly lower than the first two factors (Watkins, 2000). This is consistent with Sisley, Hutton, Goodbody, and Brown's (2011) results. They provided an explanation of how one participant understood of her distress. The participant's example demonstrated limited awareness of psychological distress. The participant stated, "I just thought I was a little blue...Everybody's a bit blue...but you just...pick yourself up and start all over again...”, (Sisley, Hutton, Goodbody, \& Brown, 2011, p. 396). These and other participant statements from Sisley et al. (2011) align with Fischer and Turner's (1970) idea of interpersonal openness regarding one's problem, as a component of help-seeking attitude and behavior.

When considering these factors, participant concerns about seeking help, social and cultural influences (Mitchell, 2004; Sisley, Hutton, Goodbody, \& Brown, 2011) connected to the help-seeking process (Sisley, Hutton, Goodbody, \& Brown, 2011), and finding alternative ways of managing distress (Mitchell, 2004; Sisley, Hutton, Goodbody, \& Brown, 2011; Watkins, 
2000) such as using church as a resource (Mitchell, 2004; Watkins, 2000) and spirituality (Watkins, 2000) are not necessarily unexpected. Although the above components are important to mention, because the development of help-seeking attitude and help-seeking behavior is complex and dynamic, it also seems important to address spirituality and its effect on helpseeking attitude.

Spirituality. Of the research cited, Watkins (2000) was the only researcher who made a distinction between religious activity and spirituality. She reported, along with informally talking to family and friends, that participants initially used prayer to ameliorate mental health concerns (Watkins, 2000). Furthermore, therapy was not identified as a 'first response' in addressing emotional problems (Mitchell, 2004; Watkins, 2000). A casual support network and the strength of religious or spiritual beliefs may also explain why this population is unlikely to view therapy as a 'go-to' for addressing emotional concerns (Watkins, 2000). Watkins (2000) contended religion was used as a "philosophical rationale for Blacks to endure poverty and discrimination... [and] that all life problems and situations have a spiritual dimension" (p. 23), thereby making its use as a resource to address psychological stressors familiar within the Black community. This asserts that the belief in God, as God is understood in the context of the lives of some Black women, is intimately woven into life experiences and that life and spirituality emanate from the same source.

Watkins (2000) went on to discuss four elements that determined how support was chosen by the participants. She highlighted trust as critical in using systems of support (Watkins, 2000). Watkins (2000) implied similarities in cultural and religious or spiritual background, along with understanding experiences of racism and oppression, were deemed important by 
participants. Although Watkins (2000) was not clear about the relationship between trust and cultural similarities, she acknowledged the role of spirituality in the support seeking process.

While Watkins' (2000) results are fairly consistent with prior research in this area, she offered that a connection between the uses of religious or spiritual resources was beneficial for the women included in her study. She stated "it is assumed that these internal expressions of spirituality [attend church, pray, and daily contemplation and mediation as spiritual practices] are being reinforced and supported by the Black church" (Watkins, 2000, p. 128). She reported no 'significant' relationship was found between engaging professional help-seeking behavior and religiosity or spirituality (Watkins, 2000). Furthermore, Watkins (2000) suggested the use of spirituality in therapy can "provide the type of support and direction [in the lives of African American women] that can empower and enhance one's spiritual values" (p. 132). Overall, it seems that Watkins (2000) maintains the idea that spirituality, the client's or the clinician's, is an important part of the therapeutic process.

According to Watkins (2000) many Black women have a strong spiritual or religious point of reference. She reported many study participants expressed transpersonal experiences, suggesting an integration of "core spiritual beliefs and experiences into a constructive mechanism" that aides them in dealing with difficult life circumstances and stressors that "arise during activities of daily living" (Watkins, 2000, p. 124). Her results also indicate a "belief in their [participants] own actions and behaviors as the controlling force in their lives" (Watkins, 2000, pp. 124-125). These results seem to suggest participants were grounded in reality while, at the same time, embracing transpersonal factors.

Research connections. Although different research methods were employed, comparison between Mitchell (2004) and Fischer and Turner's (1970) research provides a way to think about 
factors consistent and salient in both studies. The themes found in the research of Fischer and Turner (1970) and Mitchell (2004) describes factors that can be viewed as a connection between the studies. While Mitchell's (2004) qualitative approach, acts as substantiation of Fischer and Turner's (1970) quantitative method, it appears that the studies underscore an analogous concern, the underutilization of mental health services of Black women.

Prior research reveals that help seeking is hindered by a variety of factors. Among them, failure to provide treatment modalities tailored for people of color (Atkinson, Jennings, \& Liongson, 1990; Wallace \& Constantine, 2005), and the lack of availability and access to mental health care (Alvidrez, 1999; Davey \& Watson, 2008) is problematic. Sisley and colleagues (2011) reported many of the study participants used general practitioners for mental health concerns. They also noted one of the women felt as if services for Black women were 'hidden' and not readily available (Sisley, Hutton, Goodbody, \& Brown, 2011). One participant “expressed disappointment that health professionals failed to provide information about a local 'black Caribbean and African service' and that stigma may impede Blacks from seeking information and/or services (Sisley, Hutton, Goodbody, \& Brown, 2011, p. 398).

Summation. Finally, Mitchell (2004) charged the "American Psychological Association to commit to moving programs toward a standard of training whereby students graduate from their programs with a more principled, moral, and ethical standard of practice" (p. 104). Sisley et al., (2011) suggested several ways to further research in this area. Three are listed: use of a community sample to address gaps in knowledge about help seeking and coping strategies for this population; investigate the impact of other dimensions of diversity on coping strategies; and a community psychology approach to engage this population in action research that addresses service inequalities (Sisley, Hutton, Goodbody, \& Brown, 2011, p. 401). 
Sisley, Hutton, Goodbody, and Brown, (2011) also discussed the complexity in trying to understand coping and help seeking, in response to stressful experiences important in conducting research in this area. Additionally, Sisley and colleagues (2011) suggested the emergence of the super-ordinate themes "illustrate how understanding and managing distress is an individual and developing process, modified by personal experience, [and] encounters with new ideas and sociocultural beliefs" (p. 401). They went on to state that having information, "readily available" that "matches personal conceptualisations has proved important in accessing community selfhelp workshops and other services” (Sisley, Hutton, Goodbody, \& Brown, 2011, p. 401).

Black women are shaped by many of the same factors that influence help seeking in other populations. Yet, "there is much conjecture about the support systems African-American women use" which "are not clearly identified" (Watkins, 2000, p. 3). In other words, there are factors that influence help seeking which are unique to Black women (Mitchell, 2004, Sisley, Hutton, Goodbody, \& Brown, 2011). Nevertheless, in spite of the invariable themes of church, religion, and/or spirituality found in the research of Watkins (2000), Sisley, Hutton, Goodbody, and Brown (2011) and Mitchell (2004) a paucity of literature on psychological help-seeking attitudes of Black women remains. While it is appears that these support resources are important in the lives of many Black women, the lack of research on the effect of spirituality on help-seeking attitude suggest otherwise and may reduce the chance to understand the help-seeking process of Black women.

\section{Spirituality.}

Overview. Religiosity and spirituality are dynamic and complex constructs, often with points of commonality (Zinnbauer \& Pargament, 2005) that emphasize relationship and selftranscendence (Boyatzis, 2005). Because the constructs are difficult to fully capture, many 
writers make distinctions between religiosity and spirituality (Hill \& Pargament, 2008; Nelson, 2008; Paloutzian \& Park, 2005; Richards \& Bergin, 2000) in hopes of bringing clarity to an imprecise idea. For this study, spirituality and religion will be defined separately. The terms religion, religious, and religiosity, however, will be used interchangeably throughout the study to convey one distinct construct.

Historically, religion, religious, or religiosity has been viewed as a subset of spirituality (Holmes \& Hardin, 2009; Richards \& Bergin, 2000). Koenig, (2009) opposed this assertion reporting "spirituality [nonrational creation] as distinctly religious throughout most of Western history" (p. 284). He went on to suggest that as the term was adopted by Eastern religions, spirituality came to mean people who were classified as spiritual "were a subset of religious people" and that their "lives and lifestyles reflected the teachings of their faith tradition" (Koenig, 2009, p. 284). While Zinnbauer in 2005 described spirituality “as a personal or group search for the sacred" he characterized religiousness "as a personal or group search for the sacred that unfolds within a traditional sacred context” (Zinnbauer \& Pargament, 2005, p. 35).

Notably, Boyatzis (2005) believed the constructs overlap and he used them interchangeably in his writing. Holmes and Hardin (2009) who cited Paloutzian and Ellison's (1982) definition stated, spirituality is comprised of "both religiosity and general meaning in life or existential well-being" (p. 105). This definition is similar to Boyatzis' (2005) and suggestive of an expanded conceptualization of spirituality that includes both religious and spiritual factors. Pargament, Magyar-Russell, and Murray-Swank (2005) contended that, "the multiplicity of these definitions may be an accurate reflection of the multifaceted nature of religious life" (p. 667; Paloutzian \& Park, 2005); while Nelson (2008) suggested "religion has almost as many meanings as writers on the subject" (p. 406). 
Religiosity defined. Richards and Bergin (2000) defined religious as having to do with "theistic beliefs, practices, and feelings that are often, but not always expressed institutionally and denominationally as well as personally" (p. 5n). They went on to suggest that religion manifests itself in "denominational, external, cognitive, behavioral, ritualistic, and public" expressions that may or may not include a "closeness, harmony or connection with God..." (Richards \& Bergin, 2000, p. 5n). Nelson (2008), who defined religion in similar terms, suggested religion references "individual and corporate beliefs and practices dealing with our relationship with some ultimate being or reality" (pp. 406-407; Koenig, 2009). Pargament, Maygar-Russell, and Murray-Swank (2005) used Pargament's 1997 definition of religion. They defined religion as "a search for significance in ways related to the sacred" (Pargament, MaygarRussell, \& Murray-Swank, 2005, p. 667; Koenig, 2009). The definitions presented thus far display shared aims in the discussion of relationship, God, transcendence, and the sacred. They also propose that religious experiences are inclusive of practices and rituals endorsed by a community of believers.

Sacred defined. In explaining sacred, Pargament, Maygar-Russell, and Murray-Swank, (2005) referenced the 1989 version of the Oxford English Dictionary which stated "sacred refers to things that are holy, 'set apart' from the ordinary, and worthy of veneration and respect" (p. 668). They contended that "sacred includes concepts of higher powers, such as the divine, God, and the transcendent" as well as an association or representation of the divine (Pargament, Maygar-Russell, \& Murray-Swank, 2005, p. 668). Koenig (2009) defined the sacred "as that which relates to the numinous (mystical, supernatural) or God, and in Eastern religious traditions, to Ultimate Truth or Reality" (p. 284). 
Religion as concept. Hill and Pargament (2008) implied the concept of religion is being treated as a tangible object. They stated "religion is becoming reified into a fixed system of ideas or ideological commitments" (Hill \& Pargament, 2008, p. 3). They cited Wulff (1996) in suggesting that religion is not representative of the "dynamic personal element in human piety" (Hill \& Pargament, 2008, p. 3). Thus, religiosity does not account for the complexity of experiences that are specific, contextual, and within an individual's ascribed faith. Koenig (2009) furthered the idea of religion as concept by stating "religion is often organized and practiced within a community, but it can also be practiced alone and in private. However, central to the definition of religion is the thought that religion is rooted in an established tradition that arises out of a group of people with common beliefs and practices concerning the sacred" (Koenig, 2009, p 284).

Religion and research. Much of the current research on the psychology of religion can be traced to noted psychologist Gordon Allport (1897-1967). Allport (1950) wrote:

The subjective religious attitude of every individual is, in both its essential and nonessential features, unlike that of any other individual. The roots of religion are so numerous, the weight of their influence in individual lives so varied, and the forms of rational interpretation so endless, that uniformity of product is impossible" (p. 26). Allport (1950) considered religiosity a 'quest' that was as distinctive as it was specific to each individual. He noted, "there are as many varieties of religious experience as there are religiously inclined mortals upon the earth" (Allport, 1950, p. 27). He seemingly defined religion in terms of developmental processes (Allport, 1950) that contained immature (extrinsic) and mature (intrinsic) orientations (Kahoe, 1985). 
Extrinsic religion. Allport (1950) characterized immature religion as "largely concerned with magical thinking, self-justification, and creature comfort" (p. 63). Furthermore, he stated immature religious outlook "is highly derivative in its origins. Born of organic unrest, of selfinterested desire of juvenile interpretation" (Allport, 1950, p. 64). In short, extrinsic religious orientation exists as a means to solely meet the needs and/or drives of the individual. It implies the use of religion for personal gain, such as "to provide security and solace, sociability and distraction, status and self-justification" (Kahoe, 1985, p. 409). Kahoe (1985) simplified the extrinsic orientation this way the theological construct of individuals with an extrinsic orientation asserts the individual "turns to God, but without turning away from self" (p. 409).

Intrinsic religion. Intrinsic religious orientation, on the other hand, represents mature or "functionally autonomous" individuals in that their relationship to religion "cannot be regarded as a servant of other desires" (Allport, 1950, p. 64). Functionally autonomous decides "religious sentiment is the best instrument for dealing with life, the self, as it were, and of providing motive power to live in accordance with an adequate frame of value and meaning, and to enlarge and energize this frame" (Allport, 1950, p. 64). Kahoe (1985) viewed this as the integration of religious beliefs, whereas, religious beliefs are actively lived out in the individual's life (Allport, 1950; Kahoe, 1985). Despite the fact that, the definitions of extrinsic and intrinsic religious orientation present a compelling argument about the nature and function of religion, the characterizations appear to possess factors which are helpful in understanding both religiosity and spirituality within the context of help seeking.

Spirituality defined. The definition of spirituality is a bit more complex. Heath (2006) viewed spirituality as a broader, boundless, and independent concept that is self-existent and "not dependent upon a collective or institutional context" (Heath, 2006, p. 158). Whereas, Hodge 
(2001) identified spirituality as "a relationship with God, or whatever is held to be the Ultimate that fosters a sense of meaning, purpose, and mission in life" (p. 204; Heath, 2006). Nelson (2008), on the other hand, maintained spirituality "typically refers to the more experiential component of that relationship [with some ultimate being or reality], or more broadly to one's core values or search for meaning" (p. 407).

Nicolas, Gonzales-Eastep, and DeSilva (2008) described spirituality in terms of "animating forces of life" which are often represented by images such as "breath, wind, vigor, or courage" (p. 444) and associated with "an individual's search for meaning”(Heath, 2006, p. 158). Furthermore, Heath (2006) intimated spirituality is linked 'to one's most animating and vital life issues and concerns" (Heath, 2006, p. 158). Some researchers go on to report spirituality is a "capacity and tendency that is innate and unique to all persons" and that spirituality is a "personal experience" obtained through different paths, both inside and outside formal religion" (Nicolas, Gonzales-Eastep, \& DeSilva, 2008, p.444; Bregman, 2004; Gall, Malette, \& GuirguisYounger, 2011; Hill \& Pargament, 2008; Koenig, 2009; Mattis, 2002).

Spirituality as concept. Richards and Bergin (2000) classified spiritual as "experiences, beliefs, and phenomena that pertain to the transcendent and existential aspects of life" (p. 5n; Mattis, 2002). Spiritual experiences are described as "universal, ecumenical, internal, affective, spontaneous, and private" which suggest "closeness, harmony, or connection with God or the transcendent" (Richards \& Bergin, 2000, p. 5n). Holmes and Hardin (2009) contended that spirituality extends beyond religion and encompasses all of life, including religious experiences. Spirituality is deemed a general construct that includes religiosity (Holmes \& Hardin, 2009). Models of spirituality. Finding a definition that will subsume the diverse spiritual experiences of people is a daunting task. Mattis (2000) identified definitions of spirituality within 
psychology as having "developed out of the intellectual formulations of researchers rather than out of the direct experiences and articulations of lay people" (p. 103). Three schools of thought seem to dominate the religiosity and spirituality literature reviewed for this study. Those conceptualizations are reflected below. Figure 2, the Koenig Model, infers that spirituality is a subset of religion, while Figure 3, the Holmes, Hardin/Hill, and Pargament Model view religion as a subset of spirituality.

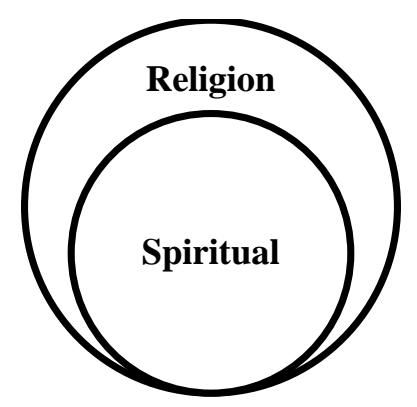

Figure 2 (The Koenig Spirituality Model)

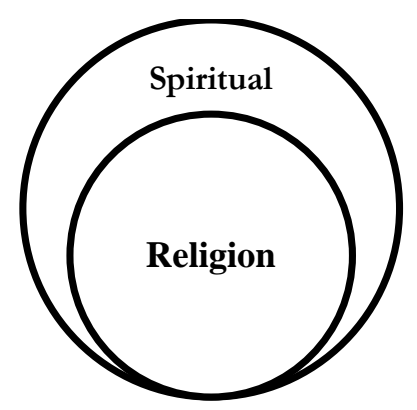

Figure 3 (The Holmes, Hardin/Hill, and Pargament Spirituality Model)

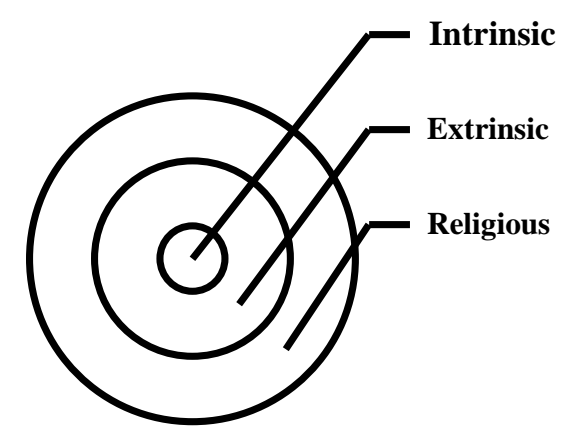

Figure 4 (The Allport/Kahoe Spirituality Model) 
Lastly, Figure 4, the Allport/Kahoe Model suggests a developmental approach to religious orientation. Allport (1950) and Kahoe (1985) alleged religious orientation contains both religious (extrinsic) and spiritual (intrinsic) elements that are expressed developmentally.

In light of the many definitions of religion, religiosity, for this study, is defined as engagement in an organized system of beliefs, practices, and rituals. This definition includes the elements of extrinsic and intrinsic religious orientation identified by Allport (1950).

Furthermore, religious beliefs are actively lived out in an individual's life in ways that are specific, contextual, and within an ascribed faith. Spirituality, conversely, is defined as a search for the sacred through the activation of faith. Spirituality suggests an internal and/or intrinsic process that also involves a relationship with God. Because the constructs are not necessarily viewed as distinct constructs within many Christian churches, both are considered.

Spirituality and research. Research specific to spirituality and psychological helpseeking attitude is lacking. Schiele (2000) proposed human service and social service paradigms "have traditionally viewed spirituality as too esoteric to examine" (p. 7). The work of Carl Jung and other schools of thought inclusive of existential, humanistic, and transpersonal orientations are thought to take holistic approaches (Schiele, 2000). Holistic strategies were developed to encourage understanding of and service to people of color. The goal was to use strategies that extend beyond Eurocentric and White American perspectives (Schiele, 2000) and that aid African Americans in transcending 'the self' in ways that "empower rather than devalues the individual” (Nicolas, Gonzales-Eastep, and DeSilva, 2008, p.444). Schiele (2000) went on to assert a 'materialist focus' or conceptualizing human beings as "primarily material and physical beings" (p. 7) reduces the legitimacy of the unseen or spiritual realm. The implication is that, due 
to difficulty in measuring the invisible constructs, researchers may have inadvertently dismissed the value of conducting scholarly research on religious or spiritual issues.

Cultural factors in research. Moreover, the lack of cultural sensitivity found in measures of religiousness and spirituality is also evident and related to inadequate sample representation (Hill, 2013). Hill (2013) stated that although religious and spiritual factors impact adequate representation, cultural elements do too. Hill (2013) reported "differences in religious and spiritual perspectives, affiliations, and practices are often related to cultural factors and, thus, the representation problems is not just one of Protestant overrepresentation... [but] also one of Caucasian, American, educated, and middle-class overrepresentation as well” (p.51).

Gullatte (2006) contended "conceptual and theoretical frameworks in psychosocial studies" are not clearly represented in research done on spirituality and religiosity, particularly with African American women (p. 90), Schiele's (2000) perspective may provide explanation for what appears to be a continuing trend in this type of research. Additionally, Gullatte (2006) stated "there is strong evidence that attention to the cultural relevance and inclusion of spirituality and religiosity are important constructs relative to understanding health and health seeking decisions among African American women" (p. 90).

Spirituality and mental health. Spirituality and mental health fared slightly better terms to be used in identifying research and writings relevant to the subject (Heath, 2006; Hodge, 2001). Heath (2006) and Hodge (2001) reported the existing research on spirituality and mental health primarily focuses on religion with "very little scientific data on spirituality" (Heath, 2006, p. 157; Hodge, 2001). One might think the opposite would be true due to research outcomes that suggest religion and/or spirituality primarily have a positive effect on mental health and overall well-being (Heath, 2006; Hill \& Pargament, 2008; Koenig, 2009; Seybold \& Hill, 2001). 
Spirituality and black women. Mattis (2002) noted the full story of the role of religion and spirituality is not currently told in research. She suggested "despite considerable evidence regarding the authoritative roles of religion and spirituality in the lives of women, generally, and African American women in particular, explorations of the spiritual lives of women remain limited in research on both the psychology of religion and the psychology of women" (Mattis, 2002, p. 309). For many Black women, spirituality is identified "as a practical means of living" and inferred as cathartic (Cook \& Wiley, 2000, p. 372). This may suggest that implementation of spiritual resources in daily living may reduce the need for therapy.

Furthermore, spirituality and religiosity, although used interchangeably in some studies, are different constructs (Hill \& Pargament, 2008; Hodge, 2001; Mattis, 2000, 2002; Nelson, 2008; Paloutzian \& Park, 2005; Richards \& Bergin, 2000) especially within the African American community (Mattis, 2000, 2002; Nelson, 2008). The transposable use of these constructs implies that beliefs, values, and experiences attached to spirituality and religiosity are the same (Mattis, 2000, 2002). Although this may or may not be accurate, the idea that spirituality is a coping mechanism in the lives of many Black women is clear (Mattis, 2002). What remains unclear is how spirituality and religion are used as a resource in the life experiences of this population.

Role of the Black church. Some answers may be found in the role of the church. Harley (2005) stated, "the Black church continues to function as an institution that affects the psychological health of African Americans" (p. 191). She described the strength-based approach found in many Black churches as a means to build upon positive attributes of the Black community (Harley, 2005). The goal in using the church to reduce psychological stressors is 
similar to strength-based approaches used in counseling, in that using church as a resource necessitates change and forward movement in the lives of the client (Harley, 2005).

Spirituality, as viewed through the role of the church potentially "honors the relationships among all life" (Heath, 2006, p. 159). Church and church relationships, in many ways, signify the breadth and depth of spirituality, via connection with humanity and through connection with God, respectively. Church and relationships within religious and spiritual communities act as a source of healing for many Women of Color (Heath, 2006).

The spirituality of many African Americans constitutes recognizing the importance of personal experiences, building community, communing with nature, and sharing in significant interpersonal relationships (Heath, 2006; Lauver, 2000). Additionally, it is believed that spirituality lies "at the center of reflection and practice rather than at the margins" (Heath, 2006, p. 160) in the lives of countless Black women.

Table 1, Utilization of Clergy vs. Traditional Mental Health Services, provides an overview of Harley's (2005) supposition. Table 1 offers a look at what support through clergy or spiritual leaders compared to traditional counseling or mental health services might look like.

Table 1

Utilization of Clergy vs. Traditional Mental Health Services

\begin{tabular}{ll}
\hline Clergy & Traditional Psychological Services \\
\hline No cost & Fee, copay, insurance \\
No paperwork & Completion of forms required \\
No referral required & Consultation, referral required \\
Personal/home visits & Office visits \\
Long-standing relationship & Formal professional relationship \\
First source of contact & Mediated contact \\
\hline
\end{tabular}

Note. Adapted from "The Black church: A strength-based approach in mental health," by D.A. Harley, 2005, Contemporary mental health issues among African Americans, pp. 191-203. Copyright 2005 by the American Counseling Association. 
Working within the confines of the church may be easier and less cumbersome for many African Americans seeking emotional supports. Furthermore, the relational component may explain why Black women historically have turned to religion and spirituality as means to cope with life stressors (Harley, 2005; Mattis, 2000, 2002; Schiele, 2000). It can be assumed the familiarity often found in same-race dyads (Carkhuff \& Pierce, 1967; Goode-Cross, 2011; Kelly \& BoydFranklin, 2005; Maki, 1999) may also translate to religious and/or spiritual relationships, thereby increasing the level of comfort in disclosing personal information.

African American women, whose experiences and lives are intersectional and not easily or adequately explained (Heath, 2006; Thomas, 2004), may find solace in God, church, religiosity, and/or spirituality. Thus, "truly understanding the social and cultural factors that influence Black women's life experiences is essential to understanding the context in which the realities of Black women's mental health is shaped" (Heath, 2006, p. 162). Therefore, the importance of this research is positioned around the idea that understanding help-seeking attitude in Black women can illuminate other areas that potentially impede Black women from seeking professional psychological services, namely religion and/or spirituality. 


\section{CHAPTER 3}

\section{Methods}

\section{Research design.}

I used Interpretative Phenomenological Analysis (IPA) for this research project to explore the lived experiences of Black women with regard to therapy, spirituality, and the connections between the two with the hope of understanding their help-seeking attitudes in this domain. Interpretative Phenomenological Analysis is "committed to the examination of how people make sense of their major life experiences" (Smith, Flowers, Larkin, 2009, p. 1) and provides a way to study how a phenomenon is experienced and thought about; and how those experiences are understood and interpreted. Interpretative Phenomenological Analysis, which emerged circa 1996, is "centered in psychology" and draws concepts and ideas from phenomenology and hermeneutics (Smith, Flowers, \& Larkin, 2009, p. 4). Interpretative Phenomenological Analysis offers itself as "applied psychology" or "psychology in the real world" (Smith, Flowers, \& Larkin, 2009, p. 5).

Interpretative Phenomenological Analysis describes, explores, and provides a chance for research participants, in this case Black women, to reflect on their understanding of therapy, spirituality, and the connections between the two. This information was analyzed with the intent of understanding the development of help-seeking attitude in African American women. Mertens (2010) stated "researchers consciously and explicitly position themselves side by side with the less powerful" (p. 21) to bring about a change. For Black women, exploring the help-seeking process may prove transformative as they reflect on their experiences and their understanding of therapy and spirituality. 


\section{Interviews.}

There are a variety of interview styles that can be used to elicit data from participants such as structured, semi-structured, unstructured, and group interviews (ESDS Qualidata, 2013; Heppner, Wampold, Kivlighan, 2008). Structured interviews utilize a standardized format that facilitates covering the same topic with each participant (Smith \& Osborn, 2007) and semistructured interviews, which uses the same format, affords the researcher opportunities to probe for emergent themes (ESDS Qualidata, 2013; Smith \& Osborn, 2007). The unstructured interview offers the flexibility to, "adapt questions for respondents" with the understanding that "the responses would not be quantified" (Heppner, Wampold, \& Kivlighan, 2008, p. 287). Group interviews are traditionally known as focus groups and provide a collective perspective in understanding a particular research question (Heppner, Wampold, \& Kivlighan, 2008).

For this study, I used a semi-structured interview format with a phenomenological emphasis, as demonstrated by the questions asked during the interview. Semi-structured interviews enhanced the rigor of the study by providing a consistent set of questions for participants to answer; this aided in the credibility of the study. Semi-structured interviews allowed participants to expand on their processes without being led by the researcher (Osborne, 1994; Smith \& Osborn, 2007) highlighting individual experiences, and how those encounters are experienced and understood by the participant.

"The aim of phenomenological interviewing is to get as close to the prereflective experience of the person as possible" (Osborne, 1994). This was achieved by presenting a minimally intrusive interviewing process that allowed the natural presentation of the participants' experiences (Osborne, 1994; Smith \& Osborn, 2007). Osborne (1994) purported an 
"open-ended" and "less structured interview" format was more favorable because it enhances exploration of phenomenon. This is the approach taken in this study.

\section{Participants.}

Black women, 18 years old or older who self-identified as Christian and lived in Akron, Ohio were selected for this study. The women selected were also members of local churches in the Akron area or attended a church in their home towns. All participants ascribed to the Christian faith. I lived in the Akron area for approximately two years and chose women from this locale because of ease and accessibility to the intended study population. Additionally, the relationships I developed while in Akron facilitated quicker connections and access to Black women who identified as Christian.

Even though Akron was convenient, it was also chosen due to the complexity of its religious landscape. Denominational and non-denominational, as well as, independent churches have a home in Akron. Therefore, selecting a sample from Akron, potentially increased the chance to sample women from different faith traditions. One potential limitation to choosing the sample solely from Akron was homogeneity. Although Akron is in the Midwest region of the United States, migratory patterns of African Americans during the $19^{\text {th }}$ and $20^{\text {th }}$ centuries created a blend of Midwest and southern people (Ohio History Central, 2015) which might have affected the principles of living and way participants thought about help-seeking attitudes. This presented a limitation, in that the sample was limited in generalizability within African American culture and across regions of the country. Additional limitations will be discussed later in this chapter.

\section{Apparatus.}

The interviews were recorded on a digital Sony MP3 IC Recorder, with additional recordings on a Samsung Galaxy Stellar and a LG GPad 8.3 LTE. The recorder includes two 
built-in microphones, speakers, and a built-in USB port. The Samsung and LG devices also included build-in microphones, speakers and the ability to connect to a laptop or desktop computer via a USB port.

\section{Instruments.}

Interview Protocol. The Interview Protocol (Appendix A) consisted of five questions that focused on spirituality and therapy. The researcher formulated the questions, which are below. The questions were open ended to allow for deeper exploration of the participant's thoughts and beliefs about spirituality and therapy.

1. What thoughts can you share with me about spirituality?

2. What factors influenced your thoughts on spirituality?

3. What are your thoughts on seeking therapy?

4. What factors influenced your thoughts on therapy?

5. What, if any, are the connections between therapy and spirituality for you?

\section{Procedures.}

Sampling. Mertens (2010) suggested sampling "should be done with attention to withingroup variation and to the influence of particular contexts" (p. 312). Several sampling strategies exist within qualitative research that could attend to within group differences (Mertens, 2010). For this study, convenience sampling, which utilizes individuals who are "readily available" and purposeful sampling, which identifies a specific population from which the study can solicit indepth information in the area of research (Mertens, 2010; Patton, 1990; Patton, 2002) were employed. The blended sampling approach works well with Interpretative Phenomenological Analysis, and as reported by Mertens (2010) either is appropriate for qualitative research.

To ensure Akron was the most appropriate location to recruit study participants in Ohio, I accessed the Center on Urban Poverty and Social Change, Mandel School of Applied Social Sciences, Case Western Reserve University (NEO CANDO, 2012) database to obtain information on counties in the Cleveland/Akron metropolitan area that were highly populated by 
African Americans. In 2010, Cuyahoga (29.705), Summit (14.42\%), and Lorain (8.56\%)

counties, were identified as having significant African American populations (NEO CANDO, 2012). Resultant of this information and use of the convenience sampling strategy, I recruited from Summit County, which contains Akron.

Prior to collecting data, I contacted three pastors of local churches via email to request access to Black women who attend their churches and were potentially interested in participating in the study. I also discussed my research project with a pastor in my neighborhood whose church was outside of the Akron area and he referred me to a local pastor who might consider participating in the study. Four pastors received a Recruitment Letter (see Appendix B), a copy of the Recruitment Flyer (see Appendix C), and the IRB Approval Notice (see Appendix D). One pastor did not respond to my inquiry. I then contacted a member of his church and asked if she was aware of individuals who might potentially be interested in participating in the study. This individual was also provided a Recruitment Letter and a Recruitment Flyer to share with members of her church or other women who met the research criteria.

Interpretative Phenomenological Analysis suggests only a small sample size is required due to the in-depth approach to analysis (Larkin \& Thompson, 2012; Smith, Flowers, \& Larkin, 2009; Smith \& Osborn, 2003). Smith, Flowers, and Larkin (2009) suggest that for professional doctorate programs, interviews that ranged between four and ten participants "seems about right" (p. 52). They then suggest for a student's first project "a sample size of up to six will be sufficient for a good IPA study" and that they "would often advocate three as an optimum number" (Smith, Flowers, \& Larkin, 2009, p. 106).

Potential participants learned of the study through church announcements during services, flyers placed throughout churches or distributed by church members, and during a 
presentation on the study in one of the identified churches. Interested participants contacted the researcher via email or phone. Their questions about the study were answered via phone or email. During the initial contact, participants and I identified mutual availability. They were then informed them I would send the application packet, which consisted of a Cover Letter (Appendix E), Demographic Questionnaire (DQ) (Appendix F), and an Informed Consent (Appendix G) via email or U.S. mail. The participants were then randomly assigned a four-digit participant code.

The cover letter outlined the next steps in the research process for participants. This included the date, time, and location of the interview, and which documents they needed to bring with them to the interview. In addition, the cover letter briefly described the study and the rights and responsibilities of participants. The Demographic Questionnaire captured data specific to within group difference (Mertens, 2010). Information such as such as age, race and ethnicity, sexual orientation, relationship status, occupation and length of time on job, educational level, and income was gathered. Participants were also asked if they had been in therapy within the last five years.

Although not required by West Virginia University's Institutional Review Board, due to the exempt status of the study, I provided a consent document informing participants of their rights before, during, and after the study. The purpose of the Informed Consent was to ensure participants were aware of their rights and to assure they were not pressured into participating in the study as noted by their signatures. As a reminder of the interview and to re-confirm their availability, each participant was contacted by email or phone between two and four days before the interview.

Eleven individuals responded to the request for participants. Eleven participants, met the study requirements, agreed to participate in the study, and were recruited; with the expectation 
that the transcripts would yield manageable data, as "successful analysis requires time, reflection and dialogue, and larger datasets tend to inhibit all of these things" (Smith, Flowers, \& Larkin, 2009, p. 52). Of the eleven, one participant canceled her scheduled interview and did not reschedule after several occasions of trying to coordinate our schedules. After she did not respond to the third request to provide me with a date of when she would be available for the interview, I informed her I would not contact her again regarding participating and thanked her for her willingness to participate.

Participant interview. Ten participants were interviewed. The interviews began with introductions and a brief overview of the study. An opportunity to answer participants' questions related to the study was also provided after the overview. In addition, the assurance of confidentiality was stressed and participants who expressed concern about their pastors having access to their interview were informed that pastors would not receive any information related to who participated in the study or have access to their interview or transcript. They were also informed they could stop the interview if at any time they felt uncomfortable.

The interviews were conducted at the main branch of Akron-Summit County Library in Akron, Ohio and recorded on the apparatuses described previously. The application packet was received and reviewed for completeness. If participants forgot their documents, they were asked to complete the requisite documents before the interview began. Two participants were provided with consent forms and one participant was provided with an application packet to complete before the start of the interview.

Participants were informed that I would be recording on two to three devices to avoid loss of information in the event there were challenges with the technology used. I shared with participants that the devices would be kept secure until the data would be transferred to a secure 
location. Participants were also made aware that I would be taking notes during the interviews and after the interviews concluded. They also expressed no discomfort with this process. The interview process began. After the interviews concluded, participants were thanked for their time and informed I would forward a copy of their transcript for their review, should they be interested. The digital interview files were downloaded and secured on a computer in my home office. Each file was saved under the participant's four-digit code and are password protected to ensure security. To assure confidentiality is maintained, the Informed Consent and Demographic Questionnaire, which contain identifiable participant information but not the four-digit code, were also stored in a secure location in my home office.

After all were completed, interview transcripts were transcribed. Nine of the 10 transcripts were usable for this study. One participant acknowledged her interest in participating in the study was related to a desire to talk to a counselor. She said this was "what made me decide to participate in this, "cause I said, I told my mother, I think I need to talk to somebody." She discussed a variety of factors that she found distressing; as a result of some of the things discussed and the level of distress during the interview a mental health "need for services" assessment was conducted.

At the end of the interview the participant was provided with referral information for agencies in the area that worked specifically with African Americans or from a spiritual perspective and encouraged to seek additional support for her emotional concerns. She was able to identify protective factors that would keep her safe and contracted for safety in the event her worries escalated. Additionally, she was provided with local crisis information. The participant took the information and said she would use it if she felt the need or her distress level increased. Consequently, her interview contained extensive data unrelated to the interview questions. This 
made the interview transcript difficulty to transcribe in its entirety. Also, a significant portion of the interview material unusable for the study as it primarily related to her distress. Her responses to the interview questions centered on emotional challenges and work-related concerns. The interview lasted for 1 hour and 38 minutes.

The interviews, on average, were about 26 minutes in length and were transcribed verbatim, using colloquial language and regional dialect. Natural speech patterns of myself and those of the participants were also transcribed, including "mmhm," "um", pauses, and laughter. After transcription was completed, participants were contacted by phone or email with regard to reviewing their transcripts. Participants were given five days to review the transcripts, make changes, clarify, or expand on their thoughts and comments.

\section{Data Analysis.}

Data were analyzed using Interpretative Phenomenological Analysis (IPA). The aim in interpretive analysis is "to develop an organized, detailed, plausible and transparent account of the meaning of the data" (Larkin \& Thompson, 2012, p. 104) in a manner that worked for the researcher (Smith, 2004; Smith, Flowers, \& Larkin, 2009; Smith \& Osborn, 2007). While, using an interpretive method of data analysis is consistent with qualitative research methods (Richards \& Morse, 2013; Smith, Flowers, \& Larkin, 2009) IPA, in particular "aims to explore in detail participants personal lived experience and how participants make sense of that personal experience" (Smith, 2004, p. 40). Phenomenologically, IPA is concerned "with individual's perceptions of objects or events" while recognizing that the role of the researcher, in part, is to make sense of those experiences (Smith, 2004, p. 40) in ways that validate the participants' experiences. 
Interpretative Phenomenological Analysis allowed me to explore the influence of spirituality on Black women's thoughts about therapy. I hoped this approach would help me understand the role spirituality has on seeking professional psychological help and in developing help-seeking attitude of Black women. With this population, in particular, this was important because interpretative analysis emphasized explaining the participant's experiences and how those experiences were understood by the participant (Richards \& Morse, 2013). This approach, led to some understanding of why some African American women do not pursue professional psychological help.

Interpretative Phenomenological Analysis revolves around the researcher's interaction with the data. Biggerstaff and Thompson (2008) indicate the dictates of analysis in IPA are cyclical processes that take the researcher through several iterative stages. They identified the stages as follows: "Stage 1: first encounter with the text; Stage 2: preliminary themes identified; Stage 3: grouping themes together as clusters; [and] Stage 4: tabulating themes in a summary table" (Biggerstaff \& Thompson, 2008, p. 11). This was accomplished as I read and re-read the text. I made notes of my thoughts, observations, and reflections during this process.

Transcript analysis. As the transcripts were read, emergent themes, significant or salient themes, and/or comments were underlined, then annotated in the left-hand margin of the transcript (Smith, Flowers, \& Larkin, 2009; Smith \& Osborn, 2003, 2007) using a 'line-by-line annotation' of the transcript (Larkin \& Thompson, 2012) and “emerging theme titles" or developing emergent themes were annotated on the right-hand side (Smith \& Osborn, 2007, p. 68; see also, Smith, Flowers, \& Larkin, 2009). This allowed the entire transcript to be treated as data; and allowed me to engage "with the text in detail, exploring different avenues of meaning" while "pushing the analysis to a more interpretative level (Smith, Flowers, \& Larkin, 2009, p. 
91). The Developing Emergent Theme (see Appendix H) table was created. The table included the four-digit participant code, interview question, emergent themes, and extracts from the original or revised transcript for 610 themes.

I documented recurring phrases, my questions, thoughts, and emotions in the left-hand margin. This allowed me to analyze participant transcripts in an open, critical, and speculative manner that facilitated a level of understanding of the participant's processes around making sense of salient experiences. Themes consistent in the transcripts were gathered to form a 'structure' or overview that represented a summary of the analysis, while highlighting what was important to participants (Biggerstaff \& Thompson, 2008; Larkin \& Thompson, 2012).

Themes. Themes are experiential claims, concerns, and understandings of participants that emerge in patterns within and across transcripts (Smith, Flowers, \& Larkin, 2009). As suggested by Smith, Flowers, and Larkin (2009) I looked for connections within patterns found within participants' transcripts, by separating out themes and moving them around to form clusters of related themes. Connections and themes were classified according to vocabulary, meaning, and the understanding conveyed by the participant during the interview. The themes were grouped, clustered, tabled, and written up "outlining the meanings inherent in the participants' experience” (Smith \& Osborn, 2003, p. 76; see also, Smith, Flowers, \& Larkin, 2009; Smith \& Olson, 2007) and in chronological order (Smith, Flowers, \& Larkin, 2009; Smith \& Osborn, 2007).

I used an abstraction method, of identifying patterns between emergent themes, to develop super-ordinate themes (Smith, Flowers, \& Larkin, 2009). This approach was useful in highlighting patterns in and across transcripts due to the amount of data, developing a structure for the data (Larkin \& Thompson, 2012) and to ensure a clear connection was documented in the 
participant's words (Smith \& Osborn, 2007). An abstraction table was created to reflect the abstraction process, presenting themes for all participants. While, a second method, modified for this study and was employed to search for connections across transcripts, and to address the potential for a large and unmanageable dataset. Emergent themes were examined for specific function (Smith, Flowers, \& Larkin, 2009) across transcripts. To identify function the following steps were taken; 1) I examined themes related to the research questions; and, 2) I identified recurrent themes across transcripts endorsed by $88 \%$ or eight or more of the sample population. Although, no rule for identifying recurrent themes was suggested by Smith, Flowers, and Larkin (2009), I chose this metric because it allowed me to concentrate on broader themes and to focus on idiographic content, without being overwhelmed by a potentially over-large dataset. Additionally, this approach, allowed themes that were recurrent across the study population to be emphasized, tabled (Table 4), and discussed in detail in Chapter 4. Again, these steps were taken to allow the reader to review the data yielded from the transcripts (see Table 3 ) and provided the reader with an opportunity to interact with data in ways that are meaningful, but not overpowering. Furthermore, this approach facilitated the management of the data, while being mindful of time constraints of the study.

The themes were translated into a "narrative account" where the "themes are explained, illustrated and nuanced" (Smith \& Osborn, 2007, p.76; see also, Smith, Flowers, \& Larkin, 2009). As presented in Chapter 5, participants' responses were selected from participant transcripts to formulate "narrative argument interspersed with verbatim extracts from the transcripts to support the case" (Smith \& Osborn, 2007, p.76; see also, Smith, Flowers, \& Larkin, 2009) and, to assist readers in distinguishing between participant statements and my interpretation of those statements. 


\section{Credibility.}

Credibility is parallel to internal validity in quantitative research and therefore, tantamount in qualitative research. Credibility is also important in establishing trustworthiness, as discussed below (Elliot, Fischer, \& Rennie, 1999; Lincoln \& Guba, 1985; Patton, 1990). Lincoln and Guba (1985) viewed credibility as, "activities that make it more likely that credible findings and interpretations will be produced" (Lincoln \& Guba, 1985, p. 301). For the purpose of this study, two credibility strategies were employed, member check and peer debriefing.

Member checks allowed participants to review transcripts. As discussed in Participant Interview, participants were provided with a chance to provide additional information and to summarize their thoughts and ideas (Lincoln \& Guba, 1985). Additionally, member check extended to participants a chance to ensure their words and intentions are accurately represented in the study; while, providing an opening for their voices to be heard. Two participants actively participated in member check. Participant 6887, after reviewing her interview transcript, reported agreement with the transcription. She also noted she desired to make no changes to the transcript. Participant 9209, used member check as an opportunity to clarify and expand on some of the comments she made during the interview. She disclosed the interview caused her to think more deeply about the questions asked and that she was grateful for the opportunity to clarify statement made during the interview.

Peer debriefing, on the other hand, was specific to analysis of the transcripts and interpretations. A peer debriefer is described as 'someone who is in every sense the inquirer's peer, someone who knows a great deal about both the substantive area of the inquiry and the methodological issues" (Lincoln \& Guba, 1985, pp. 301-30). The debriefer, was identified through personal contacts. She self-identified as a Black woman enrolled in an APA approved 
doctoral program in clinical psychology. She was familiar with qualitative research methodology and interested in working and conducting research in the African American community. She reviewed the data, as described in the Transcript Analysis section, and focused on developing emergent and super-ordinate themes. The data was reviewed to ensure accuracy in the identification of themes and that clear connection between the themes and the participant's words were documented and acceptable. All themes were presented in the Master Themes table (see Chapter 4). This included divergent or unique themes found in four or less transcripts; convergent themes found in at least five of the transcripts (Smith, Flowers, \& Larkin, 2009; Smith \& Osborn, 2007) and the super-ordinate themes endorsed by eight or more participants.

\section{Trustworthiness.}

Because "qualitative research must be judged by criteria which are appropriate to it" (Smith, 2003, p. 232) validity and reliability, although important constructs in quantitative research, are not necessarily appropriate as a means of assessing 'truth' in qualitative research. Truth is viewed through the lens of trustworthiness in qualitative research. Trustworthiness suggests "that the findings of an inquiry are worth paying attention to, worth taking account of" (Lincoln, \& Guba, 1985, p. 290).

In this study, trustworthiness was established by bracketing, sensitivity to context, owning one's perspective, and researcher biases. Bracketing is defined as the researcher's “identification of vested interests, personal experience, cultural factors, assumptions, and hunches that could influence how he or she views the study's data" (Fischer, 2009, p. 583; see Giorgi, 2011; Smith, 2009). Bracketing also suggest that the "researcher does not influence the participant's understanding of the phenomenon" (Chan, Fung, \& Chien, 2013, p. 1) and that it is 
cyclical in nature (Smith, Flowers, \& Larkin, 2009). Smith, Flowers, and Larkin (2009) also suggest that bracketing "can only be partially achieved" (p. 25).

Although this is an important step in most qualitative research methodologies, IPA originally did not necessarily, advocate the use of bracketing (Finlay, 2009; Smith 2004). More recent iterations of the approach suggest bracketing be interspersed throughout the research, although according to Giorgi (2011) IPA does not clearly provide steps in executing “bracketing” as defined by Edmund Husserl (1859-1938). Giorgi (2011) viewed Husserl’s perspective on bracketing as "parenthesizing of the natural attitude" which produces “phenomenological reduction" (p. 198; Smith, Flowers, \& Larkin, 2009). Parenthesizing of the natural attitude addresses the level of reflection and how reflection of the data is done (Giorgi, 2011).

To address bracketing, as suggested by Smith, Flowers, and Larkin (2009) I used it throughout the research process. During interviews, I focused on "attending closely" to participants' words, recognizing they possess "experiential expertise" (Smith, Flowers, \& Larkin, 2009, p. 64). This allowed me to bracket my pre-existing ideas and hypothesis about their experiences. I also modeled Chan, Fung, and Chien's (2013) ideas of bracketing, by keeping bracketing in the forefront of my mind as I moved through the research process. I also identified areas of biases, as discussed in the Researcher Biases section below. I was reflexive in my examination of my values and what I expected to experience with participants during the interview and after, based on their sect of Christianity (Chan, Fung, \& Chien, 2013). For example, I was aware of my thoughts related to denominationalism and how spirituality might be expressed in terms of intrinsic or extrinsic orientation, as described by Allport (1950). This is discussed in the Religion and Research section. Plus, I honored many of the values present in my 
understanding of Christianity. For instance, two central values for me are relationships are important and being fully present in encounters. To accomplish being present, my cell phone was on silent and no calls were taken during or between interviews. I took care of personal needs prior to the arrival of participants and secured a location free of distractions.

As proposed by Chan, et al. (2013) I actively put my knowledge and understanding about therapy and spirituality aside, adopting an air of curiosity during the interviews. I tried not to make assumptions regarding participant's definitions of spirituality, where they were going in the interview, and continually asked probing questions to flesh out and learn more about their experiences. In these instances, it seemed as if participants were wondering why I asked certain questions that maybe I should have known the answers to, especially, being a part of the Christian faith tradition. Chan and colleagues (2013) called this adopting "an attitude of conscious ignorance about the issue under investigation" (p. 4). This was the best I could do regarding "parenthesizing of the natural attitude" as discussed by Giorgi (2011; Smith, Flowers, \& Larkin, 2009). Other challenges in bracketing were being sensitive to context while embracing those parts of myself that helped to create a warm and welcoming environment. Yet, understanding my values and these aspects of myself were a part of my biases in research, made it difficult to balance bracketing, while trying to make a connection with participants that would help them feel safe and produce rich data.

Sensitivity to context consists of an awareness of the theory and the work of others in a particular area of research, as well as understanding the context (i.e., linguistic and dialogic) of the phenomena being explored (Yardley, 2000). Sensitivity to context was visible in my awareness of the impact of my salient identities (Black, woman, engages in spiritual practice, etc.) may have on the study. Sensitivity to context was also evident in my familiarity with 
euphemisms within Black and Christian spiritual communities, spiritual constructs, scripture used during the interviews, and the use and understanding of Black colloquial speech.

Furthermore, sensitivity to context was represented in "verbatim extracts from the participants' material to support the argument being made” (Smith, Flowers, \& Larkin, 2009, pp. 180-181) in the results section. Owning my perspective was visible throughout the study as I explored my values, interests, and assumptions, and examined the interaction between what participants revealed during the interview and how I examined and communicated the information shared.

Researcher biases. Lastly, acknowledging researcher biases was also important to establishing trustworthiness (Lincoln \& Guba, 1985). Yet, according to Patton (2002) inquiry that is value-free is impossible. My biases and expectations were necessary in evaluating my research through a qualitative paradigm (Heppner \& Heppner, 2004). My presumptions shaped how the data was evaluated and discussed, showed the interdependence between me and the phenomena under study and hopefully, managed the tension between my biases and the data (Patton, 2002).

The biases I acknowledged and considered for this study were as follows: I am a Black woman who participates in the Christian faith with a background in church leadership. I actively practice a form of spirituality consistent with many of the participants of the study. Although my background is in church leadership, I am no longer actively involved in church leadership nor did I have a leadership role in the churches from which participants were selected.

Pre-existing knowledge, including prior research projects on help-seeking attitude, shaped how I conducted the interview. Additionally, the follow up questions would impact how I analyzed the data based on the information yielded from each question. In light of this, I took 
great care to treat the data with the respect it deserved. I also created a different set of questions for the interview protocol. Additionally, being a Black woman who is a part of the Christian faith, and my way of being with others, positioned me to engage in ways that felt warm and welcoming before, during, and after the interviews. This was extremely important in that I did not interview women I knew, with whom I had a personal relationship or engaged with socially. This approach seemed to allow me to make an initial connection to participants and to help create an alliance that made the interview process easier for participants and myself.

My training in Counseling Psychology assisted me in asking clarifying questions, and using restatement, paraphrase, and summarization as a way to ensure I accurately understood what each participant stated. Additionally, I documented thoughts and salient themes during the interview and used this information to help form my restatements and summaries of participants' statements. I found that the participants were, more often than not, interested in continuing the dialogue after the interview concluded. They appeared comfortable and appreciative of the opportunity and shared thoughts that emerged after the interview as well as wishing me well in the project.

During transcription, I was able to review my experience with each participant. Listening to the interview helped me to better understand some of what participants may have been experiencing during the interview. I listened carefully to follow-up questions and corresponding responses. This practice helped me to understand how my interaction with participants shaped the flow of the interviews. I also monitored and documented my thoughts and feelings during analysis. I examined how these thoughts and feelings formed what I saw in the data and how I arrived at subordinate themes and clusters of themes. This allowed me to revisit each participant's interview and to again focus on my thoughts and feelings with each participant and 
interactions during the interview. Revisiting elements of the interview ensured that I had truthfully captured the participants' experiences.

Additionally, I have been trained in human development, social psychology, and multicultural psychology at the master's and doctorate levels. That training assisted me in understanding some of the contextual experiences of Black women. I also have training in pastoral counseling from Loyola University Maryland, where I earned a Certificate of Advanced Study. This training may have further facilitated a pastoral encounter, helping the participants to feel safe enough to be authentic in their presentation, transparent, and vulnerable during the interview. Lastly, I have extensive experience in working with Black women in clinical and religious settings. This experience allowed me to bring a solid understanding of the help-seeking process of Black women to this project. I also had intimate awareness of some of the challenges and ideologies surrounding the development of help-seeking attitude and the pursuit of professional psychological services for African American women. In light of this familiarity, I took great care to limit assumptions, ask clarifying questions, and provide a space for participants to feel safe and validated in their responses. 


\section{CHAPTER 4}

\section{Results}

This chapter includes a detailed data analysis for this project. Themes and illustrated quotes from participants were provided. Both a themes table listing all of the themes identified in this study and a table identifying super-ordinate or recurrent themes, which included the central meaning of themes is also provided. As discussed in Chapter 3, interviews from 9 participants was a part of this study. Emergent themes, both divergent and convergent themes are classified and briefly discussed. Super-ordinate themes are discussed in detailed, which facilitate the examination of spirituality on the development of help-seeking attitude. A summation of the themes and how they relate to the research questions is given in the corresponding section. This section also contains participant information and the research and interview questions.

\section{Participants.}

Interview information for nine participants was used in this study. Participants completed the Informed Consent and Demographic Questionnaire (DQ) prior to beginning the interview. All of the participants self-identified as heterosexual African American or Black women, and Christian. Other salient information, such as relationship status, occupation and income, highest degree earned, and whether or not the participant has participated in therapy within the last five years were obtained from the DQ. This, and supplementary data gathered about prior therapy during the interview, is described in Table 2 (Demographic Features) and were listed in chronological order.

As seen in Table 2, the nine participants were between the ages of 37 and 65 at the time of the interview. The average age of the participants was 54 with a standard deviation of 9.8. Five were married, two divorced, and two identified as single or never married. Their occupational 
statuses included unemployment, a journalist, a computer programmer, a psychologist, and an administrative coordinator. Two participants worked in higher education and one was a psychology intern. The all held a bachelor's degree or higher and their yearly at the time of the interview was between $\$ 0$ and $\$ 105,000$. Three participants had participated in therapy within the last five years and two disclosed a prior treatment history during the course of the interview. Participant responses were identified by the four-digit code assigned to participants prior to the interview. From this point forward, all data and related information discussed was specific to the nine participant responses.

Table 2

Demographic Features

\begin{tabular}{|c|c|c|c|c|c|c|}
\hline \multicolumn{7}{|c|}{ Demographic Features } \\
\hline Participant/Age & $\begin{array}{c}\text { Relationship } \\
\text { status }\end{array}$ & Occupation & $\begin{array}{l}\text { Degree } \\
\text { earned }\end{array}$ & Income & $\begin{array}{l}\text { Therapy } \\
\text { in last } \\
\text { five years }\end{array}$ & $\begin{array}{l}\text { Prior } \\
\text { therapy }\end{array}$ \\
\hline $5251 / 65$ & Divorced & Journalist & Bachelor's & $45 \mathrm{k}-75 \mathrm{k}$ & $\mathrm{N}$ & Y \\
\hline $1308 / 48$ & Single & Unemployed & Bachelor's & $0-15 \mathrm{k}$ & $\mathrm{N}$ & Y \\
\hline $9209 / 65$ & Married & Higher Ed. & Bachelor's & $75 \mathrm{k}-105 \mathrm{k}$ & $\mathrm{Y}$ & ND \\
\hline $6918 / 55$ & Single & $\begin{array}{c}\text { Computer } \\
\text { Programmer }\end{array}$ & Master’s & $75 \mathrm{k}-105 \mathrm{k}$ & $\mathrm{N}$ & ND \\
\hline $4551 / 48$ & Married & Psychologist & Doctorate & $0-15 k$ & $\mathrm{~N}$ & ND \\
\hline $8790 / 46$ & Married & $\begin{array}{l}\text { Administrative } \\
\text { Coordinator }\end{array}$ & Bachelor's & $15 \mathrm{k}-45 \mathrm{k}$ & Y & ND \\
\hline $3944 / 37$ & Married & $\begin{array}{l}\text { Psychology } \\
\text { Intern }\end{array}$ & Master's & $15 \mathrm{k}-45 \mathrm{k}$ & $\mathrm{Y}$ & ND \\
\hline $6887 / 59$ & Divorced & Higher Ed. & Master's & $15 \mathrm{k}-45 \mathrm{k}$ & $\mathrm{N}$ & ND \\
\hline $1365 / 63$ & Married & Higher Ed. & Master's & $75 \mathrm{k}-105 \mathrm{k}$ & $\mathrm{N}$ & ND \\
\hline
\end{tabular}

Note. $\mathrm{Y}=$ Yes; $\mathrm{N}=\mathrm{No} ; \mathrm{ND}=$ Not Disclosed. Prior therapy was not information captured on the Demographic Questionnaire or a part of the interview protocol. Participants with a Y under this column disclosed prior therapy information during the course of the interview.

Several of the participants reported experiences with professional psychological services resultant of accessing services for someone other than themselves; as a part of an educational training program related to psychology or counseling thru volunteering; within their spiritual 
communities; through friends in the profession; or, via friends who pursued therapy and shared their experiences with the participant. Knowledge of family members who experienced mental health concerns also appeared to provide familiarity to therapy for some of the participants, and seemed to have shaped their understanding of professional psychological services. During the interviews, it was clear, prior knowledge, experiences within their spiritual communities, as well as, the factors identified above, shaped how the participants thought about therapy and the connections between therapy and spirituality, as they shared their experiences during the interview.

\section{Research questions.}

Because prior research has not fully addressed the intersection of help-seeking attitude and spirituality, the following research questions, as discussed above, were identified for this study:

1. What do Black women believe or think about seeking professional psychological services?

2. What role does spirituality play in shaping the help-seeking attitude of Black women? The hope was that the guiding questions provided a basis for understanding help-seeking attitude of Black women and the role of spirituality in help seeking. To capture information relevant to the research questions, the following interview questions were formed:

The questions were general and specific, in an effort to capture participants' understanding of the phenomena and questions, while providing structure. This approach allowed participants' to reflect on their personal lived experiences related to spirituality and help seeking.

The purpose of the questions was to connect with everyday experiences and to focus on 'the particular' (Smith, Flowers, Larkin, 2009). This strategy supported the use of Interpretative 
Phenomenological Analysis (IPA), which values "nuanced analyses of particular instances of lived experience" (Smith, Flowers, Larkin, 2009, p. 37). IPA also provided opportunity for a detailed examination of each participant's experience, to extrapolate information that might be useful, and to contribute to understanding these experiences.

The order in which the questions were presented to participants' was based on my understanding of this population. I chose to lead with questions on spirituality, as the interviews were with women who identified as Christian. I felt this tactic would produce a level of comfort and familiarity with religious or spiritual practices would, in some way, make the subsequent questions easier to answer thereby producing thoughtful responses, and additional salient information on the participant's experience.

The ease of talking about spirituality seemed to increase the comfort level in discussing the questions that focused on therapy. Participants readily shared information that might not have otherwise be discussed, increasing the chance to understand these experiences. I realized the value I placed on spirituality and therapy, as well as my familiarity with Black women played a role in how comfortable the participants felt again, increasing the chance of meaningful interviews.

\section{Themes}

\section{Emergent Themes.}

Six hundred and ten thematic elements were identified in the nine transcripts analyzed for this project. As discussed in the Transcript Analysis section in Chapter 3, these elements were catalogued in the Developing Emergent Themes table (see Appendix H) and included, the fourdigit participant code, interview questions, emergent themes, and excerpts from the original transcripts to support the themes. Abstraction and functional methods were used to identify 
broader patterns across transcripts (Smith, Flowers, \& Larkin, 2009) and to manage the amount of data yielded from the interviews and will be discussed later. This will be discussed later. Table 3 (Themes) displayed divergent, convergent, and super-ordinate patterns identified in this study and discussed in this chapter.

First, I started with the eight emergent constructs that did not relate to the research questions salient to this study. These items were a hodge-podge of statements presented by participants during the interview. For example, participant 1308 talked about dreams being deferred as she discussed how interactions with her mother resulted in being discouraged from pursuing higher education. While participant 3944 talked about the blessings of positive things due to her relationship with God and not feeling judged by other women who were a part of her women's group at church. Other hard to categorize themes were provided by participant 6887 who shared her belief that therapy and spirituality are both valuable in maintaining the right frame of mind. Lastly, participant 1365 revealed doubts about going into the counseling profession due to low self-efficacy that may have been related to how she was trained. She also seemed to accept as true that impatience and other personality traits she felt she had would have negatively impacted her therapeutic style and ability to work with clients.

The outcome of the abstraction process led to the development of 17 themes. This process was recorded in the Abstraction Table (Appendix I). Due to the number of themes identified, a sample of emergent themes, which fit into each category, was provided to keep the data manageable. Subjectively, I chose statements from each transcript in an attempt to display the diversity of participants' responses. One notable distinction was the spirituality theme, which comprised a significant number of themes for participants. The results of the steps to identify function in the themes resulted in seven super-ordinate themes, which were highlighted for this 
study and presented in Table 4 (Recurrent Themes). Considerations on convergent and superordinate themes were discussed below and later in this chapter.

Approximately $38 \%$ percent or six of the 17 themes were recorded as divergent. Themes were defined as divergent if fewer than five participants reported the theme as salient. The themes did not highlight particular patterns or characterizations, but addressed things that were not often spoke about in many environments, as it related to therapy. Divergent themes, although no less significant, were recorded in Table 3 and were identified by a " $\mathrm{D}$ " in the second column of the table, next to the corresponding theme. Table 3 provided a visual overview of participant supported themes and allowed readers to understand divergent themes across participants. Although divergent themes may contain interesting content, they were not the primary focus of this study and are discussed at the end of this chapter.

Convergent Themes. As discussed at the beginning of this section, 610 themes were identified. Examining themes across transcripts provided one way to continually manage the data yielded from the interviews, yet, provided readers with significant and interesting information on the participants' experiences related to the phenomena being researched. With that, approximately $64 \%$ or 11 of the 17 themes were classified as convergent and indicated by the theme endorsement of five or more participants. Convergent themes, also displayed in Table 3 , ranged from awareness and access, connections between therapy and spirituality to God is enough, shame/stigma, and the consideration that therapy was a temporary fix (see Table 3 for the complete list). Convergent themes focused on a variety of factors that potentially shaped help-seeking attitude in the Black women who participated in this study. The themes also explained how these women thought about spirituality and therapy. Furthermore, convergent themes were only identified across transcripts. 
Participants that endorsed particular themes were designated by placing a " $\mathrm{Y}$ " in the column under participants' numbers and were shaded in black. If the theme was not endorsed by a particular participant, it was specified by an " $\mathrm{N}$ " and was recorded without shading. This was also in the column under participants' numbers. Participants whose responses were neither yes nor no, but discussed a parallel between spirituality and therapy were identified by placing a "PR" in the corresponding column of the participant. PR also represented participants responses that alluded to connection in their response to ne question, but not the question that specifically asked about a connection between therapy and spirituality or vice versa. A theme identified as convergent, was based on the endorsement of five or more participants and was connoted by a "C" and placed in the column next to the themes column. Super-ordinate themes, a part of convergent themes, were also identified in Table 3. Super-ordinate were signified by the recurrence of the theme in eight or more participant transcripts. These themes were bolded to make them distinctive. Super-ordinate or recurrent themes were also highlighted in Table 4 (Recurrent Themes) in the Super-ordinate Themes section of this chapter. All themes were included in Table 3 to provide readers with an overview of the themes identified and by whom. The examination of convergent themes acted as an introduction to the super-ordinate themes identified for this study.

Table 3

Themes 


\begin{tabular}{|c|c|c|c|c|c|c|c|c|c|c|}
\hline Themes & $\mathrm{C} / \mathrm{D}$ & 5251 & 1308 & 9209 & 6918 & 4551 & 8790 & 3944 & 6887 & 1365 \\
\hline $\begin{array}{l}\text { Awareness and } \\
\text { Access }\end{array}$ & $\mathrm{C}$ & $\mathrm{Y}$ & $\mathrm{Y}$ & $\mathrm{N}$ & Y & Y & $\mathrm{Y}$ & $\mathrm{Y}$ & $\mathrm{Y}$ & Y \\
\hline $\begin{array}{l}\text { Connection between } \\
\text { therapy and spirituality }\end{array}$ & $\mathrm{C}$ & $\mathrm{Y}$ & $\mathrm{PR}^{*}$ & $\mathrm{~N}$ & $\mathrm{Y}$ & Y & $\mathrm{PR}^{*}$ & $\mathrm{Y}$ & Y & $\mathrm{PR}^{*}$ \\
\hline Effects of slavery & D & Y & $\mathrm{N}$ & $\mathrm{N}$ & $\mathrm{N}$ & $\mathrm{N}$ & $\mathrm{N}$ & $\mathrm{N}$ & Y & $\mathrm{N}$ \\
\hline God is enough & $\mathrm{C}$ & Y & $\mathrm{N}$ & $\mathrm{Y}$ & $\mathrm{Y}$ & $\mathrm{Y}$ & $\mathrm{Y}$ & $\mathrm{Y}$ & Y & $\mathrm{Y}$ \\
\hline God Provides & D & $\mathrm{N}$ & $\mathrm{N}$ & Y & Y & $\mathrm{N}$ & Y & $\mathrm{N}$ & Y & $\mathrm{N}$ \\
\hline Informal therapy & $\mathrm{C}$ & $\mathrm{Y}$ & $\mathrm{Y}$ & Y & Y & $\mathrm{N}$ & $\mathrm{Y}$ & $\mathrm{Y}$ & $\mathrm{Y}$ & $\mathrm{Y}$ \\
\hline $\begin{array}{l}\text { Levels of therapy and } \\
\text { spirituality }\end{array}$ & $\mathrm{C}$ & $\mathrm{Y}$ & $\mathrm{N}$ & $\mathrm{Y}$ & Y & $\mathrm{N}$ & $\mathrm{Y}$ & $\mathrm{N}$ & $\mathrm{Y}$ & $\mathrm{N}$ \\
\hline $\begin{array}{l}\text { Life is hard, but I'm } \\
\text { resilient }\end{array}$ & $\mathrm{C}$ & Y & Y & $\mathrm{Y}$ & $\mathrm{Y}$ & $\mathrm{N}$ & $\mathrm{Y}$ & $\mathrm{Y}$ & $\mathrm{Y}$ & $\mathrm{N}$ \\
\hline Privacy & $\mathrm{D}$ & Y & Y & $\mathrm{N}$ & $\mathrm{N}$ & $\mathrm{N}$ & $\mathrm{N}$ & $\mathrm{N}$ & Y & $\mathrm{Y}$ \\
\hline $\begin{array}{l}\text { Relationship with God } \\
\text { does not exclude } \\
\text { therapy }\end{array}$ & $\mathrm{D}$ & $\mathrm{N}$ & $\mathrm{Y}$ & $\mathrm{Y}$ & $\mathrm{Y}$ & $\mathrm{N}$ & $\mathrm{Y}$ & $\mathrm{N}$ & $\mathrm{N}$ & $\mathrm{N}$ \\
\hline Relationships & $\mathrm{C}$ & $\mathrm{Y}$ & $\mathrm{Y}$ & $\mathrm{Y}$ & $\mathrm{Y}$ & $\mathrm{Y}$ & $\mathrm{Y}$ & $\mathrm{Y}$ & $\mathrm{Y}$ & $\mathrm{Y}$ \\
\hline Shame/Stigma & $\mathrm{C}$ & Y & Y & Y & $\mathrm{N}$ & Y & $\mathrm{N}$ & $\mathrm{Y}$ & Y & $\mathrm{N}$ \\
\hline Spirituality & $\mathrm{C}$ & $\mathrm{Y}$ & $\mathrm{Y}$ & $\mathrm{Y}$ & $\mathrm{Y}$ & $\mathrm{Y}$ & $\mathrm{Y}$ & $\mathrm{Y}$ & $\mathrm{Y}$ & $\mathrm{Y}$ \\
\hline $\begin{array}{l}\text { Therapy as a } \\
\text { resource }\end{array}$ & $\mathrm{C}$ & $\mathrm{Y}$ & $\mathrm{Y}$ & $\mathrm{Y}$ & $\mathrm{Y}$ & $\mathrm{Y}$ & $\mathrm{Y}$ & $\mathrm{Y}$ & $\mathrm{Y}$ & $\mathrm{Y}$ \\
\hline $\begin{array}{l}\text { Therapy is a temporary } \\
\text { fix }\end{array}$ & D & $\mathrm{Y}$ & $\mathrm{N}$ & $\mathrm{N}$ & $\mathrm{N}$ & $\mathrm{N}$ & $\mathrm{Y}$ & $\mathrm{N}$ & $\mathrm{N}$ & $\mathrm{N}$ \\
\hline Upbringing & $\mathrm{C}$ & Y & $\mathrm{Y}$ & $\mathrm{Y}$ & $\mathrm{Y}$ & $\mathrm{Y}$ & Y & $\mathrm{Y}$ & Y & $\mathrm{Y}$ \\
\hline You are not alone & D & $\mathrm{N}$ & $\mathrm{N}$ & $\mathrm{N}$ & $\mathrm{N}$ & $\mathrm{N}$ & $\mathrm{Y}$ & Y & Y & $\mathrm{N}$ \\
\hline
\end{tabular}

Note. $\mathrm{C}=$ Convergent; $\mathrm{D}=$ Divergent; $\mathrm{Y}=$ Yes; $\mathrm{N}=$ No; $\mathrm{PR}=$ Parallel Response. PR (Parallel Response) was used when participants did not clearly or definitively endorse nor deny the connection between therapy and spirituality, but identified characteristics that suggested some intersection.

Super-ordinate themes. Super-ordinate or recurrent themes were determined by the frequency and significance of thematic content shared by participants across transcripts. Seven themes were acknowledged, and were as followed: 1) awareness and access; 2) God is enough; 3) informal therapy; 4) relationships; 5) spirituality; 6); therapy as a resource; and 7) upbringing. Table 4 (Recurrent Themes) provided a summary table of thematic results, including the central meaning of the themes, and which participants endorsed particular themes.

Table 4 


\begin{tabular}{|c|c|c|}
\hline Theme & Endorsements & Central meaning \\
\hline $\begin{array}{l}\text { Awareness } \\
\text { and access }\end{array}$ & $\begin{array}{l}\text { All except } \\
9209\end{array}$ & $\begin{array}{l}\text { Awareness of and access to therapy and related services } \\
\text { produced both positive and negative emotions about therapy. }\end{array}$ \\
\hline God is enough & $\begin{array}{l}\text { All except } \\
1308\end{array}$ & $\begin{array}{l}\text { God is sufficient to handle life challenges, and all that is } \\
\text { needed to experience health and wellbeing, including } \\
\text { emotional health, can be found or is based in God. }\end{array}$ \\
\hline $\begin{array}{l}\text { Informal } \\
\text { therapy }\end{array}$ & $\begin{array}{l}\text { All except } \\
3944\end{array}$ & $\begin{array}{l}\text { "Therapy" can be experienced in interactions outside of a } \\
\text { professional setting, through meaningful, supported, and safe } \\
\text { exchanges and interactions that produce unbiased, relevant, } \\
\text { and profound advice. }\end{array}$ \\
\hline Relationships & All & $\begin{array}{l}\text { Supportive relationships with God and others, experienced } \\
\text { throughout a lifetime, produces feelings of being cared for and } \\
\text { feeling connected in ways that provide considerations about } \\
\text { how to live. }\end{array}$ \\
\hline Spirituality & All & $\begin{array}{l}\text { An understanding of God creates instant connection and a } \\
\text { paradigm with which to begin to understand oneself and the } \\
\text { connections between self, what one believes, and how one } \\
\text { functions; this understanding reinforces the relationship with } \\
\text { God and provides assistance in times of distress, in that God } \\
\text { acts as a resource and guide, as well as, a deterrent to } \\
\text { experiencing the full impact of negative life experiences. }\end{array}$ \\
\hline $\begin{array}{l}\text { Therapy as } \\
\text { resource }\end{array}$ & All & $\begin{array}{l}\text { Therapy is a resource that is beneficial to and for all, by } \\
\text { providing a type of support that might not be readily available } \\
\text { or accessible to some. }\end{array}$ \\
\hline Upbringing & All & $\begin{array}{l}\text { Where and how individuals are raised, provides a solid } \\
\text { foundation, which people did not often stray, and that } \\
\text { continually acted as an influence throughout life. }\end{array}$ \\
\hline
\end{tabular}

The primary characteristics of the super-ordinate themes seemed to be dedicated to using spirituality as a way to address challenges in life; even if the tool, as identified by God, is therapy. Additionally, an integrated understanding of spirituality and therapy seemed to be present in the all the themes. Furthermore, the super-ordinate themes were closely aligned with convergent themes, and even some of the divergent themes. For example, the theme 'life is hard, but I'm resilient' was addressed by seven of nine (78\%) of participants. Participants discussed the idea that resiliency was derived from overcoming trauma experienced by others or themselves. They seemed to be saying, as espoused by participant 6918 , regardless of the challenges life proffered "this is life, keep going." In the discussion that followed, the recurrent 
themes, at times, were interspersed with other themes to provide a fuller picture of the experiences of the participants and how those occurrences were faced.

Awareness and access. Participant reflection on awareness and access yielded a variety of events, concerns, and emotions related to psychological services. All participants, except 9209, shared information about therapy awareness. Some, like 1308, intimated awareness of therapy was based upon what was or was not discussed within their families or churches, which linked awareness to upbringing and spirituality. Participant 1308 had this to say:

I do feel that in our community, the Black community, I do believe coming up in a Black family, you never hear the word therapy, you never hear the word counseling; you never hear the word seeking help. ... Yeah, the thought of therapy, that's what I'm saying like as a child you know, you're not thinking about therapy. And, when I'm looking back, in hindsight, nobody I ever knew said anything about therapy. Even coming up in the church, the, that I grew up in, you didn't talk about therapy, never heard counseling. I never heard that term at all.

Participant 4551 suggested the type of exposure to therapy influenced if and how an understanding about therapy was developed:

I think it depends on how much expos, positive exposure you have. Aah, because I think many people, um different cultures may have had some kind of impact but it could've been our um, you know initiation of, of mental health services; but, if it's a very negative, aah experience for them or someone close to them then they hold onto a non-truth about therapy

She went on to suggest, reported awareness of therapy may be hindered by one's relationship with God: 
Um, sometimes therapy wasn't even mentioned; just pray, pray it away. That's what a lot of the older people thought. You don't need to go talk to anyone else; just talk to the Lord. ... Because, he was always taught, you know, just rely on God. So, he probably felt like he didn't need it. ... I don't know if he was taking his medication the way he was prescribed to take it or if he just, was praying. I hope he was praying. 'Cause that's how he was raised too, you know. ... Um, yeah, I think that some people could feel that if they're seeking a therapist that they may not or they may be perceived as not having a strong relationship with God. But, that again I think it's a, a lack of being informed and understanding.

Participant 6887 shared these sentiments as she talked about an uncle who struggled with mental health concerns:

I think at some point he probably felt like all he needed was his spirituality to get him through it, and he don't want to take the medication that was prescribed, I believed by a White doctor, you know.

As she recounted her uncle's story, elements of stigma and shame, and cultural mistrust were deeply woven into what she recounted:

But, he really didn't want others to know that. Just the family knew. He went to therapy, they gave him medication. I believe he started taking the medication. But not as regularly as he should have. ... Eventually, one day he came home, put a gun to his head, and killed himself. It was a big shock to the whole family. We knew he had problems. We thought he was on his medication. Apparently, he just felt like he couldn't take it anymore. 
The negative impact of her uncle's suicide and another uncle's subsequent attempt may have shaped her understanding of therapy in a way that suggested, therapy was ineffectual on some level or needed to be coupled with something else. Yet, she also seemed to recognize the value in therapy, as she stated "it can really help, if you use it, you know the way you should. If your take your medication, go to your sessions." She appeared to be suggesting therapy takes effort on the part of the client, but effort may be spoiled by issues of trust.

Other participants reported watching family members and/or friends who pursued therapy. They talked about an increased awareness, which, in some way, normalized the process and pursuit of therapy. Some revealed positive experiences. For example, 1308 disclosed her daughter's experience with therapy after being raped:

But, I will say this though [pause] um, my oldest daughter was raped and um when she was a teenager by some neighbor boy. So, for me it was such a traumatic experience, because that was, because that happened to me from a family member though. And, because I had tried everything as the mother, I tried to do everything to protect my children. So when this happened to her, I felt like a complete failure. You know like, I was, I was supposed to protect her, this, this should not have happened to her. And, when I went through the steps to do all I need to do with that, I think it was somebody who said, I think it was somebody who, I don't remember, I honestly don't remember where I got it from, but somebody had mentioned to me about [counseling center name redacted] and how I could probably get her in there and get her some counseling. So, that was probably my first, [slaps the table] first incident in my life that I had to, went outside to professional counseling, ... Oh, as soon as I heard it, as soon as I heard it I jumped on it! ... But she [pause] did wonders in there. She loved it. She didn't reject it. She welcomed 
it. So, I was very thankful to God that I was told about that. 'Cause I, I didn't know anything about [counseling center name redacted] you see. And, and that's another thing too. So, the resources, and again back to that home of origin, where in even this situation, I went back to child, my, back to my own childhood and nobody in my family knew about this situation, because I went back to my own situation that nobody knew about. And nobody in my family would've said 'hey you should get some counseling' or 'go' it would have been more like 'you should've did this' and 'how come this' and 'you.' It would have been more 'you' you know and I already felt guilty enough. So, I was thankful that, that that was brought to my attention. So, you know, that was my first experience with dealing outside the, a, a, the norm and just trying to deal with it on your own or just tellin' your friend or a close friend why you know that you need to share something with.

Participant 6887 talked about a friend's therapy experience:

I've known friends that have gone through tough times. Um, my first girlfriend went through a divorce before I did. And, she was just broken. ... And, she admitted that she had gone and sought help, professional help. ... And, it helped her. It pulled her out of that rut. She'd doing well now.

Participant 8790 shared her premarital counseling experience, which spoke to her familiarity and ease with the therapeutic process. She also talked about the stigma attached to therapy, for many people of color:

So, I did um marriage and uh, my husband and I we had to do premarital counseling before we got married. So, it's something that I'm use too. Also I know, it's still stigma for a lot of people, um, especially people of color 
While, participant 5251 disclosed how her father seemed to present therapy to the family, after it was determined her sister was in need of additional support:

I don't even think, at the time, I was aware of what was going on. I knew she was going to a doctor. I think I was older before we even had; I don't even know it came up that it was actually a psychiatrist. I don't think it was anything cloak and whatever, in the house, it was just like hey, whatever, and, um she's having some problems and she's going to a doctor. I found out later it was a psychiatrist, so it was just okay.

It was interesting that as 5251 talked about her sister's experience, she felt the need to discuss the lack of access to Black therapists when exploring the factors that shaped her thoughts about therapy, which may have been important in creating a safe space for her sister to face what she needed to face.

Several participants talked about how their level of education, volunteering, and other life experiences, seemed to facilitate increased knowledge about therapy. Participant 6918 shared: But, I think, from just my personal experiences and my background. Um, not to sound boastful, but I think given, how can I say it [pause] I, I, I was gonna say, given my education level, but I hate to kinda, and I don't want it to come out sounding that way, but, but I think because I'm knowledgeable, I understand. Because, I realize that mental illness exist. I realize that there are chemical imbalances. Um, I've worked with mental health agencies. I've done volunteer work. I've served on boards. I understand there's a need for that.

Participants 8790, 3944, and 1365 spoke about the impact of education on their awareness of therapy: 
8790: I eventually landed on um psychology as a major. ... I was for, a little over a year I was in a Master's/Ph.D. program in clinical psychology; because my ultimate goal was to do counseling work with adolescents. ... I guess psychological study and different things like that. And understanding that it has a very, a lot of important information has come out of the study and out of the research, helping us to help other people.... I guess all, through the different experiences that I've had, I've grown to have appreciation for um, you know just, just what serves as the basis for therapy...

3944: Um, well as a doctoral student in counseling psychology ... I would say a lot of in in addition to like, what I've learned in school ... just experiences [laughs]. ... so not just what I learned in school um you know, going to the trainings and things...

1365: I have my, I have a master's degree in counseling. ... for me um especially being in the, the counseling program, you know, you have your practicum and you have your internship that you have to do

Participant 5251, disclosed therapy was an integral part of the church she attended. She voiced regret about not being aware of what was available to her and other members of her church community. She also expressed discontent about what she considered a delayed response by African Americans, in accessing and engaging in psychological services, especially when those services were free. She said:

I just wish that we would take advantage of it. I do. I'm starting to hear it more often now in other camps, and now that we no longer have Pastor [name of licensed clinician on church staff] as a professional on our staff. ... And, many times, we, as people of color get in on the last end caboose and then we wish we had taken advantage of it, you know, a long, long time ago. 
It was clear that a variety of things created or increased awareness of therapy in the participants. Access, on the other hand, may have been hindered by lack of awareness, as discussed by a majority of the participants. Stigma, and the idea that God is sufficient may have also discouraged the access of services. Although not clearly documented in the excerpts from transcripts, an undertone of therapy as cheating on God seemed to resonate with some participants, reducing the consideration of therapy as a viable resource for moving through life.

Those that pursued therapy, discussed therapy as a way to put out fires, to use during times of crisis, or when something traumatic is experienced and spiritual resources have not effectively reduced the pain. Additionally, how others in participants' lives, responded to therapy, obviously, shaped whether or not access to professional psychological services would be pursued by participants. Participant 4551 supported these assertions and introduced the idea of using therapy preventatively:

... I think that individuals who are going through, not only crisis, obviously if you're in a crisis but, preventatively, aah people should not be afraid to seek therapy. Aah, that is, it can be very helpful, um to prevent major issues aah, developing into a crisis; that kind of thing.

Participant 4551 summed up the full impact of the limited awareness of therapy in two ideas, fear and mystery:

... Um, I think, just the fear of the unknown. Aah, that they, you know therapy is kinda still mystified; also, the negative stigma that goes along. Specifically, in certain cultures aah with saying that you have a counselor or therapist um lot of people are just afraid to, a fear of the unknown and the fear of being stereotyped as someone who is unable to appropriately care for themselves from a mental health standpoint. 
Black women may simply be afraid of what is not familiar, not consistently experienced within the Black community, or not conducted by those they relied on and trusted, seemed to undergird some of the participants' responses related to this theme.

Upbringing. As stated earlier, it is clear that a lot of factors impact what communities are aware of and how that awareness effected functioning. The link between awareness and access and upbringing was clear. Participants were also emphatic about the effect of how they were raised and by whom. Participant 1365 said:

Um, belief in Jesus Christ. Um, my Christian upbringing. Um, my aah current, um pursuit of um being a better person based on the Bible and its tenets. Um, I may have said this already, but you know, working to be a better person, to be a kinder person. Um, to be a person who is pleasing to God.

While, 3944 stuck with what was familiar in her Christian upbringing. She shared: ... Um [pause] I guess I would say, my upbringing, my mother, my grandmother, like church was just a part of the family. So, like that's, that's what we did. We believed in God, it was nothing different. Um, I grew up going to church at an early age [pause] um and so, I really just, just from early on, you know. Belief in God, is what was valued in my family, and so, I just stuck with that; and, that made sense to me and I felt like the experiences I've been through. I felt like there's always been something solidifying, you know, my beliefs.

Participant 9209 shared the influence of her upbringing as it connected to her spiritual growth and development. She remarked that she believed spirituality was inherent in the Black community and culture. Her comments were perceived as access and awareness of spirituality was more frequent than therapy. Here is what she had to say: 
I think that because we, we are [pause] culturally it's a part of who we are as well. If you look at the different cultures, our culture, as Blacks, it is [pause] a very, very strong part of who we are; and we need it, we have to have it because we, it's our survival. So, for that part yeah, that's what I would say. ... [Pause] we need it 'cause if ever you have a conversation with, a Black, such as myself, who has been brought up in the church, who's been around spiritual people, grandmas, uncles, and the like, people in the church, um we can we can tell you something 'bout what each one of those things mean to us and how they define us. How they mentored us, how they made us, uh grow into the beings that we become as adults. And, I think with each season of our lives, whether it's with, you know from our childhood into our, um adult, all the way into our senior years. We, we actually pull from that. We pull from what those foundations were, you know from the church, from family, and aah, even a lot of times, even the neighborhood. Because I can remember in the neighborhood, aah, as kids we grew up, we were impoverished and we grew up in an area where, ah even if you didn't go to church there was always somebody who had bible study in their house, in their living room or you always had the minister in the neighborhood who was preaching to you, so yeah. It was always, we were always surrounded by religion.

Based on her perspective, engaging in spirituality seemed to be an open invitation, compared to the perception of limited access to therapy for people of color.

She went on to say:

Umm, we were raised up in the church from little kids and we were always raised up in a way that God is first in your, in our lives. Um, we are to be respectful, we are to be 
mindful, so all of that teachings from our younger years, for those who have that, and getting into our older or our later years of life, it defines us in terms of spirituality. Additionally, participant 9209 reported church, in many ways, was an extended family. She discussed spiritual mothers, who mentored and guided Black women, were a part of her collective community and how she was shaped. Her compelling experience was provided below: ... [Pause] we moved to Ohio when I was probably ten, and the church that our parents took us to was the church in the neighborhood, to this day I still go to that church.... And, in that church there was mothers, mothers of the church; and the mothers of the church was as much your mother, spiritually, and guidance, mentors, as your own birth mother and for a lot of those who did not have mothers, they were they served that role. And one mother in particular, uh her name was [redacted], she lived to be 100, a 103, 104, she just passed away last year; [pause] she served as all of the women's mentor, and everything, all of her knowledge, all of her teachings, all of her everything. She passed it on to us and we all sit as church members, as individuals, and even some of the other mothers who are still alive, we still talk about what [name redacted] gave us. [Pause] so, I would say it's probably something along that line, in that it's ingrained in you.

Participant 6887 also discussed the impact of being raised with and by extended family members. She considered these experiences foundational in her development of a relationship with and understanding of God. She said "I was thankful. That's when I looked backed on that foundation, that my mother and grandmother raised us in." She reported that her connection with God was used as encouragement to move through tough spots in life. She said “no, you don't have to do this alone; you do have a connection with God. He knows what you're going through; pray to Him; rely on Him. You can't handle it all. You don't have all the answers, but He does." 
Participant 4551 revealed her mother's profession was integral in how she thought about therapy. She stated:

Aah, again I would say upbringing [laughs]. My mother, actually was a psychologist. So, being able to see her aah, help individuals um was aah very impactful um for me. And also, seeing aah you know or hearing how um people could be helped out in certain situations that chose not to seek therapy um has influenced me as well.

Being able to witness the positive benefits of therapy, at an early ages, seemed to help 4551 formulate her thoughts about therapy; in that, her discussion on how negative experiences may have skewed thoughts about therapy are fully noted.

Participant 6918 disclosed freedom in childhood, especially as it related to spirituality. She discussed going to church was a part of her family tradition, but seemed to be provided with a balanced experience and understanding about spirituality.

... And, I also wanna stress too [pause] my childhood was not like a hell stone, hell fire, brimstone. I mean you know, my dad went to church, um, my mom, you know, they went but it's, we still as kids did what, you know; we could do stuff. It wasn't like some families, you know that's all you do. We were not in church all day on Sundays. It was, I had a very good balance childhood ... with being, and again as I said, I attend the church that my parents were attending when I was born. Um, we still when we go to [location redacted] both my parents are from [location redacted]. But my family's, we go back to my father's church, which his, his grandparents, which would be my great grandparents, my grandparents, and then my dad grew up in that church. I've had a lot of consistency also. Not only was I trained that way, there was consistency. We didn't change churches. We've just been consistent ... 
Participant 6918, clearly demonstrated the central meaning of upbringing. Her experience modeled the idea that where and how individuals were raised, offered a solid foundation, which people did not often stray and that continually acted as an influence throughout life. This was also visible in participant 1308's life. She highlighted upbringing as having both positive and negative impressions on how she raised and interacted with her own children.

... I definitely [pause] have, you know they say the apple don't fall far from the tree [laughs] so, you know I've had to take a lot of self-inventory over the years, to [pause] try not to do or, like my mother did me and my sister, aah in ways that can be damaging. And sometimes, some things you really don't heal from. You just kinda recover from them and they can be very subtle, uh you know where you can function and go, but that wound, if, if you bump it hard enough, it'll still hurt. So, um [pause] I, I, I really try to be different in that, in that sense.

As hard as she tried, it was evident that 1308 had difficulty managing the influence of the relationship with her mother on the relationship with her own children. This was evident as she discussed her own struggle with the rape of one daughter and the eating concerns of another. She shared her story about her daughter with the eating concerns below:

... So, when I talked to her doctor, we were talking about getting her some counseling; she could talk to someone. And, we never actually did that [pause] though [name redacted] was okay with doing it. But the reason why, I chose not to do it um 'cause some of the stuff she, she would have been one-on-one with someone and I didn't want her to say; I was afraid she would get labeled. That's what it was. I was afraid she would get labeled suicidal or something. I just had this fear of that and [pause] she has never tried to do anything to herself. 
Her intent to do and be different was clear; her ability to develop attitude that supported this intent, however was not. Participant 1308 may have been influenced by her upbringing, stigma, and other factors that were not yet visible. She revealed her internal struggle in trying to do things differently than her mother. She said "I'm not against it [therapy] in any way. It just that I, I felt [pause] I just didn't think that was the right time for us to do it [therapy] for her." She went on to discuss having her own negative and forced experience with therapy. Her own sense of timing, may have been shaped by past experiences of her mother deciding things for her.

But, I had to go there every week and sit with the lady. Sometimes we, it was just me and then sometimes they would have um both of us in the room together. [Pause] but I, I never was open to it. I, I never li, I didn't like it at all, at all, so. And I was kinda quiet, kinda sheltered, timid young lady so, I wasn't; you know I would be damned, if I was like to have an attitude. You know an attitude, far as verbally bein' rude and all that kinda stuff. So I would just, you know when she asked me questions it was just, I would just say, shrug my shoulders or you know I'd just, wasn't willing to participate.

I wondered if this interaction, in some way, made therapy prohibitive for 1308; and by not immediately pursuing therapy for her daughter with the eating concerns, she was endeavoring to be different than her own mother.

Spirituality. As a theme, spirituality encompassed, spiritual practices, spirituality as a resources, and participants' understanding of God. Through their collective voices, spirituality was distinguished as an understanding of God that created connection. A paradigm with which to begin to understand oneself and the connections between self, what one believes, and how one functions was a major component of spirituality for participants. The understanding that ensued reinforced the relationship with God and provided assistance in times of distress. God acted as a 
resource and guide, as well as, a deterrent to experiencing the full impact of negative life experiences. A consensus was obtained regarding the impact of connection and relationship with God. This was clearly stated by 8790 as she shared where her hope rested:

And so even, you know, when you're helping me to deal with my feelings or helping me find tools to face the things that I'm dealing with on a day-to-day basis, that, my ultimate peace is just knowing that there's a Creator of this amazing universe that I look at on a day-to-day basis; Who created me, Who loves me, Who wants to have a personal relationship with me. And in that relationship, has promised to never leave me or forsake me. And, that's, that's where my hope and my peace is, 'cause in the midst of some of those scenarios, sometimes if feels like there's no hope or peace to be found. And, it's in Him that I cling and not to this concept or not this idea, but um to this great Creator Being, Who is the source of who I am and He's the one walking with me moment-bymoment, day-by-day, when nobody else is there.

While participants 5251, 9209, and 6918, respectively, discussed the merits of spiritual practices like prayer and Bible reading. They reported prayer as a way to shape their understanding about life experiences, and in many ways, as a first line defense for mental health concerns.

5251: You know. We prayed together, my sister and I went aah, but now I know the seed my father was planting in us. And so that seed germinated, and it has grown much fruit, and prayer is a big part of my life.

9209: [Pause] it can, depending on how deep things are within you. Yeah, it can. But, and I, and I'll just to give you an example; during the time my father was ill and close to his 
death; you know I did a lot of praying, and praying, and praying. And, I just felt like I was getting the strength I needed from prayer.

6918: For example, if I were [pause] depressed and I was or when I'm depressed and I'm suffering a loss; I'll just say when I'm depressed. There're a lot of other things I do before I do therapy. I might go shopping, I might eat, I might just curl up, and sit, but so that's one thing I may do and I may feel better after that. But then again, I may be, I may have some depression, in which I realize, you know what my things I like to do isn't pulling me out, so now I need to take this to another level. So, I might open my Bible, um, and then I may or I may consider therapy or talking to a friend. ... For example, prayer would be something I would consider more spiritual than therapy. So um, I can see where a lot of people will stop at prayer and not go on to the therapy. But, I understand prayer is always appropriate. But again, even with, and prayer is always beneficial...

Reading the Bible also seemed to provided assistance and guidance in responding to the trials of life. Participant 5251 said:

So, we would know His thoughts and we would know how to live according to His plan for us. ... [Pause] and the Bible, to me is the fulcrum, you might say or you know, it's the center of everything... How are you going to know how to respond to certain things that happen in life, if you're not reading what God says about it?! So, that's how it came to mean so much to me. That as ah a believer, I've been reading the Bible and uh, yeah it has shaped who I am. Because it does say it transforms you if you read it. It seemed that participants had a process of moving through a variety of support levels prior to considering therapy. Additionally, spirituality as a theme was multifaceted and covered 
many aspects of how participants connected with God or viewed their relationship with God as a resource. This was evidenced by the number of times the participants mentioned factors related to spirituality. For example, Bible was mentioned 25 times; prayer, 29 times; church, 140 times, God, 203 times, and spiritual 217 times, throughout the interviews. This was noteworthy because these words were not used in the interview questions. This suggested the participants had a deep investment in spirituality and all that was contained therein. Furthermore, it put forward the idea that spirituality, which was inherent in the upbringing of participants, and God were sufficient sources of support to manage life circumstances.

Participants showcased strength in a variety of ways. For example, Participant 5251 discussed strength in this way:

A lot of people when they have issues, they stop going. [Pause] that's your strength! That's your covering! And, that's where your get healed. And people had said to me 'you know what, I didn't even know you were going through a divorce.' I was in ministry; 'you kept coming. You were at your post' and I said to them, where'm I gonna go! Where else could I go?

She saw strength as related to using what worked in the past, in a consistent manner, regardless of the current struggle. What worked for her, was church. Participant 9209, expressed similar sentiments. She said:

I think spirituality, in a lot of ways define us. It define us in how we interact with, not only ourselves, but also with those around us. I think it's how we maintain our strength, umm, I think it is, in a lot of ways what keeps us going from day to day.

She also saw strength as coming via spiritual practice of prayer. She sated "[a]nd, I just felt like I was getting the strength I needed from prayer." While, 3944 found strength in song. She reported 
"[a]nd, it's a lot of different songs out there, I think that really had helped me um you know to feel stronger.” Participant 6887, also found strength through the spiritual practice of congregational worship. She disclosed, "[t]hen, I found out that there was something missing; and, that was the spirituality that came with being in the church with a group of people that worshipped God, and looked to Him for health and strength."

God is enough. Participant 9209 started with "we were always raised up in a way that God is first in your, in our lives." Participant 4551 spoke about the completeness of God in that He did not benefit from therapy. Participant 8790 disclosed she believed God was real, and that God was her primary source of identification and support. She also expressed the importance of the constancy of God:

And, it's in Him that I cling and not to this concept or not this idea, but um to this great Creator Being, Who is the source of who I am and He's the one walking with me moment-by-moment, day-by-day, when nobody else is there.

While, 3944 also supported this assertion. She said "so, God is still, I feel like God has been with me the whole way, no matter what." She conveyed the belief that diversified experiences allowed her to tap into God in a different way and to rely on Him when things were tough.

... So, so, it's a lot of different things I feel like I've experienced or seen that for me is like, God is real, and this is what I believe. ... And, even when I'm going through something, I know that things will get better or it's just a storm. And, and, and, um it may be something I don't understand at the current moment, but there's always a reason. I feel like there's always a reason, so.

Participant 6887 said she thought God was in control, as she navigated difficult experiences. She noted: 
... But, God has helped me through everything. My parents have been supportive. Of course, they got divorced years ago and I felt like I was cursed. I'm like no, everything's in control. I might not know what's coming next, but He does.

Ultimately, the majority of participants believed that God remained a constant force, Who was sufficient to handle the challenges faced in life. Participants alleged that they understood God was needed to experience health and wellbeing. They all seemed to recognize God as a basis for emotional health and support, even though they valued the resource of therapy.

Therapy as resource. Although the women talked a lot about God, they also discussed formal therapy in ways that were quite telling. Therapy in this theme was defined as professional psychological services and participants seemed to view therapy as a resource that was beneficial to and for all. Here's what five participants had to say:

5251: I think its great [laughs]! ... I think therapy is a wonderful tool and I do understand traditionally, people of our ethnicity, why they're skeptical and suspicious. But, if you wanna get healthy; and I believe God wants us to be healthy and whole. Ah, you gotta do something.

1308: I think seeking therapy is therapeutic [laughs]. .... I think everybody needs it. It should be mandatory [laughs].... I think everybody needs it. It should be mandatory [laughs]. ... It's just that therapy is not a bad thing. It's just not a bad thing. It's a good thing. 9209: ... I think therapy is good, it's cleansing.

6918: ... I think therapy is something that is, is a good thing. I think it's something that's needed. I believe there is benefits in therapy. Um, so I have no negative feelings about therapy at all. 
8790: ... oh goodness, I, oh I think it's very um wonderful, very needed, (136) ... it's just something that's very needed to. ... I really appreciated what it has to offer, what therapy has to offer. ... that's just a long way of saying that I think therapy is very valuable ... All the participants were sincere when they talked about therapy; but, their responses were pithy, to the point, and often without elaboration. It seemed therapy, in some way, was still a mystery, as previously mentioned by 4551 . For the participants, it also appeared that the idea of therapy, still held some stigma associated with mental health concerns or pursuing psychological services. As discussed in the awareness and access section, participants seemed to consider therapy as a resource that provided support, but was not readily available or accessible to some. Yet, a handful of participants talked about how their willingness to pursue therapy seemed to be shaped by how they understood their relationship with God. Hence, therapy is good, but for me, God is better.

It was also acknowledged that having this type of conversation with Black women, would play out in a variety of ways with participants. But, the overall discomfort, for many, was apparent. Without the increased awareness of therapy and/or mental health concerns, I wondered about the type of responses I would have received. Again, the interconnectedness of the themes was clear. Moreover, talking within the confines of relationships was viewed as therapeutic and was visible in many of the themes already discussed, and the themes of informal therapy and relationships.

Informal therapy. "Therapy" can be experienced in interactions outside of a professional setting, through meaningful, supported, and safe exchanges and interactions that produced unbiased, relevant, and profound advice. Participant 5251, led the discussion as she parleyed her 
experience of speaking with a church elder and the pastor about getting a divorce. She explained her experience in the following passage:

... And, um [pause] I, I talked to [name of pastor redacted]'s father. [Pause] and he was so, such a beacon of, of guiding light for me, and I also talked with [pastor's name redacted] because, uh I didn't think I had a problem, at the time 'cause what the Bible said about divorce. And, he gave me some very, profound advice. He says I John 1:9 says 'if you confess your sins, He faithful your sins and cleanse you from all unrighteousness' ask the Lord to forgive you and go on. Because, see we beat ourselves up a lot of times, and if we don't seek an outside voice, to let us know 'you're okay' or 'this is what you need to do from this point on.' It didn't stop the, um [pause]. Well! I remember how long. It wasn't a series of sessions I talked with him, but I did talked to him.

She seemed to walk away feeling the encounter was therapeutic based on the assumption that outside perspectives are important and that the advice/support provided was profound, and reduced distress related to the conversed subject matter. She also noted the wisdom of others or the ability to find confidence in another individual contained therapeutic elements. This was seen in the passage below:

$\ldots$ and, then if the person is wise or if you gain the confidence of the other person, then you might be able to refer them or usher them, direct them or say, well you know I'm not a therapist and I don't want to tell you anything wrong, but may you want to talk to somebody, who could probably, you know if they're amenable to that. You see an open door, and you might have started something that might not have taken place. I do believe in sharing and talking to other people is cathartic. 
Participant 6887, also had elements of profound advice/support, as evidenced in the passage below:

Because some of the things she had already gone through. I shared with her. She said 'wow that happened to me too.' And you know, you're thinking you the only one. I said, man I went through that too. It was just, it was a comfort to have somebody there that could, really understood what I was going through. And encouraged me to seek the help I needed.

She highlighted the influence of the relationship and saw the importance of relying on others. She also discussed interactions within her faith community were a way for support to be received. She said "[a]nd, we're, we're, members of the same church also. So, yeah, we rely on each other." Participant 8790, also revealed therapeutic features related to interactions in church: [T] hat was just a cool experience too, to me because, we would talk about so many different things. Then you would have the, the perspectives of all these different folks. And, and in my eyes you know, when I think about what therapy looks like in those types of, it kinda includes um, you know, I guess it's that idea of getting feedback from someone regarding, you know, the important things and events of your life; the things that you're experiencing or the things that you have questions about. Participant 9209 told of being encouraged to talk to someone informally. Below she shared her understanding of informal support:

I think, [pause] there was a stigma in our family and in a sense it was a stigma in the church. If you were hurting, if you were grieving, you were just taught to pray or go and talk to a minister. Ahm and a lot of times in the household, ahm, they were not well educated, but they felt ahm, you'll get over it. 
She relayed the few options, available, due to stigma included, pray or talk to a minister. The minister was most likely untrained in providing emotional and psychological support. However, the option to 'get over it' was provided by family members.

Participant 3944, on the other hand sought the comfort of women in her church group for support. The group was a constant in the lives of the women who participated in the group, and seemed to provide opportunities for deep connection. She said:

... So, I felt like they were real people. I guess, they are Christians, but, they also, you know they're moms um, they go through things, you know, and so I felt like I learn, learned a lot from them. ... And, none of us anymore, I think are really active in [type of church group redacted]; however we are very close friends. Um, and so we've, we text each other regularly, we support each other, we pray for each other, um we know what we're going through, and we don't do it in such a way that um, you know you're judging anybody. So I felt like, you know, not judged. I felt like everybody was there to support each other. And just, teach each other. Like this is how God would want you to work... Participant 1365 agreed with this premise, but opened up who the interactions could take place with. She stated:

... I think that you know, a conversation between two individuals can be therapeutic. ...that we as two people, can, can dialogue and you know make one another feel better. ... Um especially if, if there's, if there's really dialogue between the two.

She went on to say:

... Yeah, well um because if I can get; let's say it's you and I and we're friends and I can get what I need from, from you as my friend um along with my belief system, I don't wanna count that out at all because, that is my foundation... ... but if I can, as a friend 
have someone who's hearing what I'm saying, understanding what I'm saying, aah to the best of her ability, and then giving me, giving me something back, that you know, encourages me or, or, or um if nothing else you know, I know what you, you know, I, what you are saying' um then that would decrease, at least for me, in my head um, the need for any kind of a formalized therapy session.

Participant 1365 emphasized the need for the dialogue to be between individuals on the same spiritual level that facilitated being heard.

Whereas, 1308 saw the importance of alternate forms of support for her youngest daughter, found within the family structure:

Everybody gravitates to her; like nothing's happening to [name redacted] bad [laughs] you know if anything, the world will get turnt upside down over this girl, you know, so she has a strong family support and she know it, you know and she had, and then she has five other sisters that she can tell, but see they all had each other in school. ... In my house, it's, its five girls and two boys and me, so [pause] I had a big load to, to try to you know, raise these kids up. So, and, and try to get them as healthy and feel like they can; and I'm not sayin' they talk to me 'bout everything. Sometimes I'll wanna to know. As a mother, I'm like, oh God. But they have each other and they're all close and you know, sometimes I can talk to them about my stuff.

She also disclosed the negative effect of needing a space to talk about her own traumatic experiences, but not feeling as if this was available to her:

I just, I'm just saying for me the things I know that happened to me; that I know were, were definitely traumatizing [pause] but then if you don't have anybody to talk you 
through those feelings that you're feeling, you just learn to deal with it in your, on your own way; and that's what I did. For me it was just be quiet.

What's interesting about 1308's experience, as recorded earlier, was feeling as if therapy was forced upon her by mother. Maybe, she would have been open to the process were there informal opportunities to discuss her experiences or a positive or supportive relationship had been developed with her mother or another adult woman in her life; and, the issue of timing may not have presented itself when she wrestled with what to do with her youngest daughter's eating related concerns.

Participant 6918 divulged having a friend in the field of psychology. She said:

Um, I have friends that um, are psychologist and work in the field and I have talked to them about issues of depression and they've shared information, so in that sense I've sought therapy. So, I would say that I’ve definitely sought therapy.

There appeared to be a lack of awareness, on 6918's part, regarding ethical parameters surrounding dual relationships within the profession. In spite of her friend's limited capacity, as a psychologist under these circumstances and albeit informal, 6918 felt the encounter, for her, constituted therapy. Participant 1365, on the other hand, discussed the impact of limited access to a friend in the profession:

Um, in fact I actually was planning on speaking to [name of psychologist redacted]. And, and it was about some dreams that I'd been having. Um, and then I couldn't reach her aah for whatever reason. And then I decided that I knew what the reason was. So, um I didn't actually get that far. I would have, had I been able to reach her the day that I tried to contact her. But, since I didn't and I'm, and I'm tryin'a always figure out what is causing the, the dream issues. Aah, I did finally figure out, I think, what the issue is. 
Maybe the idea that she had someone to talk to was sufficient to help her move forward. It also appeared that informal therapy was seemingly, facilitated through the strength of the relationships that participants had with the individuals they identified in their stories.

Relationships. Supportive relationships with God and others, experienced throughout a lifetime, produced feelings of being cared for and feeling connected in ways that provided considerations about how to live. In the discussion on informal therapy, the alliance or relationship between participants and other important persons in their lives, stood out. To share private things with someone, at least for the participants who endorsed the theme of privacy and/or discussed silence being modeled, suggested a relationship needed to be in place, in order for informal support to be effective. Secondly, who the relationship was with also seemed to be important. Participants discussed relationships within their families, churches, communities, society, and with God as relevant.

The passages below highlighted several of the most prevalent types of relationships described by participants. These relationship types were visible in factors related to both, spirituality and therapy. Participant 8790 discussed how parental involvement and engagement with school personnel shaped her thoughts on therapy. She noted support was modeled for her and this was appealing:

$[\mathrm{M}] \mathrm{y}$ parents have always been very involved in my life; and to the point where my dad was a frequent visitor to the school. ... a lot of times we would just have conversations growing up, you know, with teachers, and you know, it'd just be causal conversation after school or after practice or whatever. ... when I talk about all those things earlier, about some of my career thoughts, I think when I thought about doing counseling work that was one of the first thoughts that I had was being a school guidance counselor, something like 
that. But then, I remembered, I worked in the office of my school guidance counselor when I was in high school. And, I really liked a lot of what she did and her interactions with students and that type of thing. ... Um 'cause I also worked in the office of the guidance counselor when I was in junior high as well. Um, who was an African American woman and then um my guidance counselor in high school was a woman; she was Caucasian and the man that I mentioned he was a Caucasian, you know.

The idea of her parents being available to and for her, seemed to give 8790 pride and confidence in choosing a career path in the helping field. Those relationships were also important in developing her understanding about therapy.

Participant 6887 noted what was modeled in her family was important, as well. She intimated that the relationship within the family structure encouraged younger family members to remain true to how they were raised.

... There was a big connection. Big modeling there. Like I said, my grandmother. I remember her most, my mom's mother. And then, after she passed away, the same modeling I saw in my mother, and in my dad's mother, and it just went on down the line through the generations. Like wait, they're on to something [laughs].

Participant 6918 concurred and provided the best example of this. She said:

... Um, given that foundation, then as I grew older I just, again my faith grew out of what I was taught as a child; because of what they experienced and what they shared with me. So, I think then I, as a young adult started to make my own decision; this is what I choose to do. I choose to continue down this path. So, I think as a young adult, I, it was just a choice to continue down the path. 
Relationships within the family and upbringing were intimately linked as participants talked about understanding spiritual factors, therapy, and how to live. This was exampled in 9209's idea that spirituality was needed and the relationships that facilitated that were in the church. She conveyed the importance of being around and mentored by spiritual people:

... [Pause] we need it 'cause if ever you have a conversation with, a Black, such as myself, who has been brought up in the church, who's been around spiritual people, grandmas, uncles, and the like, people in the church, um we can we can tell you something 'bout what each one of those things mean to us and how they define us. How they mentored us, how they made us, uh grow into the beings that we become as adults. And, I think with each season of our lives, whether it's with, you know from our childhood into our, um adult, all the way into our senior years. We, we actually pull from that.

She recognized that those relationships also extended into the community, which acted as a bastion for growth, in many communities. This excerpt communicated much:

We pull from what those foundations were, you know from the church, from family, and aah, even a lot of times, even the neighborhood. Because I can remember in the neighborhood, aah, as kids we grew up, we were impoverished and we grew up in an area where, ah even if you didn't go to church there was always somebody who had bible study in their house, in their living room or you always had the minister in the neighborhood who was preaching to you, so yeah. It was always, we were always surrounded by religion.

The intimate connections between relationships and spirituality were clearly developed in 9209's words. This connection was also seen in 3944's excerpt below: 
... And, then also getting involved in my church was really helpful too. So, um, I'm actually pretty close to our first lady of our church. And, then our pastor too, but really the first lady. She, um implemented this aah, sister's leadership like, sister's conference. So, it's an annual bonding conference and um, we're actually going into our fourteen year. But, I'm on the executive leadership team and my mother was always an active participant too. So, that was also another way me and my mother would bond. But, it was always like a way to bond with your, um, sisters, and learn more about Christ. But, it was also real as well and I think that really helped me to connect.

She highlighted the dimensions found in relationships in church. She also revealed church provided a chance to develop deeper relationships with old and new individuals in ways that were meaningful.

Participant 1365 delivered a blended understanding of relationships, spirituality, and therapy. She stated the importance of being cared for as central in the relationship:

... I think it's more along the lines of, of what I've just been expressing about having a, um relationship, being in a relationship with someone who um who, who cares about you. Um, who understands, pretty much who you are. Aah, and the, the two things because, you know, my friends are gonna be, for the most part, I'm not saying I don't have friends who aren't Christians, but my, the my, my, close friends are Christians. So, um if, if I can connect, aah on a level with my, with, with my close friends um that allows us to a dialogue and share with one another um on, on any subject that we might be talking about; to me that connects them both.

Participant 8790 disclosed finding a hope in her relationship with God that surpassed other relationships, based upon what produced in the relationship. She averred: 
And so even, you know, when you're helping me to deal with my feelings or helping me find tools to face the things that I'm dealing with on a day-to-day basis, that, my ultimate peace is just knowing that there's a Creator of this amazing universe that I look at on a day-to-day basis; Who created me, Who loves me, Who wants to have a personal relationship with me. And in that relationship, has promised to never leave me or forsake me. And, that's, that's where my hope and my peace is, 'cause in the midst of some of those scenarios, sometimes it feels like there's no hope or peace to be found. And, it's in Him that I cling and not to this concept or not this idea, but um to this great Creator Being, Who is the source of who I am and He's the one walking with me moment-bymoment, day-by-day, when nobody else is there.

She also discussed the indwelling of the Holy Spirit as having influenced her life; while, 4551 shared her belief that her relationship with Christ encapsulates spirituality

8790: Um, I would definitely say, as um, as a follower of Christ based in, as a part of that belief system, just believing that the Holy Spirit dwells in me and that, that, that the Person of the Holy Spirit influences my life on a daily basis in terms of spirituality. 4551: Um, I believe that spirituality is um well for me personally, it has to do with a relationship um as opposed to a religion aah, but, some people aah view it as a religion. And um [pause] yeah. ... Christ, Jesus Christ.

Participant 4551 stressed that "the further you gain a knowledge in um, especially with regards to relationship with Christ aah the more influential it, it, it really does have an impact and is a factor." 
As identified earlier by participant 8790 , relationship produced peace and hope. She also posited that a relationship with God produced security and allowed access to greater levels of strength to help her cope with difficult events:

And, I think um just in that relationship with God and in that security that people [pause] will find in the One who created them, and who loves them, and wants to be in relationship with them that they find a, I guess, a strength that they maybe never knew was available to them; you know to be able to cope.

Whereas, 5251 talked about her family, in particular, her relationship with her father and grandmother. She primarily talked about those relationships as she shared stories about how she was raised. Because much of what she learned in childhood remained, the relationships were clear. Here's what she had to say:

Certainly, my family. God placed me in a, ah Godly family, with a wonderful father, who had a correct understanding of the word of God; and I'm thankful for that now. Did not appreciate it early on... we're going to church! We're going back to church! It was like aagg! You know. We prayed together, my sister and I went aah, but now I know the seed my father was planting in us. And so that seed germinated, and it has grown much fruit, and prayer is a big part of my life. So, my family, and my Godmother, my grandmother, excuse me, was a Godly woman, and ah, they lived the life. I'd have to say, my father lived the life before us.... And, I know I wouldn't be where I am spiritually, if that had not happened. 'Cause my father was, you know he prayed with us. He talked with us. And, as I said, he modeled what he believed before us.

While participant 1308 talked about a childhood friendship that shaped her in a variety of ways, but mostly spiritually. In the following passage, she talked about her introduction to 
spirituality and that church became a safe haven, as she sought opportunities to escape her home life. ... the influences I had coming up as a child. ... And for me, as it happens, it wasn't really family influence, it was more peers. So I had a young girl, a young friend of mine actually, we were best friends, second and third grade, used to talk to me about God, and Jesus, and the Holy Spirit, and speaking in tongues; all the time. ... And, I, I went to church though. My mom didn't go with us. My mom would drop us off then go back home, so I, it was just my sister and I. I liked going to church. For me church was an escape from home. So for me church was a, a way from all the stuff that I had to deal with at home. So, when me and [name redacted] were friends her, her family, they all went to church together. They were [denomination redacted] I went to a [denomination redacted] church. .... But for me, as I said before, it was a safe haven for me to get away, if I didn't go to church [pause] my, my week was off. Everything was off for me. So, um once [name redacted] left, that, that didn't stop me from going to church; I still went to church.

The impact of this relationship on 1308 seemed to continue even into adulthood as she described traumatic experiences and viewing God as a hope and anchor when she encountered difficult times. She seemed to place great value in her friend who facilitated her introduction to God. Because of that relationship participant 1308 seemed to view church as a safe place and a way to escape and survive though life events.

Divergent Themes. Six divergent themes were identified. The themes are effects of slavery, God provides, privacy, relationship with God does not exclude therapy, therapy is a temporary fix, and you are not alone. A few selections were chosen to showcase some of the 
divergent themes and facilitated the start of participants' telling their stories. The passages were interesting, in that, they provided insight into the experiences of participants. In many ways, these excerpts highlighted the importance of exploring things that are, oftentimes, not spoken of in the importance of exploring the spiritual perspective of clients and the impact of those perspectives in the pursuit of psychological support.

For example, participant 5251 and participant 6887 discussed the effects of slavery on the experiences of Blacks in America and how this potentially impacted the development of helpseeking attitude and seeking therapy. To highlight this point, an excerpt from participant 5251's transcripts was highlighted as she discussed her thoughts on seeking therapy. She noted:

...Well, I guess I would have to say, it goes back to slavery. For one thing, we don't have any clear, we haven't severed the tie, the emotional ties ah, from slavery. Physically we may not be enslaved, but emotionally, we still carry those scars generation after generation after generation.

She went on to discuss issues with cultural mistrust and the myriad of challenges faced by Blacks in America, due to what she thought of as betrayal experienced resultant of slavery. She said "But we, we have this fear of trusting because of the betrayal, I guess I can use that word, down through the years, the way we've been treated." Participant 5251's experience was expressed in ways that suggested the African American experience, as it related to the impact of slavery on psychological functioning, may be more impactful in ways that were not always recognized or acknowledged by Blacks or White Americans. She went on to say:

We know we live in the fallen world, and we know that uh, well, I remember something that [pastor's name redacted] said years ago when we were, might, might have been during Martin Luther King’s month or Black History Month or something; we were 
talking about race and some other things and he, oh how does it go, what did he say [pause] it wasn't a danger, what was the word. Being Black, everyday being Black in America, is oh what the word was. I shouldn't of mentioned it, I can't think of the word. But, here again this was something, like the residuals of slavery, that every day we're faced with, we have to make monumental and we, we're facing all kinds of dif [sic], discrepancies, deficiency all the heavy D words. That's what I call them, the negative heavy D words.

Even though, only two participants identified this theme, it was worth mentioning, as unspoken things often influence how attitude is developed. Participant 5251, also seemed to link the idea of slavery as potentially having an adverse impact on the pursuit of therapy for some African Americans.

Participants 8790, 3944, and 6887 identified the theme of you are not alone as important. These participants all reported they experienced the loss of loved ones by death or incarceration, which may explain the saliency of this theme for these participants. Participant 8790's comments were presented as an example, as she discussed the idea of not being alone.

And, I think [pause] I think it just ultimately um, if I was just trying to, to simplify it, it's just realizing that I'm really not in this alone. And, even when I feel like it, because of my experiences with all the people around me, even when I feel like I'm alone that ultimately, I'm not alone. I'm not abandoned. And, I think um just in that relationship with God and in that security that people [pause] will find in the One who created them, and who loves them, and wants to be in relationship with them that they find a, I guess, a strength that they maybe never knew was available to them; you know to be able to cope. 
She appeared to connect the idea of the constant presence of God in her life, provided a level of unexpected strength to cope with difficult life experiences. In some ways, she seemed to intimate a relationship with God produced security in addressing concerns that would reduce the need for formalized therapy; especially if therapy were viewed as a strategy to cope with life challenges.

Three divergent themes God provides, relationship with God does not exclude therapy, and therapy is a temporary fix underscored the role of God in the lives of participants and intimated continual provision for God's people through a variety of resources, which were inclusive of God, church, and therapy. The theme of privacy on the other hand truly spoke to an unwillingness or inability to share past experiences in ways that would demean or diminish participants' their understanding of themselves or others. Privacy, also seemed to highlight what participants desired to present to their families, communities, society, or themselves. Divergent themes provided a solid lead-in for the discussion of convergent themes.

Summary of results. Data from nine participants were explored and a summary of their responses was provided in this chapter. The interviews were analyzed using Interpretative Phenomenological Analysis. Seven super-ordinate themes were identified. The themes were: 1) awareness and access; 2) God is enough; 3) informal therapy; 4) relationships; 5) spirituality; 6); therapy as a resource; and 7) upbringing. The mixture of convergent and divergent themes demonstrated through participants' responses showcased the complexity of developing helpseeking attitude and the role spirituality played in the participants' understanding of therapy. Other themes, acknowledged by one or two individuals, also may have enhanced the understanding of these factors for participants.

Eight thematic elements were found that did not relate to the emerging master themes. Six divergent themes were also found. Themes like shame/stigma, God provides, and therapy is 
a temporary fix, though not endorsed by all participants, were an important part of understanding participants' responses, in that they offered insight to unknown factors that shaped help-seeking attitude. How participants discussed some of the divergent themes, primarily connected to fear, cultural mistrust, and lack of awareness about therapy, was also important to mention. Although, some themes were not well endorsed, they seemed interspersed throughout statements provided by participants. Eleven convergent themes were identified. Of these 11, seven themes were classified, based on frequency and thematic significance, as super-ordinate themes, and are listed above. Three of the super-ordinate themes, which were consistently represented in participant responses included, upbringing, relationships, and spirituality predominated in the findings.

The theme of upbringing was endorsed by each participant. The cultural and contextual factors for this theme, included the age of participants, how they were raised, and by whom. Additionally, the region and the social and cultural climate of the time of their birth and childhood, may have dictated a certain response to particular events, again, shaping thoughts on spirituality and therapy in unexpected ways. Many participants came from households of parents who were professionals, some of which were engaged in helping behavior as a career or way of life. Some participants were exposed to the ideas of immediate and extended family, as well as, community members. Such interactions appeared to increase the prospect of participants being subjected to a variety of perspectives.

The relationship theme was woven into upbringing and spirituality, and acted as a bridge between the two. The influences of relationships were clearly delineated in participants' interactions with family, friends, community members, and God. The relationship theme provided foundational understanding of spirituality and therapy, advanced those understandings, and seemed to encourage participants to consider the value found in therapy. Although primarily 
positive, the effect of relationships held undertones, not so positive. The relationships found in participants' families that encouraged privacy is one such example. Though not always clearly linked, this theme seemed tied to shame and stigma. Also, when relationships were described as wounding or harmful, the influence on therapy was often experienced as negative; whereas, spirituality was used to counteract this negativity. By helping participants expand their ideas about therapy, awareness of services and considerations about accessing treatment, were increased.

Spirituality, was the largest category within themes. Spirituality encompassed spiritual practices, spirituality as a resource, and a variety of spirituality concepts. Participants mentioned Bible reading, praying, inspirational music, worshipping, and church attendance as important spiritual practices. Whereas, spirituality as a resource was visible based upon how certain practices were used. For example, prayer was viewed as a resource when used to reduce the impact of life stressors. Participants discussed spirituality throughout the interview and assured me of the effect of their spiritual foundations including, spiritualty as a resource for resiliency.

The above information granted readers a fuller picture of how past experiences potentially shaped participants' current thinking on pursuing therapy; especially, when viewed in light of the themes. It was also clear that the three themes, upbringing, spirituality, and relationships were crucial features of how participants understood both spirituality and therapy and impacted how they developed help-seeking attitude. The discussion to follow explored the themes presented in this chapter as they related to the research questions of this project. 


\section{CHAPTER 5}

\section{Discussion}

This study is one of a few studies to explore the connection between help-seeking attitude, spirituality, and therapy. It was one of the first projects to explore these constructs specific to Black women and the development of help-seeking attitude. By examining these constructs together, this study provided a unique opportunity to survey the lived experiences of Black women to better understand what factors influence how they cultivate help-seeking attitudes. Interpretative Phenomenological Analysis (IPA), used to gather, analyze, and report data from the nine participants was described.

The study focused on two major research questions: 1. What do Black women believe or think about seeking professional psychological services; and 2. What role does spirituality play in shaping the help-seeking attitude of Black women? This final chapter provides a discussion of the results which, includes answers to the research questions, gleaned from the results. Additionally, limitations and the implications of the findings for religious and spiritual communities, and the profession of psychology are provided. Lastly, recommendations for future research are incorporated.

\section{Results.}

Use of IPA was effective in pinpointing the meaning behind everyday events and to uncover the lived experience of participants. Detailed examination of the transcripts, yielded information that might be useful for faith-based communities and mental health practitioners, with regard to increased understanding of these experiences for African American women. The outcome of the study supported prior research related to help-seeking attitude in people of color. For example, self-disclosure was identified in past several (see; Kahn, Achter, \& Shambaugh, 2001; Morell \& 
Metzl, 2006; Sisley, Hutton, Goodbody, \& Brown, 2011; Watkins, 2000) as having an influence on help-seeking attitude in people of color. For this study, self-disclosure paralleled what participants identified as privacy. It was clear that privacy issues impacted the decisions of many participants to pursue professional psychological help. Cultural mistrust was another factor reported by participants (see; Cooper-Patrick, Gallo, Powe, Steinwachs, Eaton, \& Ford, 1999; Mitchell, 2004; Nickerson, Helms, \& Terrell, 1994; Townes, Chavez-Korell, \& Cunningham, 2009) in subtle ways. How participants utilized social networks (Golding \& Wells, 1990; Wallace \& Constantine, 2005); and, results related to stigma (Ang, Lim, Tan, \& Yau, 2004; Morrell \& Metzl, 2006) were also supported by the results of this study. Lastly, participants' understanding of availability and access to mental health services, in this study, seemed to also support what Alvidrez (1999) and Davey and Watson (2008) found in their studies.

Though discussed by only one participant, the impact of not having access to a therapist of Color, in many ways supported the premise of Carkhuff and Pierce (1967). Carkhuff and Pierce (1967) submitted that increased efficacy, often times found in same race and ethnic therapy dyads, were related to creating environments for a depth of self-exploration. This seemed important enough for participant 5251 to bring it up during the interview. She said “... you couldn't readily go to a therapist of any kind, and certainly not a therapist of Color." Moreover, her statement alluded to the work of Guthrie (1998), Daniel (2009) and other researchers (see; Chandler, 2011; Hammond \& Yung, 1993; Moradi \& Neimeyer, 2005) who discussed the importance of diversity in the research and practice of psychology.

The notion that strength was found in spirituality was clearly articulated by several of the participants. The saliency of this construct, as it related to Black women, was initially discussed in Chapter 2. Chisholm (1996), who viewed strength as inherent in the experiences of Black 
women and others, who saw both positive and negative aspects of strength (see; BeauboeufLafontant, 2005; Harley, 2005; Woods-Giscombe, 2008) provided the groundwork to examine strength within the context of spirituality for research participants.

Additionally, participants' responses were also consistent with prior research conducted by Fischer and Cohen (1972) who identified educational level as a positive correlate with helpseeking attitude. This was evident by the fact that all of the participants held a bachelor's degree or higher and help-seeking attitudes were positive; however, this positive correlation did not necessarily translate into being actively engaged in help-seeking behavior. The discussion below on beliefs and thoughts related to seeking services, highlighted the complexity of help-seeking attitudes versus help-seeking behaviors.

Beliefs and thoughts about seeking professional psychological services. The first research question explored beliefs and thoughts about seeking therapy. Two interview questions were used to elicit this information from participants. Participants were asked "What are your thoughts on seeking therapy?" and "What factors influenced your thoughts on therapy?" The fundamental message presented by participants, on seeking therapy, was that therapy was a viable resource and option, if one were in need of support. Each participant seemed to view therapy as helpful when responding to the questions above. To fully comprehend the degrees of understanding by participants, it was important to examine both convergent and divergent themes related to therapy.

The range of beliefs about therapy was expansive. All participants viewed therapy as a source of potential support. Although considered a resource, participants 5251 and 8790 did not see therapy as substantial enough to address the root of problems. In many ways, they considered therapy a temporary fix for most of the problems they encountered in life. For 5251, her thoughts 
about therapy may have been shaped by her beliefs about the effects of slavery on the mental health of African Americans. In her discussion of this subject matter, she talked about generational markers, cultural mistrust, and lack of access to Black therapists, as well as, "heavy D words" (discrepancy, deficiency, etc.) which, appeared to reveal some of what she believed was resultant of the African American experience of being enslaved.

Participant 5251 highlighted the work of attitude formation researchers in very salient ways. According to Albarracín, Johnson, Zanna, and Tarcan Kumkale (2005) attitudes, in part, were developed through the interaction of memories, judgments, and beliefs, which may not be joined to a specific thing but, suggested linkage to a particular idea, person, or thing. Although 5251 was not born during slavery, she intimated that memories, judgments, and beliefs were passed on from prior generations, and that those recollections of past hurts, still had the ability to negatively impact African Americans. She also appeared comfortable as she discussed her thoughts on informal therapy and therapy provided through or in tangent with spiritual resources seemingly contrary to the idea that therapy is sufficient to stand on its own.

This was consistent with other participants. They would agree that a construct was great, but, as the interview progressed, elements that could potentially render that agreement null and void, would emerge. This was most noticeable in that participant responses were integrated with spiritual overtones. God was everywhere; even as they acknowledged difficult experiences. The strength of their relationships with God was found in their upbringing and other interpersonal connections. The way participants engaged with the phenomena reminded me of the passage of scripture that admonished parents to train up a child in the way they should go; suggesting that as they aged, they would return to foundational truths learned in childhood. Example after example of participants returning to their spiritual roots was provided even as they talked about therapy. 
With the unity of overarching themes presented by participants, the dissonance was also striking. Clear distinctions were made when participants considered whether or not there was a link between therapy and spirituality. Participants 5251, 6918, 4551, 3944, and 6887 suggested this was the case. While, participants 8790, 1308, 1365, and 9209 disagreed. All participants, except participant 3944, agreed there was variability in what constituted therapy. Most of the participants identified family, close friends, and/or clergy members as important parts of an alliance they considered as similar to the therapeutic alliance. They acknowledged that these individuals were adept enough to provide an abundance of sage advice, as well as, had the ability to create environments that facilitated authentic exchange. This combination of factors seemed to produce change and growth in some of the participants.

Ultimately, the help-seeking attitudes presented by participants aligned with, as mentioned earlier, past research studies. According to Albarracín, Johnson, Zanna, and Tarcan Kumkale (2005) this should help to predict help-seeking behavior, and would suggest that participants would have been actively engaged in therapy especially during difficult times. This was not the case for this group of women signifying other, unspoken or unknown factors may have been involved in their development of help-seeking attitude. For example, although participants were positive about therapy, approximately $56 \%$ of participants reported seeking treatment in their lifetime.

Additionally, strength, a construct not studied in this project, was presented in a myriad of ways by participants. Strength seemed to be changing or articulated inversely by this population. Strength also seemed to be understood differently by participants. It wasn't a matter of I have to do this alone; it seemed more so like, I am not alone, because God is with me. That idea permeated the study, potentially reducing feelings of deep loneliness or isolation. How they 
talked about therapy, in light of the questions about spirituality, and whether or not they saw a connection between therapy and spirituality, yielded complex and nuanced results. Furthermore, spirituality seemed to act as a deterrent to participants being swallowed up by traumatic experiences (Holmes \& Hardin, 2009). The idea that it, spirituality, was working positively during challenging times may suggest a decreased need to access mental health services (Holmes \& Hardin, 2009) and could be the missing factor in understanding help-seeking attitude in this population.

The role of spirituality in shaping help-seeking attitude in Black women. The second research question explored the role of spirituality in shaping help-seeking attitude in Black women. Based on the information presented in the last section, it is clear that understanding participants' thoughts, as they responded to questions about spirituality, was essential to understanding this phenomena. Participants were asked "What thoughts can you share with me about spirituality?" and "What factors influenced your thoughts on spirituality?"

The spirituality theme, as a whole, was replete with elements that supported the models of spirituality, as discussed in Chapter 2 and endorsed by $100 \%$ of participants. The dispositions of Holmes and Hardin (2009) and Richards and Bergin (2000) were endorsed by many of the participants (see; Chapter 2, Spirituality as concept). How participants answered these questions, seemed to address many of the spirituality models discussed in Chapter 2. Many of the participants, seemingly endorsed the Allport/Kahoe Model of spirituality ((Allport, 1950; Kahoe, 1985) as they shared both extrinsic and intrinsic elements of spirituality. Approximately $89 \%$ of the women talked about spirituality being lived out in their lives, based upon their ascribed belief system and their evolving relationship with God. Participant 8790 was unique in her response, because she did not directly discuss a relationship with God. She alluded, however, to the 
developmental aspect identified by Allport/Kahoe Spirituality Model (Allport, 1950; Kahoe, 1985). She said:

... in terms of my own experience, I always just think about [pause] the fact that I've always be, believed in God, always been taught to believe in God. And, so that's where I started and I watched that growth and understanding kinda grow over the years as I came to know Jesus um, and had different experiences. ... when I think spirituality more broadly if often brings to mind, um just the various things that I've come in contact with over the years um, you know from my college experiences and meeting folks from different backgrounds and even just understanding some of um, aspects of our, I guess Jewish heritage when I think about the foundations of Christianity and how the Lord chose to reveal Himself to um, the Jews, of course it's kinda reached all of us at this point in time.

Her responses hinted at the idea of relating to God via the information He provided about Himself in the earth and how those things shaped and, in some ways, explained her lived experience.

Responses provided by participant 3944 , on the other hand, were slightly different than that of other participants. Participant 3944 appeared to focus on spirituality as a subset of religion, which endorsed the Koenig Spirituality Model (Koenig, 2009). She talked about spiritual practices and how her identified denomination shaped her beliefs. She did not speak of a relationship with God, just belief in God and Christ, and the support she was afforded through that belief. This participant also talked about her struggle of balancing spirituality with psychology. During the interview, she shared experiences in her training where religion was looked upon as a crutch. She noted: 
But, I know, I remember when I first started school, and how it [spirituality] was like totally separated from everything. And it was looked upon as a crutch. You know, and people saw it as, you know people's religious beliefs or spirituality was a crutch.

Overwhelmingly, participants seemed to be saying, their foundational truths, established in childhood or through their upbringing and the relationship with their God was sufficient in helping them maintain a modicum of emotional health. This was substantiated by several divergent themes. Although only three participants explicitly identified the theme of you are not alone, how they talked about God suggested that others also felt they were not alone. Some participants discussed levels of spirituality that allowed them to incorporate therapy as a tool, after prayer. They seemed to be saying, that therapy became more of an option, if they were able to connect therapy to spiritual beliefs. For example, 5251 discussed the notion doing something:

I think therapy is a wonderful tool and I do understand traditionally, people of our ethnicity, why they're skeptical and suspicious. But, if you wanna get healthy; and I believe God wants us to be healthy and whole. Ah, you gotta do something.

This fit with other participants as well and, in part, explained why approximately $55 \%$ of the participants saw a connection between therapy and spirituality, including 5251 . The other piece of this was simply that therapy became a part of many of the participants' spiritual experiences. Several participants had access to mental health support within their church as professional mental health providers were on staff or their church was connected to a community mental health organization. This was also seen in the research of Mitchell (2004) and Watkins (2000) who highlighted the idea of using church as a mental health resource.

Three participants endorsed the divergent theme that a relationship with God is not mutually exclusive of therapeutic support. They said therapy that provided a foundation in God was good. 
These participants also shared they witnessed positive results from Christian therapy. They noted that they were open to whatever resources God chose to provide to address their concerns. Ultimately, they seemed to recognize that spiritual help could be provided through a variety of avenues and being open to what and how God provided for them, was essential for them to thrive. They seemed to have a relationship with God that allowed for transformative experiences to take place, both extrinsically and intrinsically. The usefulness of informal therapy as discussed by some participants was also noted in the research of Mitchell (2004), Sisley, Hutton, Goodbody, and Brown (2011), and Watkins (2000).

Mattis (2000) contended that psychologically based definitions of spirituality were deficient when talking about the spiritual experiences of regular people. This study in the exploration of the lived spiritual experiences of participants, related to how they arrived at their understanding of spirituality and therapy, does just that. The analysis provided evidence of Mattis' (2000) premise of spirituality covering all of life. This principle was specific to those women who participated in this study. Additionally, it could have been surmised that if a woman was viewed as incapable of taking care of her mental health because she sought therapy, the strength gained through spirituality, might have been diminished, negatively impacting help-seeking attitude development in Black women (Harley, 2006). Alternative thoughts were that strength, if constructed upon or contained within spirituality, would reduce the weight of responsibility for Black women associated with role strain. Secondarily, that strength found in spiritual spaces, acted as a resource to move this population forward. Furthermore, strength based in spirituality lent itself as a positive attribute that encouraged resilience and determination among Black women (Harley, 2005; Woods-Giscombe, 2008). In short, the negative connotations connected to 
strength and Black women would be reduced tremendously. Black women would know that they don't have to be superwomen, but could access help through God.

\section{Limitations and strengths of the study.}

Research is not without limitations. In theory, limitations change the face of research. In practice, awareness of and sensitivity to limitations of the study reduce the risk of error in analysis, interpretation, and presentation of results, making this approach vital for this study while mediating some of the study limitations. In spite of the limitations, this study sought to understand concepts not easily captured by or grounded in science, in ways that were resonant for the Black women who participated in this study. Additionally, this project attempted to explore help-seeking attitude, by understanding participants' thoughts on therapy and spirituality and how these constructs intersect for Black women. Because prior research has not fully addressed how help-seeking attitude and spirituality in Black women overlap, the qualitative research design used in this study was most appropriate in addressing the research questions.

That being said, this study was limited to Black women, 18 years old or older, who attended a church in Akron, Ohio or subscribed to the Christian faith. This limitation decreased generalizability and may not apply to women who are not African American or to Christian men. The study was limited to exploring therapy and spirituality, and the connections between the two via semi-structured interviews. The interviews were conducted using an Interview Protocol developed by me, which may have limited my ability to gather specific data on help-seeking attitudes.

Results of the proposed study provided insight into the lives of the women who participated in the study and generalizable, to the extent readers identify salient themes that resonate with their personal life experiences. Additionally, the fact that participants' thoughts on therapy and 
spirituality may be shaped by their church, the type and frequency of discussions on mental health in the churches they attend, the type of ecclesiastical and professional training received by pastors and/or members of their church all act as potential limitations of this study. Furthermore, the personal experiences, personal relationships and how those relationships are viewed by participants, as well as, educational or professional training of participants or those they are in relationship with may also acted as limitations.

The results of the current study were also limited due to the complexity of the constructs under investigation. For example, no universal definition of spirituality was available for use and how Black women viewed spirituality varied across the sample population. This study was also bracketed by my personal or spiritual beliefs and those of the participants. Biases, how the interviews were conducted, how the data were collected, understood, and interpreted, and the hypothetical manipulation of the data and the results were also considered potential limitations.

Additionally, the methodology for this study contained limitations. Interpretative Phenomenological Analysis (IPA) was founded on the idea of self-reflection and "understanding what the particular respondent thinks or believes about the topic under discussion" (Smith, Flowers, \& Osborn, 1997, p. 70). This proved problematic as self-reflection was assumptive and interpretation of experiences was often subjective and fluid, changing as additional data was examined. Additionally, IPA advocates for a collaborative endeavor between researcher and participant (Smith, Flowers, \& Osborn, 1997), which was not consistently possible as reflected in limited participant response to reviewing their transcripts.

The complexity of the methodology constrained what I was and was not be able to say and the conclusions I did and did not draw. Data interpretation must be reflective and representative of the participants' experiences and their understanding of those experiences. Although the value 
of the results was determined by those invested in exploring, understanding, and working with Black women, the results of the study are only generalizable to the extent that others may apply the results to their individual lives and/or work with Black women. Lastly, using qualitative methodology limits generalizability to various degrees by its fundamental tenets.

Biases of the researcher also proved limiting. As stated previously, considerable knowledge of help-seeking attitude, the Christian faith, and my background in church leadership, as well as, actively practicing a form of spirituality consistent with participants shaped how I conducted the interviews and asked follow-up questions. This approach could have easily influenced how participants' responded to questions, limiting or changing, what information they chose to share. While conducting the research, I recognized I was biased regarding how individuals from particular denominations within Christianity would respond. I was surprised that my thoughts were incongruent with participants' experiences, and worked to reduce the biases and assumptions, that allowed participants to tell their stories in their ways.

I anticipated self-disclosure would be difficult to navigate during the interviews, and was surprised by the willingness of many of the participants to be open and interested in the research process; especially, as they discussed challenging and traumatic aspects of their upbringing, spirituality, and conceptualizations of therapy. I wondered if the same-race research/participant dyad was being experienced and the exchange, somehow, benefited from elements often found in the same-race therapy dyad based on research conducted by Carkhuff and Pierce (1967).

Many of the participants were warm and full of encouragement during and at the end of the interviews. I experienced a type of mentoring and guidance by many of the participants who were older or already working in the field of psychology. The camaraderie experienced increased my comfort with the role of researcher and seemingly augmented participants desire to readily 
share their testimonies. Distinctive insights about the participants, as it related to the influence of spirituality on help-seeking attitudes, were garnered from this study as a depth of introspection was experienced during and expected after the interviews, based on comments provided by participants. Although, generalizability of the results were not recommended, the complexity of the data generated, was geared towards developing a more thoughtful approach in conducting research with this population and/or on these phenomena.

The use of colloquial language and regional dialect was vital in understanding the experiences of the participant, allowing the voices of the women to be the greatest strength of the study. The way participants articulated their experiences, also provided a window view into the complexity of their lives and natures, while producing substantial data on contextual factors salient for each participant. As discussed earlier, the results of this study supported prior studies that focused on factors that influenced help-seeking attitudes and the use of spirituality as a coping mechanism for traumatic experiences (Holmes \& Hardin, 2009). Yet, this study delivered additional data relevant to understanding how spirituality may be used in developing an attitude toward help seeking. It also illuminated some of the distinctions between how help seeking and therapy were defined for these women.

\section{Implications of findings.}

As discussed, in Chapter 1, the role of Black women in the African American community is pivotal and impactful in the lives of Black children. Conducting research that examined ways to understand the lived experiences of this population would enhance the understanding of if, when, and how psychological help seeking was pursued; lending the results of this and other studies to develop treatment protocols that specifically addressed the needs of this population in ways that feel real for them. Secondarily, this approach would potentially address challenges faced by 
Black children who lived with mothers experiencing role strain. With appropriate therapeutic support, these women could model healthier coping strategies thereby have an effect on generations to come.

The results aligned with APA's Multicultural Guidelines (APA, 2002) and may have aided in addressing the need for increased awareness and access to mental health services, as well as, engaging African American women in the process of therapy in ways that encouraged persistence in treatment. Hopefully, this would allow this population to become more open to finding ways to connect with therapy that endorsed embracing and celebrating spirituality, even in a therapeutic setting. It is also clear that more research needs to be done by and with Black women to understand the lived experiences of this population, and how those experiences effect their children and their ability to function in healthy ways. Additionally, role of spirituality may also need to be addressed; in particular, for individuals who were a part of a faith-based tradition. Participant 8790 said it best:

It's like, it's, unless you um, unless you, for me specifically, unless you know me and know my relationship with the Lord, you wouldn't, you wouldn't' know as a therapist, that my ultimate hope is in the Lord.

Nor would the therapist know that this participant believed this about therapy and what it potentially offered to her without the connection of spirituality. She stated:

... I think that you can offer them some help and it doesn't mean that it's completely useless um, if you know, or like for counselors who are not necessarily spiritually based or who don't have that as a central component of how they work with somebody or how they work through things. But, I think ultimately, um there are often things that at the root of what a person is experiencing that if they're not dealt with on a spiritual level um then they kinda go 
unaddressed. And, so I think the two are just very much connected, in that, that spiritual component is essential to really able to have, I think the most effective therapy.

Moreover, the identification of seven super-ordinate themes underscored the interconnection between upbringing, spirituality, and relationships; which were foremost in the experiences of participants. It seemed obvious that spirituality was a major factor in how the participants engaged in dialogue about therapy. It was also apparent, for many participants, that discussing something that was familiar, such as their spirituality, led to more and deeper revelations about their lived experiences. These confessions were deemed sincere, deeply personal, and unexpected; and, I felt privileged to have shared in the telling of such powerful truths. This implied, for me, the infusion of pastoral constructs, like interpathy, would be beneficial in working with this population, as interpathy, increased the potential of successful and deepened empathic encounters (Augsburger, 1993).

As noted in Figure 1 on page 41, the factors impacting help-seeking attitudes in racial/ethnic populations, are varied. Although not acknowledged as super-ordinate themes, self-concealment was comparable to privacy, as discussed earlier. Stigma, although present in the lives of a few participants, expressed itself as being unsettled by the idea of being labeled. This seemed to subside as some participants were exposed to therapy as they witnessed family members and friends talk about and benefit from support; and, as they attended churches where their pastors spoke well of therapy and its benefits. Therapy also seemed to become more commonplace as churches, in an effort to try and meet the needs of congregants, provided professional psychological services within their domains or churches were connected to community mental health centers. 
Conversely, elements of cultural mistrust and culturally relevant treatment looked as if they still held weight with some participants. This appeared as a past desire for one participant who seemed saddened by having limited access to services and no opportunity to work with a Black therapist. Secondarily, a muted concern about White providers prescribing medication and being unsure of the impact of the medication on a family member was also raised. It seemed that the care that participants took to talk about difficult subjects was in an effort to respect the profession of psychology, while expressing concerns they believe might not have been fully resolved. They may also have been trying to protect me as a researcher and member of the African American community by presenting their stories in ways that would not tarnish the reputation or diminish my association to the field of psychology.

Lastly, the hint of cultural mistrust coupled with spirituality, seemed to be enough to act as a disincentive to seeking professional psychological services for some of the participants, at least initially. Without support of the church, which these women were intimately tied too, the profession of psychology may miss a bevy of Black women who could potentially benefit from what therapy has to offer. The perceived and experienced disconnect between churches and the profession of psychology, and spirituality and therapist may well explain why some Black women are slow to pursue therapy or why some women underutilize services or do not finish their course of treatment.

Interestingly enough, much of the research on religion or spirituality could be found in the tenets developed by Gordon Allport (1950), as he conducted research that provided a way to understand the spiritual experiences of people. Allport (1950) seemed to suggest that much of life is intertwined with religious influences. His developmental approach to spirituality was evident in the lives of many the participants as their most salient themes expressed elements of 
extrinsic and intrinsic religion. For example, participant 8790 discussed the idea of a variety of experiences shaping her spirituality and 5251 talked about the outward demonstration of the inward connection to God. Most participants talked about turning to God with and without turning away from themselves, growing in God and spiritually as they aged, while they engaged in both religious and spiritual practices. This appeared to reinforce Allport's (1950) religious tenets, which caused the Allport/Kahoe Spirituality to dominate.

Although this study covered many interesting facets of the intersection of help-seeking attitude and spirituality and provided a chance to examine the phenomena of help-seeking attitude in-depth, it is not without limitations. The comprehensive examination of the explored constructs is a good starting place to consider limitations. The questions used in the interview, were introductory and designed to elicit information based upon the experience of participants. This, in part, facilitated discovery of a broad range of themes that could not be fully addressed. Given the in-group similarities and differences, diversity with regard to participants' faith traditions within Christianity, results may not be generalizable to women of different ethnic backgrounds, Black men, or other Christians. Additionally, while the study was open to Black women in the region of Northeast Ohio, only women from Akron, Ohio responded. This limited the chance to examine differences in the help-seeking attitude development process across regions or outside of Christianity. Lastly, the results of this study suggest that the spirituality models may provide a model to train current and future psychologist on how to work with Black women who view their spirituality as a significant part of their being. The models might also provide a way for therapist to understand the worldview of clients through spirituality. 


\section{Clinical recommendations.}

Several researchers in the spirituality literature suggested it was important to understand the significance of spirituality in the lives of some Black women (Harris, 1992; Mattis, 2000; Mitchell, 2004; Schiele, 2000; Sisley, Hutton, Goodbody, \& Brown, 2011). This is noteworthy because the findings support the assertion that Black women use spirituality as a resource to deal with psychological pain and that spirituality influences help-seeking attitudes, and most likely help-seeking behavior. With that in mind, the most obvious use of the results of this study could be seen in pastoral counseling. Augsberger (1993) purported "pastoral psychotherapy must offer breadth capable of addressing both universal humanness and the particular human" (p. 129) while accessing "intracultural empathy, an intercultural interpathy, [and] a transcultural pathos" (131). In other words, the approach to mental health found in pastoral counseling addresses mental health concerns through an integrated approach that facilitate the understanding of individuals-in-community and as individuals-in-depth (Augsberger (1993). Pastoral counseling could possibly act as a model of how to blend two distinct fields, psychology and religion, to work with individuals from a holistic perspective and as suggested by a few participants, tackle concerns at the root.

According to the Brief History of Pastoral Counseling provided by the American Association of Pastoral Counselors (2012) pastoral counseling began as an integration between spiritual and emotional well-being. The collaboration between ministers and psychiatrist continued, laying a solid foundation for the prescribed work. As discussed earlier, Allport (1950) and others, including Carl Jung (1875-1961), Abraham Maslow (1908-1970), and William James (18241910) all studied religious experiences. Although prominent in the field of psychology, none of these eminent writers appeared to suggest how an integrated approach of the disciplines could be 
developed and implemented within applied psychology. Whereas, counseling has been embraced by ministers and other spiritual leaders, the reverse is not true and may account for the number of Black women who engage in other forms of "therapy" based in relationship and similar belief constructs. This is documented in Table 1 that shows the distinctions between utilization of clergy vs. traditional mental health services.

Other uses of the results may not be so clear. The subtleties used by participants to reveal concerns related to cultural factors are important to note. These concerns suggest, and align with APA's Multicultural Guidelines (APA, 2002) expressing the need for research and training that incorporates diversity features of specific populations. If Black women are saying spirituality is important, then it is important to listen and to begin the process of developing treatment and training protocols that include important aspects of the lived experiences of African American women, specifically spirituality.

Additionally, helping non-pastorally trained clinicians in particular, to develop skills in creating safer spaces for connection and to build relationships within the context of spirituality may also need to be considered. This approach may warrant the deconstruction of the dynamics of psychology that exclude spirituality. Also, asking about spiritual factors, and when and how spirituality is used as a resource, by clients could potentially support the strength-based approach found in Counseling Psychology and other mental health disciplines. As with this study, talking about content that is comfortable and familiar may lead to deeper revelations and better understanding of how to talk about spiritual constructs and work with certain clients who desire this level of support. Training models that have the input of spiritual and religious leaders, and lay persons might lend itself to finding another way to connect with clients. Additionally, it will 
be important for the face of the profession to become more like the face of those who may be seeking services (APA, 2002).

\section{Recommendations for future research.}

This research strongly supported prior studies on social networks as having influence on help-seeking attitudes (Golding \& Wells, 1990; Wallace \& Constantine, 2005). Additionally, several researchers discussed social and cultural influences related to help seeking (see; Mitchell, 2004; and Sisley, Hutton, Goodbody, \& Brown, 2011) as having been impactful for certain populations. Furthermore, Watkins (2000) emphasized, in her study, the dimension of spirituality as being a part of understanding the human experience. This was most salient in that the role of spirituality in the development of help-seeking attitudes was studied and stressed the importance of recognizing spirituality as a viable support system for African American women (Harris, 1992; Mattis, 2000; Mitchell, 2004; Schiele, 2000; Sisley, Hutton, Goodbody, \& Brown, 2011). Lastly, Harley's (2005) assertion that spirituality potentiates underutilization of mental health services was significant as many participants described a belief that God was resolute in addressing life challenges, He provided what was needed, and He was more than enough for participants.

Going forward, studies conducted by and for Black women might be warranted; especially, since they seemed to be a factor in how participants shared their experiences. Watkins (2000) suggested four elements critical to how Black women identified and used emotional support. The application of these elements may be critical and necessary in research conducted by and for Black women, expressly when exploring the phenomena of spirituality. She posited the effect of cultural and religious/spiritual similarities; and understanding experiences of racism and oppression were important elements in seeking support (Watkins, 2000). It seemed correct to 
assert that in studying spirituality, these factors might connect the researcher to participants in unexpected ways that simplified the research process, and licensed participants' to tell their stories in ways that felt meaningful and allowed their voices to be heard.

Additionally, research that focused on younger generations may also prove important. The average age of study participants was 54. Younger women may have responded differently to the interview as their exposure to therapy may have increased due to some reduction in stigma related to seeking psychological services. Also, although the numbers of Black women in psychology still remains small, it is greater than when many of the participants were being raised. Therefore, the opportunity to identify and access a Black women in the field of psychology or a related profession may have increased.

Lastly, examination of convergent and divergent themes found in this study, may also be a good place to continue exploring spirituality and help-seeking attitude. The endorsement of seven themes, by all participants, seemed to suggest a possibility that these seven factors were inherent in the development of help-seeking attitude in African American women. Many of the themes underscored the potency and complexity of spirituality for this population. By recognizing the strength of spirituality in acquiring and maintaining psychological and emotional health, researchers may contribute to the body of work that examines the efficacy of spiritual tenets in working with Black women. This may assist current and future therapists in developing a skill set to work within the confines of spirituality, and to address interpersonal and other challenges that were not spiritually based, using what felt most comfortable for the client. 


\section{References}

Ajzen, I., \& Fishbein, M. (1980). Understanding attitudes and predicting social behavior. Englewood Cliffs, NJ: Prentice-Hall, Inc.

Ajzen, I., \& Fishbein, M. (2005). The influence of attitudes on behavior. In D. Albarracín, B. T. Johnson \& M. P. Zanna (Eds.), The handbook of attitudes (pp. 173-221). Mahwah, NJ: Lawrence Erlbaum Associates Publishers.

Albarracín, D., Johnson, B. T., \& Zanna, M. P. (2005). The handbook of attitudes. Mahwah, NJ: Lawrence Erlbaum Associates Publishers.

Alderfer, C. P. (1984). A White man's perspective on the unconscious processes within BlackWhite relations in the United States (pp. 201-229). In E. J. Trickett, R. J. Watts, \& D. Birman (Eds.), Human diversity Perspectives on people in context (pp. 201-229). San Francisco, CA: Jossey-Bass Publishers.

Allport, G. W. (1950). The individual and his religion A psychological interpretation. New York, NY: The Macmillan Company.

Alvidrez, J. (1999). Ethnic variations in mental health attitudes and service use among lowincome African American, Latina, and European American young women. Community Mental Health Journal, 35, 515-530. doi:10.1023/A: 1018759201290

American Association of Pastoral Counseling (2012). A brief history on pastoral counseling. Retrieved from http://www.aapc.org/about-us/brief-history-on-pastoral-counseling.aspx/ American Psychological Association (2002). Guidelines on multicultural education, training, research, practice, and organizational change for psychologists- American psychological association guideline \#4. Retrieved from http://www.apa.org/pi/oema/resources/policy/multicultural-guidelines.aspx 
American Psychological Association (2013a) PSYCArticles. Retrieved from http://www.apa.org/pubs/databases/psycarticles/index.aspx

American Psychological Association (2013b) PSYCInfo. Retrieved from http://www.apa.org/pubs/databases/psycinfo/index.aspx

Ang, R. P., Lim, K. M., Tan, A., \& Yau, T. Y. (2004). Effects of gender and sex role orientation on help-seeking attitudes. Counseling Psychology, 23, 203-214.

Atkinson, D. R., Jennings, R. G. \& Liongson, L. (1990). Minority students reasons for not seeking counseling and suggesting for improving services. Journal of Student Development, 31, 342-350.

Augsburger, D. W. (1993). Cross-cultural pastoral psychotherapy. In R. J. Wicks \& R. D. Parsons (Eds.). The clinical handbook of pastoral counseling (pp. 129-143). New York, NY: Paulist Press.

Baker, S. E., \& Edwards, R. (2013). How many qualitative interviews is enough. Discussion Paper. UNSPECIFIED. (Unpublished) National Centre for Research Methods. Retrieved from: http://eprints.ncrm.ac.uk/2273/4/how_many_interviews.pdf

Beauboeuf-Lafontant, T. (2005). Keeping Up Appearances, Getting Fed Up. Meridians: Feminism, Race, Transnationalism, 5, 104-123.

Biggerstaff, D. L., \& Thompson, A. R. (2008). Interpretative Phenomenological Analysis (IPA): A qualitative methodology of choice in healthcare research. Qualitative Research in Psychology, 5, 173-183. doi:10.1080/14780880802314304

Blue, H. C., \& Griffith, E. E. H. (2001). The African American. In, T. Wen-Shing (Ed.) Culture and psychotherapy: A guide to clinical practice (137-154). Washington, DC: American Psychiatric Press. 
Boyatzis, C. J. (2005). Religious and spiritual development in childhood. In R.F. Paloutzian \& C.L. Park (Eds.). Handbook of the psychology religion and spirituality (123-143). New York, NY: The Guilford Press.

Bregman, L. (2004). Defining spirituality: multiple uses and murky meanings of an incredibly popular term. Journal of Pastoral Care \& Counseling, 58, 157-167.

Carkhuff, R. R., \& Pierce, R. (1967). Differential effects of therapist race and social class upon patient depth of self-exploration in the initial clinical interview. Journal of Consulting Psychology, 31, 632-634.

Cepeda-Benito, A., \& Short, P. (1998). Self-concealment, avoidance of psychological services, and likelihood of seeking professional help. Journal of Counseling Psychology, 45, 5864. doi:0022-0167/98

Chan, Z. C. Y., Fung, Y., \& Chien, W. (2013). Bracketing in phenomenology: Only undertaken in the data and analysis process? The Qualitative Report, 28, 1-9. Retrieved from http://www.nova.edu/ssss/QR/QR18/chan59.pdf

Chandler, D. R. (2011). Proactively addressing the shortage of Blacks in psychology: Highlighting the school psychology subfield. Journal of Black Psychology, 37, 99-127. doi:10.1177/0095798409359774

Chisholm, J. (1996). Mental health issues in African-American women. Annals of the New York Academy of Sciences, 789, 161-179.

Comas-Diaz, L. (1994). An integrative approach. In L. Comas-Diaz \& B. Greene (Eds.). Women of color integrating ethnic gender identities in psychotherapy (pp. 287318). New York: NY: The Guilford Press.

Cook, D. A., \& Wiley, C. Y. (2000). Psychotherapy with members of African American 
churches and spiritual traditions. In P. Scott Richards \& A. E. Bergin (Eds.). Handbook of psychotherapy and religious diversity (pp. 369-396). Washington, DC: American Psychological Association.

Cooper-Patrick, L., Gallo, J. J., Powe, N. R., Steinwachs, D. M., Eaton, W. W., \& Ford, D. E. (1999). Mental health service utilization by African Americans and Whites: The Baltimore epidemiologic catchment areas follow-up. Medical Care, 37, 1034-1045

Dana, R. H. (2002). Mental health services for African Americans: A cultural/racial perspective. Cultural Diversity and Ethnic Minority Psychology, 8, 3-18.

Daniel, J. H. (2009). Next generation: A mentoring program for Black female psychologist. Professional Psychology: Research and Practice, 40, 299-305. doi:10.1037/a0013891

Davey, M. P., \& Watson, M. F. (2008). Engaging African Americans in therapy: Integrating a public policy and family therapy perspective. Contemporary Family Therapy, 30, 31-47.

Denzin, N. K., \& Lincoln, Y. S. (2005). Introduction The discipline and practice of qualitative research. In N.K. Denzin \& Y.S. Lincoln (Eds.), The Sage handbook of qualitative research, Third edition (pp. 1-32). Thousand Oaks, CA: Sage Publications.

Diala, C., Muntaner, C., Walrath, C., Nickerson, K. J., LaVeist, T., \& Leaf, P. (2000). Racial differences in attitudes toward professional mental health care and in the use of services. American Journal of Orthopsychiatry, 70, 455-464.

Diestel, G. E. (1971). An experimental test of Fishbein's behavioral intentions model in the prediction of interpersonal communication acts. Dissertation Abstracts International, 32.

Dixon, C. G., \& Vaz, K. (2005). Perceptions of African Americans regarding mental health 
counseling. In D. A. Harley \& J. M. Dillard (Eds.), Contemporary mental health issues among African American (pp. 163-174). Alexandria, VA: American Counseling Association.

Doob, L. W. (1947). The behavior of attitudes. Psychological Review, 54, 135-156. doi: $10.1037 / \mathrm{h} 0058371$

EBSCO Industries (2012). Academic Search Complete. Retrieved from http://www.ebscohost.com/academic/academic-search-complete England Journal of Medicine, 351, 603-605. doi:10.1056/NEJMe048181

ESDS Qualidata: http://www.esds.ac.uk/qualidata/support/interviews/introduction.asp (reference source accessed 1/10/13).

Elliott, R., Fischer, C. T., \& Rennie, D. L. (1999). Evolving guidelines for publication of qualitative research studies in psychology and related fields. British Journal of Clinical Psychology, 38, 215-229.

Farsimadan, F., Draghi-Lorenz, R., \& Ellis, J. (2007). Process and outcome of therapy in ethnically similar and dissimilar therapeutic dyads. Psychotherapy Research, 17, 567575. doi:10.1080/10503300601139996

Finlay. L. (2009). Debating phenomenological research methods. Phenomenology \& Practice, 3, 6-25.

Fishbein, M., \& Ajzen, I. (1975). Belief, attitude, intention and behavior: An introduction to theory and research. Reading, MA: Addison-Wesley Publishing Company.

Fischer, C. T. (2009). Bracketing in qualitative research: Conceptual and practical matters. Psychotherapy Research, 19, 583-590. doi:10.1080/10503300902798375

Fischer, E. H., \& Cohen, S. L. (1972). Demographic correlates of attitude toward seeking 
professional psychological help. Journal of Consulting and Clinical Psychology, 39, 7074. doi:10.1037/h0033152

Fischer, E. H., \& Farina, A. A. (1995). Attitudes toward seeking professional psychological help scale--Short form. Journal of College Student Development, 36, 368-373.

Fischer, E. H., \& Turner, J. L. (1969). Factors in attitudes toward seeking professional help. Proceedings of the Annual Convention of the American Psychological Association, 4, 487-88.

Fischer, E. H., \& Turner, J. L. (1970). Orientations to seeking professional: Development and research utility of an attitude scale. Journal of Counseling and Clinical Psychology, 35, 79-90. doi:10.1037/h0029636

Gall, T., Malette, J., \& Guirguis-Younger, M. (2011). Spirituality and religiousness: A diversity of definitions. Journal of Spirituality in Mental Health, 13, 158-181. doi:10.1080/19349637.2011.593404

Gibson, P. A., \& Denby, R. W. (2007). African-American mental health: A historical perspective. In S. M. L. Logan (Ed.) and R.W. Denby \& P. A. Gibson (Co-Eds.), Mental health care in the African-American community (pp. 3-14). New York, NY: Hayworth Press.

Giorgi, A. (2011). IPA and Science: A Response to Jonathan Smith. Journal of Phenomenological Psychology, 42, 195-216. doi:10.1163/156916211X599762

Golding, J. M., \& Wells, K. B. (1990). Social support and use of mental health services by Mexican Americans and non-Hispanic Whites. Basic and Applied Social Psychology, 44, $443-458$.

Goode-Cross, D. T. (2011). "Those who learn have a responsibility to teach": Black therapists' 
experiences supervising Black therapist trainees. Training and Education in Professional Psychology 5, 73-80. doi:10.1037/a0023187

Gourash, N. (1978). Help-seeking: A review of the literature. American Journal of Community Psychology, 6(5), 413-423. doi:10.1007/BF00941418

Gullatte, M. (2006). The Influence of Spirituality and Religiosity on Breast Cancer Screening Delay in African American Women: Application of the Theory of Reasoned Action and Planned Behavior (TRA/TPB). ABNF Journal, 17, 89-94.

Guthrie, R. V. (1998). Even the rat was white: A historical view of psychology, $2^{\text {nd }}$ Edition. Boston, MA: Allyn and Bacon.

Hammond, W. R., \& Yung, B. (1993). Minority student recruitment and retention practices among schools of professional psychology: A national survey and analysis. Professional Psychology: Research and Practice, 24, 3-12.

Harley, D. A. (2005). The Black church: A strength-based approach in mental health. In Harris, R. \& Dillard, J. M. (Eds.), Contemporary mental health issues among African Americans, (pp. 191-203). Alexandria, VA: American Counseling Association.

Haynes, T. (2010). Religious beliefs, attitudes towards Mental health treatment, and mental health utilization among southern rural African Americans (Doctoral Dissertation). Retrieved from ProQuest Dissertations and Theses.

Heath, C. D. (2006). A womanist approach to understanding and assessing the relationship between spirituality and mental health. Mental Health, Religion, \& Culture, 9, 155-170. doi:10.1080/13694670500116938

Heppner, P. P., \& Heppner, M. J. (2004). Writing and publishing your thesis, dissertation, and research: A guide for students in the helping professions. Belmont, CA: ThomsonBrooks/Cole. 
Heppner, P. P., Wampold, B. F., \& Kivlighan, D. M. (2008). Research design in counseling, Third edition. Belmont, CA: Thomson Brooks/Cole.

Hill, P. C. (2013). Measurement assessment and issues in the psychology of religion and spirituality. In R. F. Paloutzian \& C. L. Park (Eds.), Handbook of the psychology of religion and Spirituality Second edition (pp. 48-74). NY: The Guilford Press.

Hill, P. C., \& Pargament, K. I. (2008). Advances in the conceptualization and measurement of religion and spirituality: Implications for physical and mental health research. American Psychologist, 58, 64-74. doi:10.1037/1941-1022.S.1.3

Hodge, D. R. (2001). Spiritual assessment: a review of major qualitative methods and a new framework for assessing spirituality. Social Work, 46, 197-201.

Holmes, J. D., \& Hardin, S. I. (2009). Religiosity, meaning in life, and clinical symptomology: A comparison of African-American and European-American college students. Journal of College Student Psychotherapy, 23, 103-117. doi:10.1080/87568220902743199

hooks, b. (1981). Ain't I a woman: Black women and feminism. Boston, MA: South End Press. Howitt, D., \& Owusu-Bempah, J. (1994). The racism of psychology: Time for change. Hertfordshire, London: Harvester Wheatsheaf.

Jaccard, J., \& Blanton, H. (2005). The origins and structure of behavior: Conceptualizing behavior in attitude research. In Albarracín, D., Johnson, B.T., \& Zanna, M. P. (Eds.), The handbook of attitudes (pp. 125-171). Mahwah, NJ: Lawrence Erlbaum Associates Publishers.

Kahoe, R. D. (1985). The development of intrinsic and extrinsic religious orientations. Journal for the Scientific Study of Religion, 24, 408-412.

Kahn, J. H., Achter, J. A., \& Shambaugh, E. J. (2001). Client distress disclosure, characteristics at intake, and outcome in brief counseling. Journal of Counseling Psychology, 48, 
203-211. doi:10.1037/0022-0167.48.2.203

Kelly, S., \& Boyd-Franklin, N. (2005). African American women in client, therapist, and supervisory relationships: The parallel processes of race, culture, and family. Voices of color: First-person accounts of ethnic minority therapists (pp. 67-89). Thousand Oaks, CA: Sage Publications, Inc.

Koenig, H. G. (2009). Research on religion, spirituality, and mental health: A review. Canadian Journal of Psychiatry, 54, 283-291. Koenig, H. G., \& Larson, D. B. (2001). Religion and mental health: Evidence for an association. International Review of Psychiatry, 13, 6778.

Kushner, M. G., \& Sher, K. J. (1991). The relation of treatment fearfulness and psychological service utilization: An overview. Professional Psychology: Research and Practice, 22, 196-203.

Larkin, M., \& Thompson, A. R. (2012). Interpretative phenomenological analysis in mental health and psychotherapy research. In D. Harper, \& A. R. Thompson (Eds.). Qualitative research methods in mental health and psychotherapy A guide for students and practitioners. West Sussex, UK: John Wiley \& Sons, Ltd.

Lauver, D. R. (2000). Commonalities in women's spirituality and women's health. Advance Nursing Science, 22, 76-88.

Lincoln, Y. S. \& Guba, E. G. (1985). Naturalistic inquiry. Newbury Park: CA: Sage Publishing, Inc.

Logan, S. E. (2007). Mental health interventions and the Black community. In S. M. L. Logan (Ed.) and R. W. Denby \& P. A. Gibson (Co-Eds.), Mental health care in the AfricanAmerican community (pp. 39-55). New York, NY: Hayworth Press. 
Maki, M. T. (1999). The effects on client identification when clinician and client share a common ethnic minority background. Journal of Multicultural Social Work, 7, 57-72. doi:10.1300/J285v07n01_04

Masuda, A., Anderson, P. L., Twohig, M. P., Feinstein, A. B., Chou, Y., Wendell, J. W., \& Stormo, A. R. (2009). Help-seeking Experiences and Attitudes among African American, Asian American, and European American College Students. International Journal for the Advancement of Counselling, 31, 168-180. doi: $10.1007 / \mathrm{s} 10447-009-9076-2$

Mattis, J. S. (2000). African American women's definitions of spirituality and religiosity. Journal of Black Psychology, 26, 101-122. doi:10.1177/0095798400026001006

Mattis, J. S. (2002). Religion and spirituality in the meaning-making and coping experiences of African American women: A qualitative analysis. Psychology of Women Quarterly, 26, 309-321.

Mertens, D. M. (2010). Research and evaluation in education and psychology Integrating diversity with quantitative, qualitative, and mixed methods $3^{\text {rd }}$ edition. Thousand Oaks, CA: Sage Publications.

Mitchell, P. M. (2004). A qualitative analysis of professional psychological help-seeking attitudes among African American women. Retrieved from ProQuest Dissertations and Theses.

Moradi, B., \& Neimeyer, G. J. (2005). Diversity in the ivory white tower: A longitudinal look at faculty race/ethnicity in counseling psychology academic training programs. The Counseling Psychologist, 33, 655-675. doi:10.1177/0011000005277823

Morrell, M., \& Metzl, E. (2006). Seeking Treatment in California: Motivators, Barriers and Perceptions. Retrieved from www.camft.org 
Narrow, W., Regier, D., Norquist, G., Rae, D., Kennedy, C., \& Arons, B. (2000). Mental health service use by Americans with severe mental illnesses. Social Psychiatry and Psychiatric Epidemiology, 35, 147-155. doi:10.1007/s001270050197

Nelson, J. M. (2008). Religion. In Y. Jackson (Ed.), Encyclopedia of multicultural psychology (p. 406-408). Thousand Oaks, CA: Sage Publications.

NEO CANDO. (2012). Retrieved from NEO CANDO system, Center on Urban Poverty and Community Development, MSASS, Case Western Reserve University (http://neocando.case.edu).

Nickerson, K. J., Helms, J. E., \& Terrell, F. (1994). Cultural mistrust, opinions about mental illness and Black students' attitudes toward seeking psychological help from white counselors. Journal of Counseling Psychology, 41, 378-385. doi:10.1037/00220167.41.3.378

Nicolas, G., Gonzalez-Eastep, D., \& DeSilva, A. (2008). Spirituality. In Y. Jackson (Ed.), Encyclopedia of multicultural psychology (p. 443-445). Thousand Oaks, CA: Sage Publications.

Ocampo, C. (2008). Drapetomania. In Y. Jackson (Ed.), Encyclopedia of multicultural psychology (p. 158-159). Thousand Oaks, CA: Sage Publications.

Ohio History Connection. (2015). Ohio Central History. Retrieved from http://www.ohiohistorycentral.org/w/African_Americans

OhioLINK. (2013). Electronic Journal Center. Retrieved from http://ezproxy.uakron.edu:2078/ejc/

Olesen, V. L. (2000). Feminism and qualitative research at and into the millennium. In N.K. 
Denzin \& Y.S. Lincoln (Eds.), Handbook of qualitative research, Second edition, (pp. 215-255). Thousand Oaks, CA: Sage Publications.

Olson, M. A., \& Kendrick, R. V. (2008). Origins of attitudes. In W. D. Crano \& R. Prislin (Eds.), Attitudes and attitude change (pp. 111-130). New York, NY US: Psychology Press.

Osborne, J. W. (1994). Some similarities and differences among phenomenological and other methods of psychological qualitative research. Canadian Psychology/Psychologie Canadienne, 35, 167-189.

Paloutzian, R. F., \& Park, C. L. (2005). Integrative themes in the current science of the psychology of religion. In R.F. Paloutzian \& C. L. Park (Eds.). Handbook of the psychology religion and spirituality (3-20). New York, NY: The Guilford Press.

Pargament, K. I., Magyar-Russell, G. M., \& Murray-Swank, N. A. (2005). The sacred and the search for significance: Religion as a unique process. Journal of Social Issues, 61, 665-687. doi:10.1111/j.1540-4560.2005.00426.x

Patton, M. Q. (1990). Qualitative evaluation and research methods (2nd ed.). Beverly Hills, CA: Sage.

Patton, M. Q. (2002). Qualitative research \& evaluation methods. Thousand Oaks, CA: Sage Publications, Inc.

President's Commission on Mental Health. (1978). Report to the President. Washington, DC: U. S. Government Printing Office.

Pringle, J., Drummond, J., McLafferty, E., \& Hendry, C. (2011). Interpretative phenomenological analysis: a discussion and critique. Nurse Researcher, 18, 20-24.

Prislin, R., \& Crano, W. D. (2008). Attitudes and attitude change: The fourth peak. In W. D. Crano, \& R. Prislin (Eds.), Attitudes and attitude change (pp. 3-15). New York, NY: Psychology Press. 
Richards, P. S., \& Bergin, A. E. (2000). Towards religious and spiritual competency for mental health professionals. In P.S. Richards \& A.E. Bergin (Eds.). Handbook of psychotherapy and religious diversity (pp. 3-26). Washington, DC: American Psychological Association.

Robinson, C. R. (1983). Black women: A tradition of self-reliant strength. Women \& Therapy, 2, 135-144. doi:10.1300/J015v02n02_14

Sanders Thompson, V. L., \& Alexander, H. (2006). Therapist' race and African American clients' reactions to therapy. Psychotherapy: Theory, Research, Practice, Training, 43, 99-110. doi:10.1037/0033-3204.43.1.99

Schiele, J. H. (2000). Human services and the Afrocentric paradigm. New York, NY: The Haworth Press

Seybold, K. S., \& Hill, P. C. (2001). The Role of Religion and Spirituality in Mental and Physical Health. Current Directions in Psychological Science, 10, 21-24.

Shinebourne, P. (2011). The theoretical underpinning of interpretative phenomenological analysis (IPA). Existential Analysis, 22, 16-31.

Sisley, E. J., Hutton, J. M., Louise Goodbody, C. C., \& Brown, J. L. (2011). An interpretative phenomenological analysis of African Caribbean women's experiences and management of emotional distress. Health \& Social Care in the Community, 19, 392-402. doi:10.1111/j.1365-2524.2010.00986.x

Smith, J. A. (2003). Validity and qualitative psychology. In J. A. Smith (Ed.). Qualitative psychology A practical guide to research methods (pp. 232-235). Thousand Oaks, CA: Sage Publications. 
Smith, J. A. (2004). Reflecting on the development of interpretative phenomenological analysis and its contribution to qualitative research in psychology. Qualitative Research in Psychology, 1, 39-54. doi:10.1191/1478088704qp004oa

Smith, J. A., Flowers, P., \& Larkin, M. (2009). Interpretative phenomenological analysis. London, England: Sage Publications.

Smith, J. A., Flowers, P., \& Osborn, M. (1997). Interpretative phenomenological analysis and the psychology of health and illness. In L. Yardley, (Ed.) Material discourses of health and illnesses, (pp. 68-91). New York, NY: Routledge.

Smith, J. A., \& Osborn, M. (2003). Interpretative phenomenological analysis. In J. A. Smith, (Ed.), Qualitative psychology A practical guide to research methods (pp. 51-80). Thousand Oaks, CA: Sage Publications.

Smith, J. A., \& Osborn, M. (2007). Interpretative phenomenological analysis. In J. A. Smith (Ed.), Second edition, Qualitative psychology: A practical guide to research methods (pp. 53-80). Thousand Oaks, CA: Sage Publications, Inc.

Sohler, N. L., \& Bromet, E. J. (2003). Does racial bias influence psychiatric diagnoses assigned at first hospitalization. Social Psychiatry and Psychiatric Epidemiology, 38, 463-472. doi:10.1007/s00127-003-0653-0

Storey, L. (2007). Doing interpretative phenomenological analysis. In E. Lyons \& A. Coyle (Eds.), Analysing qualitative data in psychology (pp.51-64). Los Angeles, CA: Sage Publications.

Substance Abuse and Mental Health Services Administration, Results from the 2011 National Survey on Drug Use and Health: Mental Health Findings, NSDUH Series H-45, HHS 
Publication No. (SMA) 12-4725. Rockville, MD: Substance Abuse and Mental Health Services Administration, (2012).

Sue, S. (1999). Science, ethnicity, and bias. Where have we gone wrong? American Psychologist, 54, 1070-1077.

Sue, S., Fujino, D. C., Hu, L., Takeuchi, D. T., \& Zane, N. W. S. (1991). Community mental health services for ethnic minority groups: A test of the cultural responsiveness hypothesis. Journal of Consulting and Clinical Psychology, 59, 533-540. doi:10.1037/0022-006X.59.4.533

Surgeon General's Report. Mental Health, a Report of the Surgeon General 1999. Retrieved from http://mentalhealth.samhsa.gov/cmhs/surgeongeneral/SurGenMH.asp

Szasz, T. (1971). The sane slave: An historical note on the use of medical diagnosis as justificatory rhetoric. American Journal of Psychotherapy, 25, 228-239.

Thomas, V. G. (2004). The psychology of Black women: Studying women's lives in context. Journal of Black Psychology, 30, 286-306. doi:10.1177/0095798404266044

Townes, D. L., Chavez-Korell, S., \& Cunningham, N. J. (2009). Reexamining the relationship between racial identity, cultural mistrust, help-seeking attitudes, and preference for a Black counselor. Journal of Counseling Psychology, 56, 330-336. doi:10.1037/a0015449

Tuckett, A. (2004). Qualitative research sampling-the very real complexities. Nurse researcher, $12,47-61$.

U.S. Department of Commerce Economics and Statistics Administration Bureau of the Census (1993). Statistical brief Black Americans: A profile. Retrieved from www.census.gov/prod/1/statbrief/sb93_2.pdf

U.S. Department of Commerce Economics and Statistics Administration Bureau of the Census 
(2003). The Black population in the United States: March 2002 population

characteristics. Retrieved from http://www.census.gov/prod/2003pubs/p20-541.pdf

U.S. Department of Commerce Economics and Statistics Administration Bureau of the Census Families and Living Arrangements (2012). Table C9 Children by presence and type of parent(s), race, and Hispanic origin Black alone. Retrieved from http://www.census.gov/hhes/families/data/cps2012.html

U.S. Department of Commerce Economics and Statistics Administration Bureau of the Census (2013). Publications. Retrieved from http://www.census.gov/prod/www/general_reference.html

Van Den Tillaart, S., Kurtz, D., \& Cash, P. (2009). Powerlessness, marginalized identity, and silencing of health concerns: Voiced realities of women living with a mental health diagnosis. International Journal of Mental Health Nursing, 18, 153-163.

doi:10.1111/j.1447-0349.2009.00599.x

Wallace, B. C., \& Constantine, M. G., (2005). Africentric cultural values, psychological helpseeking attitudes, and self-concealment in African American college students. Journal of Black Psychology, 31, 369-385.

Walls, R. T. (1999). Psychological foundations of learning Research and theory. Unpublished manuscript, Department of Technology, Learning and Culture, West Virginia University, Morgantown, West Virginia.

Walther, E., \& Langer, T. (2008). Attitude formation and change through association: An evaluative conditioning account. In W. D. Crano \& R. Prislin (Eds.), Attitudes and attitude change (pp. 87-109). New York, NY US: Psychology Press.

Watkins, V. C. (2000). African-American women and psychotherapy: Exploring behaviors, 
attitudes, beliefs, experiences, and needs. Retrieved from ProQuest Dissertations and Theses.

West, C. M. (1995). Mammy, Sapphire, and Jezebel: Historical images of Black women and their implications for psychotherapy. Psychotherapy: Theory, Research, Practice, Training, 32, 458-466. doi:10.1037/0033-3204.32.3.458

Whaley A. L. (2001a) Cultural mistrust and mental health services for African Americans: A review and meta-analysis. The Counseling Psychologist, 29, 513-531. doi: $10.1177 / 0011000001294003$

Whaley A. L. (2001b). Cultural mistrust: An important psychological construct for diagnosis and treatment of African Americans. Professional Psychology: Research and Practice, 32, 555-562. doi: 10.1037//0735-7028.32.6.555

Whaley, A. L. (2004). A two-stage method for the study of cultural bias in the diagnosis of schizophrenia in African Americans. Journal of Black Psychology, 30, 167-186. doi: $10.1177 / 0095798403262062$

Woods-Giscombé, C. L. (2008, August). Superwoman schema: Implications for physical and mental well-being in African American women. Paper presented at the National Black Nurses Association Annual Conference, Las Vegas, NV.

Yardley, L. (2000). Dilemmas in qualitative health research. Psychology and Health, 15, 215228.

Zeldow, P. B., \& Greenberg, R. P. (1979). Attitudes toward women and orientation to seeking professional psychological help. Journal of Clinical Psychology, 35, 473-476.

Zinnbauer, B. J., \& Pargament, K. I. (2005). Religiousness and spirituality. In R.F. Paloutzian \& 
C.L. Park (Eds.). Handbook of the psychology religion and spirituality (21-42). New York, NY: The Guilford Press. 


\section{APPENDICES}




\section{Appendix A}

\section{Grand Round}

\section{Interview Protocol}

I'm going to ask you a series of questions related to mental health and spirituality. There is no right or wrong answer. I only want to capture what you think, feel, and believe about how professional help seeking and spirituality intersect. Answer as much or as little as you want. I may probe your responses from time to time, for deeper exploration of your thoughts, feelings, and/or beliefs. If you feel uncomfortable at any time, let me know and we'll move on. Just as a reminder, I'll be recording the session and transcribing it later. As a co-researcher on this project, you will have access to your transcript and an opportunity to provide further feedback and/or clarify your thoughts, feelings, and beliefs about your responses. Do you have any questions?

1. What thoughts can you share with me about spirituality?

2. What factors influenced your thoughts on spirituality?

3. What are your thoughts on seeking therapy?

4. What factors influenced your thoughts on therapy?

5. What, if any, are the connections between therapy and spirituality for you?

Thank you for participating in this study. I may need to contact you to clarify your response(s). Is there a number where you can be reached? 


\section{Appendix B}

\section{Recruitment Letter}

Dear Bishop/Pastor

This letter is to request your participation in my dissertation research study on the influence of spirituality on help-seeking attitudes in Black women. This study is being conducted by me, Pamela L. Jackson, M.Ed., CAS, under the direction of James W. Bartee, Ph.D. as a part of the degree requirement for a Ph.D. in Counseling Psychology from West Virginia University.

Although I am conducting psychological research, I am also an ordained minister since 2004. I have served in several capacities in ministry for over 25 years.

In bringing together these two professional identities, I seek to conduct research that will hopefully impact the Church, as well as, the profession of psychology. If psychologists understand the influence of spirituality on how Black women view pursuing professional psychological help, then the profession is better equipped to begin to address spirituality and its impact on therapeutic processes.

Bishop/Pastor , I cannot do this alone. I am asking that you give me permission to approach Black women who attend your church, and who might be interested in participating in this study. An interview format will be used and participants will have opportunities to shape how their voices are communicated. I want to present Black women with a chance to be heard; heard in ways that change experiences and outcomes for Black women, moving us toward greater health.

The number of women selected to participate will be small, no more than ten. I am asking that you distribute the Letter of Research to women who are interested in participating in the study. These women can reach me at 443-869-0072 to obtain additional information about the study. Those women who are interested will complete a Demographic Questionnaire. We will then schedule a day and time to conduct an interview which will last approximately two hours.

To help you make an informed decision about my request I've enclosed copies of the Letter of Research and Informed Consent for your review. If you would like additional information about the study, have questions, or just would like to meet with me, I can accommodate your request. Again, I need your help. I wait hopefully for your response.

Sincerely,

Pamela L. Jackson, M. Ed., CAS

Doctoral Candidate 
Appendix $C$

\title{
Recruitment Flyer
}

VOLUNTEERS NEEDED FOR A

DISSERTATION RESEARCH STUDY ON THERAPY AND SPIRITUALITY

\author{
Study is being conducted by: \\ Pamela L. Jackson, M.Ed., CAS, doctoral candidate \& Dr. James W. Bartee \\ West Virginia University \\ School of Human Services and Education \\ Department of Counseling Psychology
}

I am looking for 8-10 Black women volunteers to participate in a dissertation study that focuses on beliefs about therapy and spirituality.

Criteria to participate:

1. Must be an African American or Black woman

2. Must be 18 years old or older

3. Must be a Christian

4. Must attend a Church or live in the United States

As a participant in this study, you would be asked to: complete a background questionnaire, sign a document stating you want to participate in the study, and agree to an in-person or phone interview.

The application packet will take approximately 10 minutes to complete and the interview will take between 30-90 minutes to complete. The interviews will take place at location convenient for participants.

If you are interested, please contact:

Pamela L. Jackson at 443-869-0072 or

via email at pjackso2@mix.wvu.edu

Thank you!

This study has been reviewed and approved by: Office of Research Integrity \& Compliance West Virginia University, Morgantown, WV 26501 
Appendix D

\section{IRB Approval Notice}

\section{Acknowledgement Letter Exempt Initial Protocol Review}

To James Bartee

From WVU Office of Research Integrity and Compliance

Action Date 10/23/2014

Approval Period 10/23/2014 Expiration Date 10/22/2017

Subject Acknowledgement Letter Exempt Initial Protocol Review

Protocol Number 1409447473

Title Spirituality, Help-seeking Attitude, and Black Women

The above-referenced study was reviewed by the West Virginia University Institutional Review Board IRB and was granted exemption in accordance with 45 CFR 46.101.

- This research study was granted an exemption because the Research involves educational tests, survey procedures, interview procedures or observation of public behavior and (i) information obtained is recorded in such a manner that human subjects cannot be identified, directly or through identifiers linked to the subjects; and (ii) any disclosure of the human subjects' responses outside the research could not reasonably place the subjects at risk of criminal or civil liability or be damaging to the subjects financial standing, employability, or reputation [45 CFR 46.101(2)].

All exemptions are only good for three years. If this research extends more than three years beyond the approved date, then the researcher will have to request another exemption. The following documents have been acknowledged for use in this study and are available in the WVU+kc system:

Documents for use in this study have been acknowledged and are available in the WVUkc system in the Notes and Attachments section of your protocol.

The Office of Research Integrity and Compliance is here to provide assistance to you from the initial submission of an IRB protocol and all subsequent activity. Please feel free to contact us by phone at 304.293.7073 with any question you may have. Thank you.

WVU Office of Research Integrity and Compliance

Date: $10 / 23 / 2014$ 


\section{Appendix E}

\section{Cover Letter}

\section{Dear Participant:}

This letter is to thank you for your interest in participating in my dissertation research study on the influence of spirituality on help-seeking attitudes of Black women. The purpose of this study is to examine the role spirituality plays in developing help-seeking attitude in Black women. Your participation may increase awareness about issues related to Black women and assist therapist in developing greater sensitivity in working with Black women from holistic perspectives.

This study is being conducted by me, Pamela L. Jackson, M.Ed., CAS, co-principal investigator and doctoral candidate in Counseling Psychology at West Virginia University under the direction of Dr. James W. Bartee, principal investigator, my advisor and Training Director in the Department of Counseling, Rehabilitation Counseling, and Counseling Psychology within the College of Education and Human Services. Your participation in this study is greatly appreciated.

The study consist of an application process, which includes completion of a Demographic Questionnaire, Informed Consent, and an interview, which will take up to 90 minutes. Participants do not have to answer all of the questions and my quit the study at any time. There will be no penalty if you choose not to participate or continue with the study.

To be eligible to participate, you must be 18 years old or older, self-identify as a Black woman, attend church or live in Akron, Ohio, and be a Christian. To ensure confidentiality, you will be assigned a participant code. Your participant code is and will act as your identifier for the study. Your name and other information will remain separate and will not be linked in any way to the participant code or the study.

\section{Next Steps:}

1. Complete the attached documents.

a. You may bring your completed documents to the scheduled interview.

b. In the event you do not have printing capabilities, I will have copies at the interview.

2. Schedule an interview.

a. You are scheduled for an interview on Saturday, $\mathbf{a t}$

b. We are scheduled to meet at the Akron-Summit County Public Library, Main Branch located at 60 South High Street, Akron, OH 44326. 
c. We will use one of the meeting rooms available on the first or second floor or find a quiet place in the library to conduct the interview.

d. I will contact you between and to confirm your attendance.

3. Attend the interview.

a. The Interview Protocol consist of a script that will be read to each participant and 5 questions. Based upon your responses, I may ask follow up or clarifying questions. How you think and what you feel is what is important to me during the interview, which is informal and open.

b. A copy of the questions will be provided during the interview.

c. The interview will be recorded and transcribed.

4. Review interview transcripts.

a. You will be provided with an opportunity to review the interview transcript.

i. This will give you a chance to clarify statements or expand your answers. You may do this by phone, email, US mail, or in person if I am in the area, during a mutually acceptable time.

ii. I ask that your review be completed within a week. If I do not hear from you during this time, I will assume no changes are necessary and your transcript will remain untouched.

5. Review the themes identified in your transcript.

a. You will also be provided with an opportunity to review the themes identified in your transcript.

i. This will give you a chance to provide feedback and comments on the themes. Again, you may do this by phone, email, US mail, or in person if I am in the area, during a mutually acceptable time.

ii. I ask that your review be completed within a week. If I do not hear from you during this time, I will assume you are in agreement with the identified themes.

Lastly, your participation in my study will remain confidential. I will not disclose your participation to anyone outside of my research team, which consist of my advisor and one or two research colleagues. Additionally, your name will not be attached to any research material beyond those documents listed in this letter and this letter; only your participant code will be used.

If you have additional questions, at any time, regarding this study, please feel free to contact me at (443) 869-0072 (cell), (716)-691-7947 (home) or pjackso2@ mix.wvu.edu. My advisor, Dr. James W. Bartee can be reached at (304) 293-2227 or James.Bartee@ mail.wvu.edu. The West Virginia University Institutional Review Board (IRB) has approved this study and acknowledgment is on file. 
Again, thank you so very much for your willingness to participate in my study. Words cannot express the gratitude I feel. I look forward to meeting you.

Sincerely,

Pamela L. Jackson, M.Ed., CAS

Researcher, Ph.D. Candidate 
Appendix $F$

\section{Demographic Questionnaire}

Name:

Date of Birth: 1

Phone:

Email:

Do you self-identify as a Black woman?

$\square$ Yes

$\square$ No

Please describe your ethnicity (e.g. African American, Jamaican, etc.)

Please select only one response for each section.

Sexual Orientation: $\square$ Heterosexual $\square$ Lesbian $\square$ Bisexual $\square$ Prefer not to answer

Relationship Status: $\square$ Single $\square$ Married $\square$ Widowed $\square$ Separated $\square$ Divorced $\square$ Partnered

Occupational Status: $\square$ Administrative/ Professional $\square$ Laborer/Trade worker $\quad \square$ Retail/Sales $\square$ Support Personnel $\square$ Other (please list)

Occupation:

How Long:

Please select the highest education level attained:

$\begin{array}{llll}\square \text { Elementary School } & \square \text { Middle School } & \square \text { High School } & \square \text { H. S Graduate } \quad \square \text { GED } \\ \square \text { College/Trade School } & \square \text { Associates } & \square \text { Bachelor's } & \square \text { Master's/Professional } \\ \square \text { Doctorate } & \square \text { Other (please list) } & & \\ \end{array}$

Income (check the range that accurately reflects your household income):

\begin{tabular}{lll}
$\$ 0-\$ 15,000$ & $\$ 15,001-\$ 45,000$ & \\
\hdashline $75,001-\$ 105,000$ & $\$ 45,001-\$ 75,000$
\end{tabular}

Have you been in therapy within the last five years? $\square$ No $\square$ Yes For how long?

Note: An identification number will be assigned to individuals who are eligible to participate in the study. The project adheres to strict guidelines to preserve the confidentially and integrity of participants and the study. 


\title{
Appendix $G$
}

\section{Informed Consent}

\author{
Study Title: \\ Spirituality, Help-seeking attitudes, and Black Women
}

\section{Investigator(s):}

Pamela L. Jackson, M.Ed., CAS, Ph.D. Candidate or James W. Bartee, Ph.D., Faculty Advisor

pjackso2@ mix.wvu.edu or (443) 869-0072 or James.Bartee@ mail.wvu.edu or (304) 293-2227

\section{Purpose:}

The purpose of this research study is to explore the influence of spirituality on help-seeking attitudes of Black women. You are being invited to participate in this study because little research has been done on the intersection between Black women, spirituality, and help-seeking attitudes. Furthermore, this research project is being conducted, in part, to fulfill degree requirements for a Ph.D. in Counseling Psychology from West Virginia University.

\section{Procedures:}

If you agree to take part in this research study, you will be asked to do the following:

1. Complete an application packet that consists of a Demographic Questionnaire and an Informed Consent.

2. Participate in an interview about help-seeking attitudes and spirituality.

3. Consent to be contacted after the interview for clarification purposes.

\section{Risks/Discomforts:}

There is no anticipated discomfort for those contributing to this study, so risk to participants is minimal.

\section{Benefits:}

Although you may not personally benefit from taking part in this study, your participation is important. By participating in this study, you may facilitate increased awareness about the psychological needs of Black women and the role spirituality plays in how those needs are experienced, understood, and ultimately addressed. Your participation may encourage further research participation by other Black women while assisting researchers, clinicians, and community leaders in finding ways to address the psychological needs of Black women in ways that are specific, sensitive, and inclusive of cultural and contextual factors found in the lives of Black women.

\section{Confidentiality:}

Your records will be kept confidential and will not be released without your consent except as required by law. Your identity will be kept private and your name will not be linked to any portion of this project. A four digit participant code will be created and used to provide additional privacy. The recorded interview will be transferred to a password protected, secure location, until it can be transcribed. The interview will be transcribed without any information that could identify you. All data will be stored using a password protected file. The file(s) will be 
contained on separate and secure thumb drive(s), kept under lock and key, and accessible only by the research team. If the results of this study are written in a scientific journal or presented at a scientific meeting, your name will not be used

\section{Voluntary Participation/Withdrawal:}

Your decision to take part in this research study is entirely voluntary. You may withdraw from the study at any time. If you choose to withdraw, any data collected prior to the interview will be destroyed and your information will not be included in the study.

\section{Questions:}

Do you have any questions?

If I have additional questions about the study, please contact me (Pamela L. Jackson) or Dr. Bartee via the information listed above. If you have any questions regarding your rights as a research participant, you may contact the West Virginia University Institutional Review Board (IRB) Compliance Office at (304) 293-7073 or irb@mail.wvu.edu. The protocol number is 1402207628. Thank you!

\section{Consent to Participate: Please initial in the place provided.}

I have read the above description of this research study. I have been informed of the risks and benefits involved, My questions have been answered to my satisfaction.

I have been assured than any future questions I have will also be answered by the researcher.

By completing the application packet, I confirm and confer consent to voluntarily participate in this study. 


\section{Appendix $H$}

\section{Developing Emergent Themes}

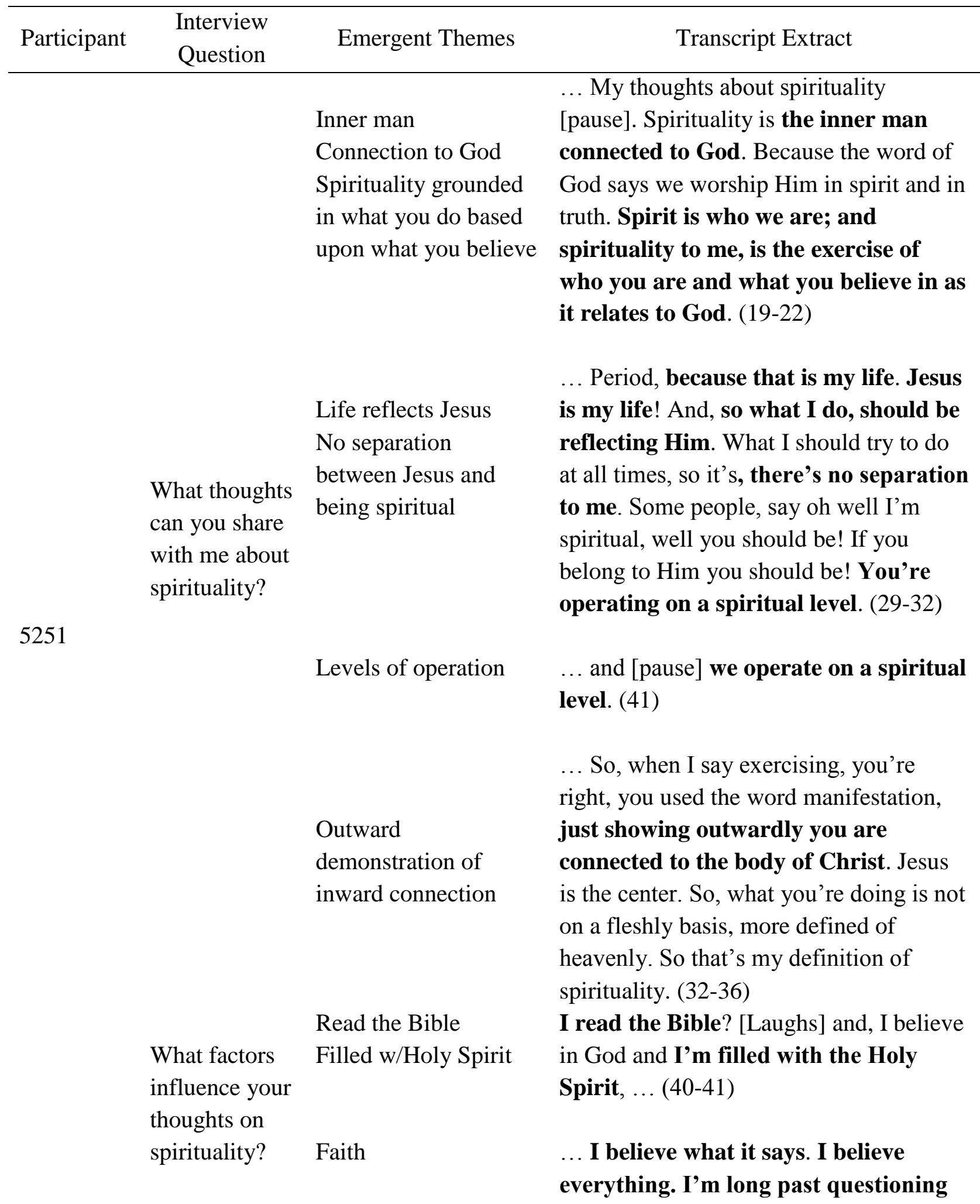


Bible reveals God's

plan for us

Bible is the center of

everything

Bible helps to respond to living

Bible shaped who I am

Bible is

transformative

Godly Family

Regular church

attendance

Prayer

Seeds planted

Godly role models little details... I believe it's the word of God to the people of God, ... (43-45) So, we would know His thoughts and we would know how to live according to His plan for us. (46-47)

... [Pause] and the Bible, to me is the fulcrum, you might say or you know, it's the center of everything. (55-56)

... Because, how are you going to know how to live it you don't read the Bible. How are you going to know how to respond to certain things that happen in life, if you're not reading what God says about it?! So, that's how it came to mean so much to me. That as ah a believer, I've been reading the Bible and uh, yeah it has shaped who I am. Because it does say it transforms you if you read it. (58-62)

... Certainly, my family. God placed me in a, ah Godly family, with a wonderful father, who had a correct understanding of the word of God; and I'm thankful for that now. Did not appreciate it early on...we're going to church! We're going back to church! It was like aagg! You know. We prayed together, my sister and I went aah, but now I know the seed my father was planting in us. And so that seed germinated, and it has grown much fruit, and prayer is a big part of my life. So, my family, and my Godmother, my grandmother, excuse me, was a Godly woman, and ah, they lived the life. I'd have to say, my father lived the life before us. (65-72) 
Shaped by what was seen and experienced in family and religious community

Openness related to spirituality is a lifestyle starting with home of origin, early Christian experiences, and living beliefs

Lived in a healthy environment

Therapy great

Talked to elder and pastor of church

What are your thoughts on seeking therapy?
... And, I know I wouldn't be where I am spiritually, if that had not happened. 'Cause my father was, you know he prayed with us. He talked with us. And, as I said, he modeled what he believed before us. (76-78)

... How did I wind up in this position of openness as it relates to spirituality? [Pause] I, let's see if I can articulate that. I guess just a lifestyle; starting from the home of origin, then being, uh saved at a very early age, and, then living, trying to live that. (263-265)

... We lived in a healthy environment. (268) ... We didn't live in a toxic environment. (299)

I think its great [laughs]! (84)

... And, um [pause] I, I talked to [name of pastor redacted]'s father. [Pause] and he was so, such a beacon of, of guiding light for me, and I also talked with [pastor's name redacted] because, uh I didn't think I had a problem, at the time 'cause what the Bible said about divorce. And, he gave me some very, profound advice. He says I John 1:9 says 'if you confess your sins, He faithful your sins and cleanse you from all unrighteousness' ask the Lord to forgive you and go on. Because, see we beat ourselves up a lot of times, and if we

Outside voice important don't seek an outside voice, to let us know 'you're okay' or 'this is what you need to do from this point on.' It didn't stop the, um [pause]. Well! I remember talked with him, but I did talked to how long. It wasn't a series of sessions I 
Talked to staff pastors

Staying connected to church

Healed in church

Therapy a wonderful tool

Cultural mistrust

Healthy and whole

Got to do something

Effects of slavery

Generational scars

Betrayal produces him. We didn't have Pastor [name of licensed clinician on church staff] then, and we didn't have anybody on staff.

You just went to the pastors and you talked to them. But, the times I talked to Elder, because I had access to him. The times I talked to Elder, he, I think he helped me to see outside of myself; 'It's nothing that you did' and 'this too shall pass' and all that. It just, you know, 'stay where you need to be.' The thing that helped me most was staying connected to the church. A lot of people when they have issues, they stop going. [Pause] that's your strength! That's your covering! And, that's where your get healed. And people had said to me 'you know what, I didn't even know you were going through a divorce.' I was in ministry; 'you kept coming. You were at your post' and I said to them, where'm I gonna go! Where else could I go? So, that is um, I think therapy is a wonderful tool and I do understand traditionally, people of our ethnicity, why they're skeptical and suspicious. But, if you wanna get healthy; and I believe God wants us to be healthy and whole. Ah, you gotta do something. (93-117)

...Well, I guess I would have to say, it goes back to slavery. For one thing, we don't have any clear, we haven't severed the tie, the emotional ties ah, from slavery. Physically we may not be enslaved, but emotionally, we still carry those scars generation after generation after generation. (120-123)

... But we, we have this fear of trusting 
lack of trust

Privacy issues

Learned early to keep quiet

Privacy can be harmful

Harmful generational patterns passed on because of the betrayal, I guess I can use that word, down through the years, the way we've been treated; and, then also privacy issues. And I do believe that, we don't, 'cause I heard someone say 'you know how it was when we grew up, our parents said, uh, there's a colloquial thing now uh what happens in Vegas stays in Vegas [laughs] or whatever, Atlanta it stays in Atlanta. Well my mother always said, what happens in the house stays in the house. (124-132) ... You don't talk these things. (139)

... but we learned early on we keep our business to ourselves. (136)

... Even to the detriment, of our good health! And, I don't think that's good, but those are the things that have been passed on; from you know, generations whether it's good or not, that's what a lot of us grew up under. (136-139)

... We know we live in the fallen world, and we know that uh, well, I remember something that [pastor's name redacted] said years ago when we were, might, might have been during Martin Luther King's month or Black History Month or something; we were talking about race and some other things and he, oh how does it go, what did he say [pause] it wasn't a danger, what was the word. Being Black, everyday being Black in America, is oh what the word was. ... But, here again this was something, like the residuals of slavery, that every day we're faced with, we have to make 
Facing heavy D words

Upbringing

Groundwork laid

What factors influence your thoughts on therapy?

Black people bombard by many things which can create bondage

Exposure to someone else in therapy monumental and we, we're facing all kinds of dif, discrepancies, deficiency all the heavy D words. That's what I call them, the negative heavy D words. (180189)

Limited access to services and therapist of Color

Resilience

Openness to therapeutic process
... But, there're so many things that bombard us as Black people. And, we can easily get [pause] bogged down, I guess, the next thing we know we're in bondage, and we don't, we don't know how we got there, we don't know how to get out of it. (192-195)

Well, I would say that it's probably a part of my upbringing. My father, my mother was not emotionally healthy, but my father was. And he talked to us about everything. Very open, uh there was nothing I couldn't go to him with and we didn't sit down and talk about it or something happened and he would share with me and we had a dialogue about it and I don't think therapy ever came up, but just the groundwork was laid, ... (146-151)

... Oh, and also, when my dad got custody of us, I thought about this [pause] my sister went to a psychiatrist! 'Cause my mother had abused her. My mother had abused her, and uhm in those days, you couldn't readily go to a therapist of any kind, and certainly not a therapist of Color. But I know, I remember she did go to a psychiatrist. My father took her because he wanted her to be able to discuss and get those things out; and she had a lot of problems. But, ah I was more resilient, I guess. I didn't go. I didn't [laughs] have to go, but she went and he took her because I think he wanted her to be able to, maybe to 
modeled

Accessing therapy normalized express herself if she couldn't to him or anybody else. (155-163)

... I don't even think, at the time, I was aware of what was going on. I knew she was going to a doctor. I think I was older before we even had; I don't even know it came up that it was actually a psychiatrist. I don't think it was anything cloak and whatever, in the house, it was just like hey, whatever, and, um she's having some problems and she's going to a doctor. I found out later it was a psychiatrist, so it was just okay.

Free access to therapy Therapy affirmed in church

... I just wish that we would take advantage of it. I do. I'm starting to hear it more often now in other camps, and now that we no longer have Pastor [name of licensed clinician on church staff] as a professional on our staff. (232-234)

... And, many times, we, as people of

Regrets about not taking advantage of services

Supported by therapist on staff at church

Open to therapy color get in on the last end caboose and then we wish we had taken advantage of it, you know, a long, long time ago. And, I have no idea how many people she has assisted or who has gone to see her.

Even though, she didn't provide counseling for me, but when I relocated my mother here from [location redacted] in [year redacted] and we were battling and going through this kind of stuff, she would listen to me and she even said a couple of things, that you know, helped me, to make decisions about what I should do, how I should proceed or whatever it was that I was discussing. 
Non-toxic

environment

Unresolved trauma or pain

Shame

Baggage free

God wants us healthy and to be well

What, if any

are the

connections

between Therapy and

therapy and spirituality lightly

spirituality for connected

you?
So, she helped me! (232-245) ... She helped me and you have to be open to it; I guess because I am open to it. Uh, it will help you. If you're not open to it. (247-248) ... So, if your mind is closed, nobody can really help you, regardless of therapy. (253-254)

... And, um we said 'you know all the people that were coming in and out of our house, no one ever touched us inappropriately. No one ever said anything out of the way to us. I considered that blessed! Certainly. And uh so, I don't have that to deal with. And there's a lot of incest and a lot of stuff that happens; skeletons in the closets that people, because they haven't taken them out of the closets they can't get the healing they need. Because they're ashamed. Pastor's preached on shame, legitimate shame, illegitimate shame and that kind of thing; but, their ashamed of what has happened to them. So they're not, they're afraid to bring it out into the open. And, thank God we didn't have that baggage to deal with. Now, I gotta find some place to put it. (289-298)

[Pause] well I think I said that I believe God wants us to be healthy; and $\mathrm{He}$ wants us to be well. (179-180)... I said that I believe God wants us to be well. (191-192)

... And, I do believe the thing, the two of them, could be lightly connected. Because if you're having a problem, first you seek God, and you can seek therapy in the process. Because I don't think that He necessarily does things we can do for ourselves. We pray for 
Therapy a temporary fix

Talking with others normalizes experience

Relationship may encourage seeking therapy or feel like therapeutic support

Wisdom of or confidence in another may increase willingness to consider therapy

What thoughts can you share
Sharing and talking is cathartic

Spirituality is

connecting with God healing, and we pray for deliverance, and we pray for all these other things. ...

Because, that can be the mainstay for you until the answer comes. Which, you know, through therapy. I mean not through therapy, I mean spiritual; through until the spiritual answer comes. (195-203)

... Because when you talk to people and you find out you're not the only one. (214)

... Its, its therapy. You can, you can, maybe not get the professional answers but, when somebody has gone through, of course the dynamics are different, we understand that, but they can empathize because they have gone through that, I believe that's a form of therapy. (217-220)

... and, then if the person is wise or if you gain the confidence of the other person, then you might be able to refer them or usher them, direct them or say, well you know I'm not a therapist and I don't want to tell you anything wrong, but may you want to talk to somebody, who could probably, you know if they're amenable to that. You see an open door, and you might have started something that might not have taken place. I do believe in sharing and talking to other people is cathartic. (224-230)

Well, spirituality to me is knowing that there's something higher than my own self, my own intellect. So, spirituality to me is connecting with something, an entity that's bigger than me; and for 


Influence of home of
origin and upbringing
Influence of peers
Friend talked about
God and spiritual
things

Church attendance

Church an escape

from home

What factors

influence your

thoughts on

spirituality? me that would be God. (19-21)

Um, that would probably go back to home of origin, upbringing, um the influences I had coming up as a child. ... it wasn't really family influence, it was more peers. (24-26) So I had a young girl, a young friend of mine actually, we were best friends, second and third grade, used to talk to me about God, and Jesus, and the Holy Spirit, and speaking in tongues; all the time. (26-28)

... And, I, I went to church though. My mom didn't go with us. My mom would drop us off then go back home, so I, it was just my sister and I. I liked going to church. For me church was an escape from home. So for me church was a, a way from all the stuff that $I$ had to deal with at home. So, when me and [name redacted] were friends her, her family, they all went to church together. They

Exposed to a variety of spiritual

experiences as a child were [denomination redacted] I went to a [denomination redacted] church.

So, I knew nnothing about denominational stuff. But, [takes a breath] and nothing about the type of stuff she was talking about. I mean she was literally talking about the Holy Ghost and being filled with the Holy Ghost, and being, speaking in tongues and all of this and so, before I ever got baptized, ... I, I

Didn't want to go to hell just knew I didn't wanna go to hell. That's all I knew and I knew I wanted to go to heaven and I knew I wanted to Wanted to believe in Jesus believe in Jesus, you know and it wasn't hard for me I just believed her; and [pause] she would tell me about baptism and how, the experiences. She 
Fearful about spiritual things

Pre-exposure to shared experience

Friendship influenced the pursuit of God and spiritual experiences increased connection

would tell me about an angel being down in the water and an angel was gonna carry you under the; and she, she would scare me to death sometimes, because I really couldn't swim. I was, I'd think about [laughs] I'm not gonna be able to swim under the water where the angel is. And, I can remember, I can see myself sittin' on the pew dressed to get baptized thinking about this angel [pause] that, maybe I wouldn't see and then I wouldn't be saved and I wouldn't have the experience that [name redacted] told me I should have. And speaking in, I don't wanna speak in tongues, you know I never even heard nobody speaking in tongues. But for some strange reason, it connected with me in a weird way. I just didn't know what it was. I never really asked her either. But I, didn't really look at her foreign either. Like, what do you're mean speaking in tongues? What does that mean? So [pause] for me um, that's where it started. I got baptized, I remember tellin' her I got baptized and she was happy ... and she, she had a big influence on me getting baptized and having a relationship with God. (30-56)

... [Pause] I prob, I would have to say so. And, like I said you know my mom

Church attendance mandatory

Friends at church

Participated in church activities would make us go to church and we wou, we would do Sunday school, and then go home; I should say that first. And then I had friends at the church, and then later on I started to sing in the choir, and then we had to be at the church service because we had to sing the choir so therefore, I had to actually 
Church a safe haven

Church impact

recognized

Friend helped to lay spiritual foundation

God put people in my life

Godly role models

Seeking therapy is

What are your thoughts on seeking therapy? therapeutic

Everybody needs

therapy

Therapy should be mandatory go to Sunday service. Prior to that it was mainly Sunday school. ... But for me, as I said before, it was a safe haven for me to get away, if I didn't go to church [pause] my, my week was off.

Everything was off for me. So, um once [name redacted] left, that, that didn't stop me from going to church; I still went to church. (59-69)

\section{... In later in life I would pick up} pieces of it and hear about it and learn about it and that kinda thing and, and I ran dead smack [claps hands] into it later in life, in my adult life, in terms of Holy Spirit, being [denomination redacted] and what they believed, and all, whose saved and whose not and how you dress and all that kinda stuff. So I ran into all that other kinda stuff later, but she [pause] she um she definitely made me think, I wanna be saved. (70-75)

... But then God blessed me with a go, a stepmother. ... But, when I, when I would, you know and she always welcomed me so, um she's always had just been an influence and then she was spiritual too. And then she was a very, had a strong relationship with God so that just kinda helped me stay in that lane. (237-244)

I think seeking therapy is therapeutic [laughs]. .... I think everybody needs it. It should be mandatory [laughs]. (83)

... I think everybody needs it. It should be mandatory [laughs]. (85) 
It's not a bad thing

Therapy not discussed in Black families

Privacy issues

Issues stifled or covered up

What factors influence your thoughts on therapy?
Desired to share but couldn't

Impact of childhood experiences not understood until later in life

Traumatic experiences

Desire to talk through feelings

Learn to be quiet

Silence only learned strategy
... It's just that therapy is not a bad thing. It's just not a bad thing. It's a good thing. (408-408)

... I do feel that in our community, the Black community, I do believe coming up in a Black family, you never hear the word therapy, you never hear the word counseling, you never hear the word seeking help. So, you hea, you do hear 'you better not tell anybody' you do hear 'this is, what goes on in this house stays in this house' you do, so everything that goes on in the home to stay in the home; so if there's issues, if there's abuse, if there's mental things going on, especially for a child who don't even realize any of that kinda impact; so, you learn to stifle. And, I as a child growing up in my home, I had to learn to stifle a lot of things and not share a lot of things, and keep a lot of things in side that I should've been able to tell an adult, including my mother and I never did. (85-94)

Mmmm, I don't think as a child you really understand the impact when things happen to you as a child. I think. And I'm speaking from my own experience, ... (96-97)

I just, I'm just saying for me the things I know that happened to me; that I know were, were definitely traumatizing [pause] but then if you don't have anybody to talk you through those feelings that you're feeling, you just learn to deal with it in your, on your own way; and that's what I did. For me it was just be quiet. (99-102) 
No one would believe or be on side

Not thinking about therapy as a child

No exposure to therapy growing up

Increased exposure later in life open eyes to therapy
Church proactive regarding therapy

Confidence about seeking services increased

Life experiences led to therapy
For me, you know, that just how I dealt with it because [pause] um I was I, it would be unbelievable if I were to say it; it's like no one would believe me or have my side. (104-105)

... Yeah, the thought of therapy, that's what I'm saying like as a child you know, you're not thinking about therapy. And, when I'm looking back, in hindsight, nobody I ever knew said anything about therapy. Even coming up in the church, the, that I grew up in, you didn't talk about therapy, never heard counseling. I never heard that term at all. (110-113)

... I do believe that um, once I was exposed to it, really, really later on in life to be honest with you. When I was a student, in college myself, and when I got exposed to some of the services that the campus offered; so that really kinda open my eyes to it. (129-132)

... And then, being at my church, having to be a part of the church who, who aa is very proactive when it comes to counseling and seeking help; so, but I did, but that's not where I come from. (134-136) ... So, for me now, I have no problem calling the church to get counseling. (262-263)

\section{... I should say [pause] just life} experiences. It wasn't one or two things that said ding, you know, you need to go talk to somebody. Because, you, again you have your, my peers, I 
Peers and friends acted as sounding board

God placed stepmother to be a constant source of support

Sought therapy for someone else in family

Comfortable with have my friends and then they tend to become your, your sounding board, and the people that you depend on. Me, God had placed for me in my life, a stepmother. So and later on, she became, you know, the, the person I could go to when I, when I didn't know what to do with all these feelings I had; when I would go through certain things in life. (137-144)

... But, I will say this though [pause] um, my oldest daughter was raped and um when she was a teenager by some neighbor boy. So, for me it was such a traumatic experience, because that was, because that happened to me from a family member though. And, because I had tried everything as the mother, I tried to do everything to protect my children. So when this happened to her, I felt like a complete failure. You know like, I was, I was supposed to protect her, this, this should not have happened to her. And, when I went through the steps to do all I need to do with that, I think it was somebody who said, I think it was somebody who, I don't remember, I honestly don't remember where I got it from, but somebody had mentioned to me about [counseling center name redacted] and how I could probably get her in there and get her some counseling. So, that was probably my first, [slaps the table] first incident in my life that I had to, went outside to professional counseling, ... (149-162) ... Oh, as soon as I heard it, as soon as I heard it I jumped on it! And it was a 


\section{Christian based therapy \\ Witnessed positive results of Christian based therapy}

Thankful to God

Limited access to therapy resources while growing up

Judgment for not doing something correct

Thankful to God Christian based therapy was brought to attention

Tried different approach than telling close friend

Volunteer experience

Worked with students
Christian based counseling service, so yeah. Aa, I can't remember how long they saw her 'cause it's based on insurance and all that. But she [pause] did wonders in there. She loved it. She didn't reject it. She welcomed it. So, I was very thankful to God that I was told about that. 'Cause I, I didn't know anything about [counseling center name redacted] you see. And, and that's another thing too. So, the resources, and again back to that home of origin, where in even this situation, I went back to child, my, back to my own childhood and nobody in my family knew about this situation, because I went back to my own situation that nobody knew about. And nobody in my family would've said 'hey you should get some counseling' or 'go' it would have been more like 'you should've did this' and 'how come this' and 'you.' It would have been more 'you' you know and I already felt guilty enough. So, I was thankful that, that that was brought to my attention. So, you know, that was my first experience with dealing outside the aa, the norm and just trying to deal with it on your own or just tellin' your friend or a close friend why you know that you need to share something with. (173-188)

... Aah, volunteer resource research. I studied through our psychology department; and [pause] because it was, you know they're still students, and they were like young, young, young ladies. Um, on a scale from one to ten, as far as it benefiting me, I did it twice. (190-193) 
Tried therapy again even though first time not the best experience

Dreams deferred

Unsupported in major life decisions
... So the first time, on a scale from one to ten, I, I, I thought it was about a three. 'Cause I really didn't get a whole lot out of it. The second time [pause] the, the young lady that I was engaging wit' um she really helped me, well she was really tryin' to help me see kinda where I was going 'cause I was really struggling with where I wanted to go with my degree, and if I had chose the right, you know, major for myself. (195-200)

... I can remember things that I would say I wanted to do to, at home, and being shot down for it. So I stopped dreaming; early in life, early, way early. (202-204) ... But it, it killed the dream again. So, I put it off probably another ten/twelve years... (212)

... Um, and I tried to go years before, but my mother again, just knocked [slapped hands together] that dream down, told me what I couldn't do. Um I couldn't go this school, 'cause she happened be at the university herself; worked there, and when she found out I was tryin' go to that university, that is what she said to me, right in front of my friend. (207-211)

$\ldots$ and then aa coworker, we were all talking about, you know, one day wanting to go back to school and I knew I wanted to go back to school. I didn't know what for. Um, at the time that, that was going on in my life, I was, I happen to be teaching down at the [location 
Support outside of family or origin to pursue dreams

Desire for strong support

Weighed down by baggage

Strong relational ties redacted] and I was doing ministry down there every week and then one of my coworkers said [name redacted] just do it. And when she said that to me [pause] it just, I don't know it just rang profound. And then next day I called [name of school redacted] and I, out of, out there and I signed up and went. It took me twelve years to do it [laughs] but, I did it (213-221)

... I think, like for me I'm a woman sitting, who did not have that strong support, family support, so God will put people in my life for certain things [pause] to have certain relationships; relationships that I wou, would've wanted to have or that probably that a young girl would want to have with a mother, I didn't have. (233-237)

But it took a while because, all that baggage I was, that I had as a kid and as a young lady and as a mother; ... (221222) ... It took me twelve years to do it [laughs] but, I did it. But it took a while because, all that baggage I was, that I had as a kid and as a young lady and as a mother; it just um it, it took a while for me to really get on that train; okay like I'm 'bout to do this. (285-288)

... Well aa, then the woman over there though could say, 'well I had a strong mother and a strong grandmother. I had a prayin' mother and a prayin' grandmother.' And then, they heard all these wisdom quotes all their lives and it's helped build their character and you know, and where they come from. 
important and take different forms

Places of refuge

Ence therapy if needed

Encouraged to pursue therapy for child

Afraid of child being
And, so, when they go through things they may have had their, that mother, grandmother, or that aunt to go to. So we all, we both have those same type of relationships whether we come from that strong family or not so strong. (242-249) ... So, I know for me when my stepmother died three months ago, there's stuff I'm going through right now that I wish she was here, that I could talk to her. 'Cause I could. I can't go to my mother and do it. You know, I, its, now it's different, because my mom is, she's still alive. It's not like we don't talk but, it's nothing like how it was with my stepmother. (252-256) ... I'm forty-eight years old, [pause] and, my mother does not know half the things I've gone through in my life. No, no, she doesn't. So for me it's, it's not a, it's not like a boohoo thing. It's just the truth, it's the reality of it, so. So, I'm still grateful that I have my stepmother though. (258-262) ... It's like we, we gravitate to those people that we feel we can get, we can go to refuge. They're like, our, our city of refuge. For us. (250-251)

... I don't have no problem telling my kids 'you need to go talk to somebody. (264-265)

... So, when I talked to her doctor, we were talking about getting her some counseling; she could talk to someone. And, we never actually did that [pause] though [name redacted] was okay with doing it. But the reason why, I chose 
labeled so did not follow through with suggestion

Timing determines pursuing therapy
Alternate support provided not to do it um 'cause some of the stuff she, she would have been one-on-one with someone and I didn't want her to say; I was afraid she would get labeled. That's what it was. I was afraid she would get labeled suicidal or something. I just had this fear of that and [pause] she has never tried to do anything to herself. (276-283)

... I'm not against it in any way. It just that I, I felt [pause] I just didn't think that was the right time for us to do it for her. (293-294) ... But, I had to go there every week and sit with the lady. Sometimes we, it was just me and then sometimes they would have um both of us in the room together. [Pause] but I, I never was open to it. I, I never li, I didn't like it at all, at all, so. And I was kinda quiet, kinda sheltered, timid young lady so, I wasn't; you know I would be damned, if I was like to have an attitude. You know an attitude, far as verbally bein' rude and all that kinda stuff. So I would just, you know when she asked me questions it was just, I would just say, shrug my shoulders or you know I'd just, wasn't willing to participate. (394-401)

... you know, she'll come to me, like [knocks on table] 'ma can I talk to you?' (306-308) ... Everybody gravitates to her; like nothing's happening to [name redacted] bad [laughs] you know if anything, the world will get turnt upside down over this girl, you know, so she has a strong family support and she know it, you 
know and she had, and then she has five other sisters that she can tell, but see they all had each other in school. (311-314) ... In my house, it's, its five girls and two boys and me, so [pause] I had a big load to, to try to you know, raise these kids up. So, and, and try to get them as healthy and feel like they can; and I'm not sayin' they talk to me 'bout everything. Sometimes I'll wanna to know. As a mother, I'm like, oh God. But they have each other and they're all close and you know, sometimes I can talk to them about my stuff. 'Cause my, I got grown women now. My oldest daughter is thirty years old. So, you know we can talk about things now, so and that's a good thing 'cause I, I can't, I couldn't do that with my mom. (331-338)

... I definitely [pause] have, you know they say the apple don't fall far from the

Doing things different so as not to wound others

Personal experience with therapy tree [laughs] so, you know I've had to take a lot of self-inventory over the years, to [pause] try not to do or, like my mother did me and my sister, aah in ways that can be damaging. And sometimes, some things you really don't heal from. You just kinda recover from them and they can be very subtle, uh you know where you can function and go, but that wound, if, if you bump it hard enough, it'll still hurt. So, um [pause] I, I, I really try to be different in that, in that sense. (324-330)

. 'Cause I, I can remember, I forgot my mother had me going to [counseling center name redacted] [pause] and, I was not willing. I was 
Just because you think I need therapy, don't mean I need therapy

Experience shameful

Might be viewed as crazy

Submissiveness

Open minded

Commitment

What, if any

are the

connections

between

therapy and

spirituality for Humbleness

you? not open-minded. I was not willing to be a participant. I did not want to be there. I didn't think I needed to be there. For some reason she thought I did. Her reason was being [pause] me being in my room a lot. And, I was in my room a lot. But, I was in my room a lot to stay out of her way [laughs]. That was my reason so. That experience for me, havin' to go there every week and get off the bus right in front of the place, when all of my peers were on the bus. And I would have to pretend and lie and say I had to go meet my mom somewhere or lie 'cause I didn't want them see me going into this [counseling center name redacted] 'cause I'm, 'cause I'm crazy, 'cause I'm goin' in here 'cause I'm crazy. So I would just, you know when she asked me questions it was just, I would just say, shrug my shoulders or you know I'd just, wasn't willing to participate. (383-393)

I think the connection between the two, they both require [pause]

submissiveness. I think they both require, a person to be open minded. I think they both require, ahm a commitment um because, you need all of those to get to the ends of where you're trying to go. So, I know in my spirituality, I have to be committed, I have to be submissive, submissive to the God I serve and if I go to counseling and open up myself to a person I don't know, it still takes an amount of humbleness and submissiveness to be able to do that. (344-352) 
Recognized need for support in church

Process in therapy has similarities with process of being in relationship with God

that provides a foundation in God is good
... 'Cause when I first got to [name of church redacted] I went through grief recovery. I never heard of grief recovery, but I know I need it. And as soon as [Pastor's name redacted] said grief recovery, I said where's that, where's that class, when it starts, how much it cost? 'Cause I needed to go [laughs] and I went... (353-356)

... So, if your restrictions, your wall are all up here, um even the questions that someone may ask you, aa and they're not asking you to, to, to penetrate any harm to you. But, if you're not open to the process, then just the same spiritually to God. If you're not open to God and you're not open to the process then God, His hands are tied. He's not gonna make us do anything. We have free choice to do. So, I think they both correlate those, being submissive, being humble to the process, and you have to be openminded and be a willing participant; on both, on both sides. I think they require both. (365-373)

... Like I never thought [pause] you can go to Christian counseling, you know what I mean? I never knew of that. That's why [counseling center redacted] was so profound to me; I'm like wow, this is for Christians. You know, 'cause that a good thing. You know, you know you're getting some kind of, at least a foundation of God is in there, somewhere and so versus secular, ... (377-382)

I think spirituality, in a lot of ways 
can you share

with me about

spirituality?

What factors

influence your

thoughts on

spirituality? define us. It define us in how we interact with, not only ourselves, but also with those around us. I think it's how we maintain our strength, umm, I think it is, in a lot of ways what keeps us going from day to day. (13-15)

Spirituality is our being

Helps us function the way God intended

Raised in church

God is first in our lives

Spirituality produces respect and mindfulness of spiritual foundations and defines us Culturally it who we are, as Blacks

We need

We have to have it for survival

Brought up in church

Around spiritual people
... So, spirituality, in the grandest scheme of things, is our being. (17)

... Without it, in a lot of ways, we don't function in a way that [pause] I would say, in a way that God sees us or wants us to function. Umm, we were raised up in the church from little kids and we were always raised up in a way that God is first in your, in our lives. Um, we are to be respectful, we are to be mindful, so all of that teachings from our younger years, for those who have that, and getting into our older or our later years of life, it defines us in terms of spirituality. (19-24)

... I think that because we, we are [pause] culturally it's a part of who we are as well. If you look at the different cultures, our culture, as Blacks, it is [pause] a very, very strong part of who we are; and we need it, we have to have it because we, it's our survival. So, for that part yeah, that's what I would say. (31-34)

... [Pause] we need it 'cause if ever you have a conversation with, a Black, such as myself, who has been brought up in the church, who's been around spiritual people, grandmas, uncles, and the like, people in the church, um we can we can tell you something 'bout 
Mentored by spiritual people

Pull from spiritual foundations

Access to spirituality

Spirituality took many forms

Surrounded by spirituality in the Black community

Attended neighborhood church

Still attend that church

Spiritual mothers who guided and mentored
Knowledge and teachings passed what each one of those things mean to us and how they define us. How they mentored us, how they made us, uh grow into the beings that we become as adults. And, I think with each season of our lives, whether it's with, you know from our childhood into our, um adult, all the way into our senior years. We, we actually pull from that. We pull from what those foundations were, you know from the church, from family, and aah, even a lot of times, even the neighborhood. ... even if you didn't go to church there was always somebody who had bible study in their house, in their living room or you always had the minister in the neighborhood who was preaching to you, so yeah. It was always, we were always surrounded by religion. (36-50)

... [Pause] we moved to Ohio when I was probably ten, and the church that our parents took us to was the church in the neighborhood, to this day I still go to that church. And, were [denomination redacted]. And, in that church there was mothers, mothers of the church; and the mothers of the church was as much your mother, spiritually, and guidance, mentors, as your own birth mother and for a lot of those who did not have mothers, they were they served that role. And one mother in particular, uh her name was [redacted], she lived to be 100, a 103, 104, she just passed away last year; [pause] she served as all of the women's mentor, and everything, all of her knowledge, all of her teachings, all of her everything. 
down

Spiritual experiences

ingrained

Therapy good

Therapy cleansing

Different levels of therapy

Therapy helps to

define where you need to be

What are your

thoughts on seeking therapy? Therapy can provide tools
She passed it on to us and we all sit as church members, as individuals, and even some of the other mothers who are still alive, we still talk about what [name redacted] gave us. [Pause] so, I would say it's probably something along that line, in that it's ingrained in you. (61-73)

... I think therapy is good, it's cleansing. (80)

... I think a lot times if we, if we have and I, I've dealt with therapy, and I think there's different levels of therapy. You can have therapy that's cleansing, in that you're just not comfortable with who you are or maybe, you're in a place in your life that [pause] you don't feel connected. So, I think, a lot times therapy helps you to define where you need to be. (82-86)

... Now, they're not telling you who you

A different level of support is needed

Therapy provides assistance for the thing you don't know how to handle should be or where you should be, but they can give you the tools that's needed. Ahm, then there is therapy where you're really, you're really sick and you need someone to kind of help get, I guess you can say, they give you the medicine, mentally emotional that you need to either pull yourself together or either give you a direction. And then there is, the last time I went to therapy was grief therapy, and then there's that. That you are dealing with something so powerful you don't know how to handle it so, you go to therapy to get the guidance on how to deal with that. (88-95) 
Good to know it's available

Therapy like medicine

Therapy serves a

purpose

Therapy is emotional and psychological healing

Therapy needed for those suffering

Therapy is necessary

Stigma in family

Stigma in church

Just pray

Talk to a minister

What factors You'll get over it influence your thoughts on therapy?
... [Pause] I guess I'm, I'm just one of those people who believe that it's [pause] good to know you have it if needed. I, I'd say therapy is something that just like medicine, it serves a purpose, it's healing. And that's the way I see therapy, healing. But, not physical, emotional and psychological healing. (105-108)

... I think it's something that's needed, um, I have no, I think anyone who, ahm may be suffering some emotional psychological setbacks in their lives, I don't see any problem with them being in touch with therapy. I thinks it's a need, it's a necessary, I think it's a necessary process that we all need at some point in our life. ... I think it's a necessary. (119-123) ... therapy was something I viewed as a necessity, if needed. (148-149)

... I think, [pause] there was a stigma in our family and in a sense it was a stigma in the church. If you were hurting, if you were grieving, you were just taught to pray or go and talk to a minister. Ahm and a lot of times in the household, ahm, they were not well educated, but they felt ahm, you'll get over it. (143-146)

... Many of the Black women [pause] in church, in Christianity, they expect,

Therapy not needed because God provides all especially, and I'm tryin' to think of friends and, and, and church family, um they just, a lot of them don't see it as something...God provides all. And since God provides all this, is not something I need to branch out to. 
(223-227)

Church provides what is needed to address concerns

Exposed to the perspective of older family members who believe therapy is quackery and prayer is sufficient for any concern

God's leading may lead to therapy

What, if any are the connections between therapy and spirituality for you?

\section{... Because the church has provided} them, in their, in their feelings, and in their teachings and in their upbringing, the church has provided them with what they need in terms of dealing with it. (227-230)

... Ahm, my aunt [name redacted] she just turned 88 or 89 , I'm not sure, just this month, and with her ... With her, she is, I mean, it's unbelievable to listen to someone of that age, who's been through everything and have a memory sharper than you and I. [Pause] and, very, very open minded, very open-minded, but if your start talkin' therapy or something like that, she goes back to religion; her God. Ahm, her sister-in-law was going through something tough with the family and she made the comment 'she going to see that old quackery, therapist and stuff, all she need to do is just pray.' So, that just kinda the way they think, but I also find it hard that a lot of them feel that medication is going to cure all. (229239)

... I think that sometimes we're spoken to spiritually, I think were spoken to, and I think that depending on where we are, He will lead us to the path where we need to go; if that is therapy, then that's how we, that's the choice we make. Ahm I don't see that, I, I, I'm not saying in so many ways that God speaks to us, he tells us go to therapy, no I'm not saying that; I'm just saying internally, you know when you pray,

Faith carries me through when you're reaching out spiritually, you know. I always say, show me the 
Spirituality carries me through

Therapy and spirituality are separate

Both can provide comfort and strength

Strength from prayer

Prayer provided insight into needing something more way; give me a feeling of what I need to do, ... and if the therapy falls into that, then I will reach out in that sense. Ahm I believe, especially now that I'm older, I believe a lot of my faith carries me through. So, the therapy is not as much, in my case, is not as much a necessity, aaa, in terms of would I go there. Now, I'm not saying I would not. I would most definitely go, if that (uninterpretable) need arise. But for me I, I depend a lot on my spirituality to get me through. So I, to say that they connect or to say, give an overview of how I feel about it, that's kind of, for me that's a little difficult. (152-158; 160-166)

... I look at 'em as two separate entities. [Pause] I think that one can give you the comfort and strength you need as well as the other. You go to therapy to get the strength and comfort you need, they can give you the strength and comfort you need. You turn to spirituality, and depending on how deep your spirituality is will give you the comfort and strengths you need as well. (168-172)

... [Pause] it can, depending on how deep things are within you. Yeah, it can. But, and I, and I'll just to give you an example; during the time my father was ill and close to his death; you know I did a lot of praying, and praying, and praying. And, I just felt like I was getting the strength I needed from prayer. But, there was something deeper I needed to balance it out; so, that's when I turned to therapy. (183187) 
What thoughts can you share with me about spirituality?

What factors

influence your thoughts on spirituality?
Spirituality is personal and individual

Spirituality is connection between individual and God
Gods provision is through a spiritual connection

Choose connection

Raised in Christian family

Upbringing
... I think spirituality is a, is very personal. I think that it's also very individual, between the individual and whomever they feel spiritually connected to; whether it be a higher being um, whether it be something tangible; but it's very personal and very individual. (13-16) ... Yes, in my personal case and individually, yes it is connected to a higher being; to God. (19-20)

Spirituality is a choice

Once choice made life correlates with choice to be spiritual or God

God provides

... I think, first of all it's a choice to [pause] be spiritual and it's a choice, and once I have made, since I've made that choice to be spiritual, then I am open to correlating my life [pause] to my spirituality or to the higher being, and in this case for me it would be God. So, for example, I choose to believe that God will provide for me. And so as I go through my life, my daily activities, if something should happen to me something unexpected or um, or even if something expected, I somehow can tie it back to God providing for me. And, and that's just an example. So, even though some people may say, you got this job because you did $\mathrm{AB}$ and $\mathrm{C}$ or you received this check because you did $\mathrm{AB}$ and $\mathrm{C}$, I, I do believe that; but, I also believe it's, it's a spiritual connection with God. (24-33) ... Right, and I make that choice to make that connection. (38)

\section{... Well, I was raised in a Christian} family. My father is, and his family was [denomination redacted]. My mother and her family were [denomination redacted] so, it's just been part of what I've 
Consistently attend

church born and

raised in

Consistent faith and teaching

Comes from family

Spiritual foundations

Faith grew out of what taught as a child Faith connected to family

Consistently chose spirituality

Stable family

environment

Positive experiences, not necessary to question faith

Grew up in church Spiritual practices

God provides

Always had a home

No childhood

experiences disrupted

faith

Faith rooted

No reason to doubt grown up with. I've actually, the church I attend, my parents were going there when I was born; so, I literally attend the church I was born and raised in. So I've had a very consistent experience, spiritually with faith, with teaching, so. I think that's it. I think it comes from, in my case my family. (4046)

... Um, given that foundation, then as I grew older I just, again my faith grew out of what I was taught as a child; because of what they experienced and what they shared with me. So, I think then I, as a young adult started to make my own decision; this is what I choose to do. I choose to continue down this path. So, I think as a young adult, I, it was just a choice to continue down the path. (48-52)

... I think again, the fact that $\mathbf{I}$

fortunately come from a very stable family environment. Not only my immediate family, my extended family, so in my case there, have never been any experiences, especially as a young, as a child, teenager, or adolescent, and then young adult to make me question that. ... But, you know, I grew up going to church, you say our grace, the Lord will provide. And, then aside from that I had a home always, not that I've not had problems; but as a young child I didn't. By the time adult life really hit, I think my faith was rooted. I had made that choice. But I, I think what has kept me on the path is I never had any reason to doubt it; ... I think maybe if 
Childhood

experiences prevail

Enact spiritual

practices and believe

Faith demonstrated
Faith worked

Firmly rooted by the time situations that would shake faith arrived

Chose to believe

Childhood firm

foundation

Parents modeled

balanced spiritual practices

Freedom in childhood

Attend parents' church

Family tradition
I'd had different experiences, my perceptions would've been different. But, I'm still experiencing what I was taught as a child. You do the right thing, you know, you go to church, you go to Sunday school, and you believe in God and you believe that $\mathrm{He}$ is the provider. That was demonstrated for me on both sides of my family. There was just never a question for me to doubt it. (61-77)

... It worked. And then by the time I got to be an adult and there were situations that would make me doubt, I was so firmly rooted that I'm like, this again is what I choose to believe and I'm going to continue on. You know. I could've changed, um again, I think because I had a good childhood and that was such a big part of it. (79-83)

... And, I also wanna stress too [pause] my childhood was not like a hell stone, hell fire, brimstone. I mean you know, my dad went to church, um, my mom, you know, they went but it's, we still as kids did what, you know; we could do stuff. It wasn't like some families, you know that's all you do. We were not in church all day on Sundays. It was, I had a very good balance childhood, with being, and again as I said, I attend the church that my parents were attending when I was born. Um, we still when we go to [location redacted] both $\mathrm{my}$ parents are from [location redacted]. But my family's, we go back to my father's church, which his, his grandparents, which would be my 
Trained in in family tradition

Consistency

What are your thoughts on seeking therapy?

What factors influence your thoughts on therapy?
Faith modeled

This is life, keep

going

Therapy is good

Therapy is needed

Therapy is beneficial

Responses to difficult circumstances modeled in family

Would seek if felt it was needed Friends who are psychologist Asked questions

Sought informal therapy

Personal experiences and background as an adult

great grandparents, my grandparents, and then my dad grew up in that church. I've had a lot of consistency also. Not only was I trained that way, there was consistency. We didn't change churches. We've just been consistent, ... (91-95; 97-103)

. And as children, and as my parents and aunts and uncles, and grandparents experienced um, loss and traumatic situations, watching how they responded, as well. They did not say, well I don't believe in God. How could there be a God? How could this happen? We've had some very traumatic things happen in my family, both on my mother and father sides. But, again it's fairly consistent. This is life and you keep going. (108-113) ... I think therapy is something that is, is a good thing. I think it's something that's needed. I believe there is benefits in therapy. Um, so I have no negative feelings about therapy at all. And, would not hesitate to seek therapy [pause] if I, if I felt I needed it. Um, I have friends that um, are psychologist and work in the field and I have talked to them about issues of depression and they've shared information, so in that sense I've sought therapy. So, I would say that I've definitely sought therapy. (118-124)

... Um, I don't think so much from my youth. But, I think, from just my personal experiences and my background. Um, not to sound boastful, but I think given, how can I say it [pause] I, I, I was gonna say, given my 
Education level and

knowledgeable

Mental illness exist

Aware of chemical

imbalances

Employment and

volunteer work with

mental health

agencies

Therapy no seen as

separate from

spirituality

Taught God provides

God's provision is for what is needed

Church has

counseling center

Therapy makes sense education level, but I hate to kinda, and I don't want it to come out sounding that way, but, but I think because I'm knowledgeable, I understand. Because, I realize that mental illness exist. I realize that there are chemical imbalances. Um, I've worked with mental health agencies. I've done volunteer work. I've served on boards. I understand there's a need for that.

Um, so that's why I don't see it in a negative concept, and, and in a negative light. And, I don't see it as separate from spirituality. What, for example, growing up we were taught that the Lord would provide, but you went to work. So, um in some individuals, for example, have the mindset the Lord will provide, so I'm not gonna get a job or I'm gonna walk off my job and I'm gonna wait for the Lord to provide. That was not my, my teaching. The Lord will provide but, you're gonna work. You are going to work; and we worked for what we had. So, um getting back to the question about therapy [pause] if I'm ill whether physically, mentally, or emotionally the Lord provides for me by being able to go to the doctor. Whatever, or seek whatever I need [laughs]. Whether it's the doctor, whether it's medicine, whether it's, you know, counseling, therapy. (130-147) ... And, as I said, I think it's because um, my church has a [counseling center name redacted] (150-151)

... I mean it just makes common sense. When we get sick we go to the doctor, so. (153-154) 
Therapy is a way that God provides help

Open to what and how God provides

Take advantage of

What, if any

are the

connections

between

therapy and

spirituality for

you? what God provides

Therapy and

spirituality not

necessarily connected

Therapy viewed as a

resource

Available if needed

Therapy is not

spiritual
... Just that it's a way that the Lord has provided to get help for something that might be going on in your life.

[Pause] that, it's that's it. He's, that's the way He provides. So, spiritually, I mean the God that I believe in, is a spirit. He's not tangible, he's not physical. So He's not going to be able to shovel my snow, and drop, you know, food on my doorstep; so He has to provide other ways. And, as

Scripture says, I will not leave you comfortless, I will provide a comforter. Um, and I'm open to that. So, I, I forgot the question; but, that's where I see the connection is. I see that's what He has provided for us, take advantage of it. (161-168)

... I, I don't necessarily think, [pause] connect therapy with spirituality, I connect if, I would wanna align therapy with all the other [pause] things or resources that it exist. For example, jobs exists, hospital exist, therapy exist. These are just things that are available if your need them. So, no more than I feel that my job is spiritual, I don't necessarily think, feel, therapy is spiritual. I just think it is a resource or something that's available for me if I'm in need of ther, therapy, of help therapy can give me. So, I don't necessarily think that therapy is spiritual. I don't. (172-179)

... For example, if I were [pause] depressed and I was or when I'm depressed and I'm suffering a loss; I'll just say when I'm depressed. There're a 
Levels of support

Don't access therapy

first

Prayer more spiritual than therapy

May stop at prayer

Prayer is always

appropriate

Prayer is beneficial

Therapy may provide a different benefit lot of other things I do before I do therapy. I might go shopping, I might eat, I might just curl up, and sit, but so that's one thing I may do and I may feel better after that. But then again, I may be, I may have some depression, in which I realize, you know what my things I like to do isn't pulling me out, so now I need to take this to another level. So, I might open my Bible, um, and then I may or I may consider therapy or talking to a friend. So, again that's where therapy comes in. It's not necessarily [pause] something I turn to first. For example, prayer would be something I would consider more spiritual than therapy. So um, I can see where a lot of people will stop at prayer and not go on to the therapy. But, I understand prayer is always appropriate. But again, even with, and prayer is always beneficial; but, it may not be beneficial in the way therapy is. (189-202)

Out of prayer directed to therapy

Faith directs type of support

God reveals what needs to be done

Prayer and therapy not
... I believe that out of prayer, I would be directed to therapy. So, it's not like I would pray, and you know, oh well, that didn't work so let me try something else. But, I think my faith tells me that when $I$ have a problem and I go in prayer [pause] I am, God will reveal what I need to do, and therapy may be one of them or buying a new purse might be one of them. I, I do believe that. I mean again, I'm not all spiritual [laughs] I mean hey, sometimes it's a purse, sometimes it's like you know, well, this is what I need. So, but I would not say that I would move, because I don't want 
the same

Prayer spiritual

Prayer connects to

God

Therapy needed in the moment

Spirituality impacts

wellbeing of the

whole person

Spirituality a major component of the individual

What thoughts can you share with me about spirituality?

4551
What factors influence your thoughts on spirituality?
Many unaware of the impact of spiritual factors on life

Addressing spiritual factors is a good idea

Spirituality is a relationship with

Jesus Christ

Upbringing

Scriptures, the Bible

Relationships with likeminded people to separate [pause]; prayer and therapy, I don't see them as the same. Therapy and, again prayer goes, is truly spiritual. That's my connection to God. Therapy is just what I need at the time. (208-218)

I think that spirituality has a major impact, if you look at the whole person, uh spirituality is a, a huge impact on a person's uh, wellbeing. (13-14)

... Yes, if you look at um not only the mental health side, the spiritual side, just different components of someone; the nutritional side, I think spiritualty has a large component of that factor. 16-18)

... I think that many individuals um, either are unaware of the impact that spiritual factors can have on their um health and other components aah of their life. Um and so it's always a good idea to aah address spiritual factors. (21-22) ... Um, I believe that spirituality is um well for me personally, it has to do with a relationship um as opposed to a religion aah, but, some people aah view it as a religion. And um [pause] yeah. ... Christ, Jesus Christ. (24-26, 28) ... I think aah, upbringing is a major influence on my thoughts. But, I also think that, the more that I've delved into the Scriptures, Bible, um and also um allowed myself to encounter with other people who are likeminded aah from that standpoint to encourage each other on their walk with Christ too, had a significant impact and influence. 
Increased knowledge Christ

Therapy used for crisis, as well as, preventatively therapy

What are your thoughts on seeking therapy? of a relationship with

Unfamiliar with
Negative stigma within certain cultures

Fear of being view incapable of taking care of self
... the further you gain a knowledge in um, especially with regards to relationship with Christ aah the more influential it, it, it really does have an impact and is a factor. (90-92)

... I think that individuals who are going through, not only crisis, obviously if you're in a crisis but, preventatively, aah people should not be afraid to seek therapy. Aah, that is, it can be very helpful, um to prevent major issues aah, developing into a crisis; that kind of thing. (45-48)

... Um, I think, just the fear of the unknown. Aah, that they, you know therapy is kinda still mystified; also, the negative stigma that goes along. Specifically, in certain cultures aah with saying that you have a counselor or therapist um lot of people are just afraid to, a fear of the unknown and the fear of being stereotyped as someone who is unable to appropriately care for themselves from a mental health standpoint. (51-56)

Seeking therapy suggest weak or lesser relationship with God

Lack of information and understanding about therapy

What factors Upbringing influence your Mother a psychologist thoughts on
... Um, yeah, I think that some people could feel that if they're seeking a therapist that they may not or they may be perceived as not having a strong relationship with God. But, that again I think it's a, a lack of being informed and understanding. Yeah. (60-63)

Aah, again I would say upbringing [laughs]. My mother, actually was a psychologist. So, being able to see her 
therapy? $\quad$ Witness to individuals
being helped

Witness to how therapy could help some

Positive exposure

Negative experiences of therapy may skew perspective
What, if any

are the

connections

between

therapy and

spirituality for
Holistic approach to life

Intertwined Spiritual concepts can be used in therapy aah, help individuals um was aah very impactful um for me. And also, seeing aah you know or hearing how um people could be helped out in certain situations that chose not to seek therapy um has influenced me as well. (65-69)

... I think it depends on how much expos, positive exposure you have. Aah, because I think many people, um different cultures may have had some kind of impact but it could've been our um, you know initiation of, of mental health services; but, if it's a very negative, aah experience for them or someone close to them then they hold onto a non-truth about therapy. (7276)

... I would have to say um [pause] you know really the training that I've had aah has been very impactful. Because you can observe something, but until

Training and studying of psychological concepts

you've actually studied it and get more of a concept aah of why things are, they way that they are from a biological standpoint, physiological standpoint, seeing such research studies and, and certain findings aah, it all kinda clicks and makes sense there. So, the further investigating, and further knowledge I've obtained um has definitely had an impact. (81-88) ... I think that, I guess I'm more of a holistic approach kinda person. So, I actually think they're very aah intertwined. Um, I think that a lot of aah spirituality um concepts can be utilized in therapy. Um, that can also be 
you?

Spiritual principles

used therapy provides

techniques and

practical applications

Build upon spiritual

principles and practice

through therapy

Spirituality as the

foundation of therapy

reinforces the

application of spiritual

principles practiced in

therapy

Therapy may be insufficient without

spirituality

Therapy is benefited

by spirituality, but

spirituality is not

benefited by therapy

God is complete

Use therapy to

understand life

Therapy, in concert

with spirituality can done in a non-threatening situation. So, whereas a lot of these principles out of spirituality can apply and be utilized aah for many people, aah who are seeking therapy but, they also need to have the techniques and practical applications, where therapy gives you those techniques and practical applications; so you can build upon the principles that you learn and practice them through therapy. (94-101)

... Yeah, I guess you can see the, if, if the foundation is spirituality, then and you can practice it out in therapy then it's just reinforcing, it reinforces it.

(117-119)

... I'm not sure that therapy, is at its best without spirituality. (122).

... I think that, if I'm dealing strictly with Christianity, not talking 'bout anything else. The assertion of who God is, has no benefit from therapy because God is who He is. But, His people can grow in their, to their greatest heights through spirituality or Chr, the Christian viewpoint and the practicing of it out in therapy. Does that make any sense? Like [pause] from a spiritual standpoint, you can't add to God. But you can, have God and then understand the workings out of a human life, through therapy. (124-131)

.. It, it can, you, you would work it out not only from the Scriptures and what God tells you but, for us to practically 
help to make life practical

Always believed in God

Taught to believe in God

Understanding of God grows over time and through different experiences

\section{Various experiences}

What thoughts can you share with me about spirituality?

\section{over the years shape}

8790 understanding of spirituality

Understanding of Jewish heritage

How God revealed Himself to the Jews

Exposure to different belief systems understand it, so it's not theoretical and abstract. You can make it more practical through the use of therapy. (133-135) ... again from a, a Christian standpoint, there is the making of the human being and the brain, particularly, um and it's intricacies and um it is, that would be the spiritual and aspect, um but the working out of that, the explaining of it and how it functions, can be found in therapy. (154-158)

... in terms of my own experience, I always just think about [pause] the fact that I've always be, believed in God, always been taught to believe in God. And, so that's where I started and I watched that growth and understanding kinda grow over the years as I came to know Jesus um, and had different experiences. (14-18)

... when I think spirituality more broadly if often brings to mind, um just the various things that I've come in contact with over the years um, you know from my college experiences and meeting folks from different backgrounds and even just understanding some of um, aspects of our, I guess Jewish heritage when I think about the foundations of Christianity and how the Lord chose to reveal Himself to um, the Jews, of course it's kinda reached all of us at this point in time. (20-26)

... But, I just think about um, just all the kinda belief systems that are out there. All the things that people believe in, 
Research conducted

even um I'm thinking from school some of the [laughs] the research I did and the interviews I did, ... (27-30)

... And just understanding that we, that all of humanity, I guess is in some way tryin'a understand who we are and why we're here. And, a lot people find themselves in places of trying to reach God or tryin'a understand, and you

Questions of existence

know, I think about those kinda things being encompassed in a larger definition of spirituality and what it means to people. Just seeking to understand is the bigger [pause] area of interest to the bigger questions to our existence. How we got here, why we're here that sorta of thing. (32-38)

Spirituality centered in Christ

Christ is way to God

Bible the revealed word of God

Jesus is the answer

God revealed through

Jesus Christ

Answer to questions about existence found in Christ

Believe God's word

Answers provided

Relationship with God
... But, for me it's centered in Christ and um just understanding that for me, He is the way to God. (38-39)

... But I, because of my belief in the Bible as the revealed word of God, then it's a more specific understanding that, that Jesus is the answer. This is how God chose, chose to reveal Himself to humanity is through His Son. And, so He's provided, I guess the answer to the, the broader questions that we have and so I think for me it aah, when I think spirituality I kinda falls into that definition. (58-63) ... I believe um, God's word and I believe what He said, in that He's given the answer to the questions that we have. (65-66)

... Umhm or relationship with God I would say. Because I think that, that, that 


\author{
Relationship \\ encompasses way to \\ communicate and \\ listen to God
}

Prayer shared in a

community

Spirituality centered

in relationship with

other members of the

Body of Christ and

God

Growing up in church

Knowing Jesus and

knowing $\mathrm{He}$ is the

way to a relationship

with God

The Bible

What factors

influence your

thoughts on

spirituality?

information to help us
Believing it's the revealed word of God

Bible provided

know God

Holy Spirit

Life influenced by

Holy Spirit

Family and friends

Attending church as a child and participating in spiritual practices relationship encompasses so many things, um you know when you think about um [pause] just prayer um as that, a way to communicate and to listen to God. Um, when I think about prayer as something that we share, um in a community, something that we do together as we're going before the Lord, oh and I think about the relationships that we have with um other people um in the Body of Christ during the; it seems like all those things are a part of our experience of spirituality. Um, but ultimately that it is like centered there. (68-75)

... I think in the church growing up, um, that's kind been my understanding in Protestant Christianity and, and just knowing Jesus and knowing Him as the way to a relationship with God. (18-20)

... Um, I would definitely say the Bible. Um and believing that it's the revealed word of God that it's what He has given us to know and understand Him. Um, I would definitely say, as um, as a follower of Christ based in, as a part of that belief system, just believing that the Holy Spirit dwells in me and that, that, that the Person of the Holy Spirit influences my life on a daily basis in terms of spirituality. Um, I mean I would definitely say um how it's been shaped over the years has been the influence of family um and friends. I mean definitely being taken to church as a child um early on and participating in a number of different things, whether it be like singing in choir or going to Sunday 
set a foundation

Having personal experiences in life, such as walking and interacting with God

Faith in God and knowing He has impact in lives

Sense of being cared for

All experiences profitable in spirituality

Influenced by parents

Modeled by parents

Influenced by church members, friends, and other adults

Involved in Christian organization in school class. Just the things that I learned even in the words of those songs um and those experiences um set a foundation and then just kind of building and growing from there. And just, having my own personal experiences through um high school, college, and you know as an older adult. Just a lot of those types of things. I mean by personal I would say, walk and interact with the Lord and seeing um [pause]. I don't know just, just faith in Him and believing His impact in, in the events of my life and the things that have happened and feeling the sense of being cared for um even, I mean in good times and bad times, in the midst crisis, but, that, that sense of being personally cared for. As I walk through those things I would say that all those things have influence my, how think about spirituality. (84-102)

... I can't imagine that there's any life experience that hasn't contributed. Um 'cause they've all helped me to learn different things and have shaped, um have shaped me and helped me to grow. Even, you know as a younger child, um you know, my experience with spirituality and what it means would've been largely influenced by my parents and just what I saw and experienced in living with them. And then, you know folks in the church, friends, and other adults in that environment. But then um when I think about college in particular, I was involved in an organization called [organization name redacted] and so, at that age, I mean 
college

Exposed to other parts

of the Body of Christ

through different

experiences

Grew up in African

American churches

Accustomed to a

particular style of

worship

Participated in

Christian organization at a same gender PWI

Interactions with

members of the

organization across

the country

Experienced different

style of worship and

how others outside of

the Black community worshipped God

Therapy is wonderful

What are your thoughts on seeking therapy? you're a young adult who, I knew and understood what I believed up to that point, but then it's like you see, begin to see the larger Body of Christ. Um and things beyond my experiences that I had. Um, and those things I think begin to add and to shape it as well. Um, even, I mean something as simple as, as growing up in a predominately African American churches all of my life and you know being accustomed to maybe one style of um the message being delivered or a certain style of music or whatever. But, then going to a predominately White school um being involved with a Christian organization where you know I was the only African American [laughs] woman who was, I went to an all woman's college, who was consistently involved with that organization, then we had of course, interaction with folks in that organization who were at campuses throughout the country. But, just having the opportunity to experience those different worship scenarios, again just broadens what it looks like to walk with the Lord, what it looks like to worship Him. Um, yeah, and just, so I think all of those things have kinda contributed. And just realizing that it's so much bigger than the little experience $I$ had in Akron growing up. (110-134)

... oh goodness, I, oh I think it's very um wonderful, very needed, (136) ... it's just something that's very needed to. (190-191)

Appreciate what 
What factors influence your thoughts on therapy? therapy has to offer offer, what therapy has to offer. (165166)

Therapy is valuable

Neutral person to discuss things with

Unbiased view of situations in life

Positive relationships with guidance counselors produced positive thoughts about therapy 189) simple as having a neutral person to is not directly involved in; and, so they're not gonna have some sort of to deal with that situation. (191-194) junior high as well. Um, who was an African American woman and then um my guidance counselor in high school
... that's just a long way of saying that I think therapy is very valuable ... (188-

... I mean, even for somebody, it's just as discuss your life experiences with, who biased view about what it is that you're facing or what it is that you ought to do

... Um 'cause I also worked in the office of the guidance counselor when I was in was a woman; she was Caucasian and the man that I mentioned he was a Caucasian, you know. I think even the, the good relationships that I had with them gave me real positive thoughts about what kind of therapy/counseling; what it represented and what it meant in the lives of people. (239-245)

\section{......, I'm a person who believes that}

God created the world Early desire to help others

God created the world, ... (340) ... I think growing up I always knew I wanted to do something that involved helping people and um, for a while there I thought it would be in medicine. (137139) ... ... I still knew that I wanted to do um something that involved helping people. But, I wasn't quite sure what form it would take or if I would pursue 
medicine or something else. (152-154)

Education

Interested in particular population

Research that helps us to help others
Encouraged by counselor to pursue career in counseling

Different experiences serve as basis for therapy and interest in school
Parent involvement

... I eventually landed on um psychology as a major... (155) ... ... I was for, a little over a year I was in a Master's/Ph.D. program in clinical psychology; because my ultimate goal was to do counseling work with adolescents. (156-158) ... I guess psychological study and different things like that. And understanding that it has a very, a lot of important information has come out of the study and out of the research, helping us to help other people. (163-165)

\section{... I guess all, through the different} experiences that I've had, I've grown to have appreciation for um, you know just, just what serves as the basis for therapy; (161-163)

... I remember um as I begin to think about counseling, in any form. I remember, probably the earliest experience, I remember somebody kinda pointing me in that direction, was [pause] he was a counselor. (207209)

... my parents have always been very involved in my life; and to the point where my dad was a frequent visitor to the school. (216-218)

Conversations with teachers influenced early career choice
... a lot of times we would just have conversations growing up, you know, with teachers, and you know, it'd just be causal conversation after school or after practice or whatever. (223-225) ... when 
Early experiences, exposure, and mentors in the field increased interest

Liked how counselor interacted with students

Wanted to be available support

Experiences and relationships related to therapy

Indirect influence in church
I talk about all those things earlier, about some of my career thoughts, I think when I thought about doing counseling work that was one of the first thoughts that I had was being a school guidance counselor, something like that. But then, I remembered, I worked in the office of my school guidance counselor when I was in high school. And, I really liked a lot of what she did and her interactions with students and that type of thing. (228-234) ... Um 'cause I also worked in the office of the guidance counselor when I was in junior high as well. Um, who was an African American woman and then um my guidance counselor in high school was a woman; she was Caucasian and the man that I mentioned he was a Caucasian, you know. (239-242)

... I just felt like I wanted to be an available support to students in the school. So, that was kinda set me on that path. (235-237)

... so I would say those, kind of experiences and those even relationships and interactions with those people over the years had an influence. (237-238)

... I would say that was another piece of if too, just having those positive experiences. And, I can't [pause] trying to remember um [pause] there maybe even have been influences at church in an indirect sort of a way. (245-247)

... when I was in, growing up in the church that I grew up in which, I was 
Exposed to different perspectives in church

Therapeutic practices modeled in church there probably from about the age of five until I left to go to college, for a little bit of time after I graduated from college. I was involved with the youth group there. And, at one point in time we had like three generations represented. (248251)

... that was just a cool experience too, to Open conversations in church

\section{$m$} many different things. Then you would have the, the perspectives of all these different folks. And, and in my eyes you know, when I think about what therapy looks like in those types of, it kinda includes um, you know, I guess it's that idea of getting feedback from someone regarding, you know, the important things and events of your life; the things that you're experiencing or the things that you have questions about. (257-263)

Even though it wasn't counseling early on therapy, the experience felt similar

Positive experience in sharing life circumstances with others

Exposed to premarital

... And so, even though it wasn't technically therapy our counseling, it represented the similar type of experience, I think that gave me a positive mindset about involving other people in my life and the decisions I was making and the questions that $I$ had. So, I, I would say that was probably an important thing too and just the perspectives that they offered. Then, um yeah I was, say from all my experiences about what, what therapy meant, were positive ones. (263-269)

Pastor's perspective on therapy

... definitely [Pastor's name redacted] has been just, he just studies a lot. And you know really, I think he had a lot of positive things to say. And of course growing up in and hearing about the 
Participating in premarital counseling

Experience of dealing with different things in life

Licensed clinicians on staff

Church supported therapy

Church practices

shaped understanding

of therapy and

modeled help seeking

Thesis committee member who was a

Christian and an African American woman

Personal interactions with faculty member in profession

What, if any are the connections between therapy and spirituality for you?
Therapy needs to connect with

Christianity

People can be helped with therapy principles Without spirituality, therapy may be importance of premarital counseling and doing the, you know the marital counseling, just how those things can be positive, um experiences in, in dealing with the different things that your face in life. In just the fact that they um, at one point in time we had licensed clinicians on staff who were able to see people as well. And so, I think just having, being involved with ... a church that kinda supported that; it just also added to the positive [pause] my positive thoughts about what it means to be in therapy, and what it means to ask for help. (271-282)

...... you know the other thing that I was thinking of too, is that when I was in, um doing my undergraduate degree, one of the professors, who was on my um, thesis committee was a Christian. And she, um she was an African American woman, who um had her Ph.D. in social psychology, I believe it was. But she was um a professor that I had for class; but she was also one of the people who was on um the committee of folks that I worked with for, um my thesis. And I think, just my personal interactions with her um in terms of like her counseling experiences, her connection to psychology. (282-289) ... I think for me it always seemed like it needed to come hand in hand with um, who I was a Christian. And, and just believing that you can help people using a lot of these principles. But, if you don't have that missing component of where they are spiritually and you don't kinda tap into that then you can, 
superficial and not address the root of what's going on for the individual

Recognized relationship with God does not exclude therapy

Spirituality and therapy help with living and life

Nothing new under the sun that God isn't aware of

Principles found in therapy are not new to God, we're just putting labels on things $\mathrm{He}$ is already aware of you're doing a lot of superficial things that never get to the root of what's going on with them. And, so that's kinda been my whole thought about um therapy. (166-172)

I mean it was just another positive um influence in my life regarding how my relationship with God, did not exclude like therapy. (282-290)

... But, how, you know the two kinda fit together in terms of us just living life and getting' through the things that we face. (291-292)

... I think like I mentioned before, I just feel, that um. Basically, I feel like there's nothing new under the sun. There's nothing going on now, in this day and age, that the Lord is not aware of. It may look a little different um compared to the things that we see, that we study in Scripture, just because of the culture, you know the time in history and different things like that. But, just a lot of those principles, just run throughout history. A lot of the things that we base a lot of the challenges that we face or just things that are there. And so, when I think about the study of psychology and the things that people have learned, and even in science, I, I just feel like we're discovering a lot of the things that God has always known. We're putting labels on things that you know, He's always aware of is, or you know maybe something that I put that in place, you know, I made that to be like that. (304-315) 
God has always been a part of the equation of science

Therapy is not truly effective if the source of creation is not accessed in regard to the creation

Addressing the spiritual component allows for an individual to be truly cared for

Therapy can be somewhat useful even if counselors are not spiritually based

The root of an issue that is not addressed at the spiritual level goes unaddressed

Spirituality important for the most effective therapy

A lot of things are based and rooted in God as the source

Our understanding of
... a lot of people feel like the study of science just somehow eliminates God from the equation. I feel like, He was always in the equation. We're kinda catching up, learning the things that $\mathrm{He}$ already knows. There's no way that we can have um, I think therapy and be, be truly effective in helping people that God created and leave Him out of the picture. So, I feel like it's just essential that we address the spiritual component of who the person is, in order to really be effective in, you know, care for them. (316-323)

... I think that you can offer them some help and it doesn't mean that it's completely useless um, if you know, or like for counselors who are not necessarily spiritually based or who don't have that as a central component of how they work with somebody or how they work through things. But, I think ultimately, um there are often things that at the root of what a person is experiencing that if they're not dealt with on a spiritual level um then they kinda go unaddressed. And, so I think the two are just very much connected, in that, that spiritual component is essential to really able to have, I think the most effective therapy. (324-332)

... and that um there's just a lot of things that underlie what we see and what we experience that have their basis and their root and their source in Him. And, so just us coming to understand how it works doesn't take 
how things work doesn't take anything away from God's

involvement

Therapy may be about figuring out what God knows

God and His creation yearns for connection and relationship, suggesting the answers of life are base in the creator of life

without spirituality can help people face the dayto-day and challenging relationship scenarios

Longing for relationship, peace, anything away from His involvement in the process, I feel. Maybe some of, often times a lot of us gettin' a glimpse into something, like I said before that, He's well aware of, understands how it works, puttin' it in place, we're just kinda comin' along figuring it out. (342-347)

... Well I, I think I'm one of those people, again, who believes that we were created by God. That um [pause] that God created us too, I mean He desires to have a relationship with us. And in us, is that longing again to understand and to know where I came from, why am I here, that sort of a thing. And, I think those answers are in Him. Um we, there's this kinda this longing in us, this emptiness, this vacuum, a lot of people would term it, that wants to like get to the root of what, what this is all about. And, I think um a lot of times in those scenarios, that's not really tapped into. (352-359)

... you can kind of, like I said, deal with things on the surface maybe of giving them [pause] tools that help them to deal with what the face on a day-to-day basis. (364-365) ..., to deal with the relationship scenarios that may be driving them to that place or whatever. (367-368)

... It's like you can deal with those various components, but often times, there is, it seems like, there's an underlying longing, um for relationship or for peace or for hope or 
hope, and security that

might bring one to therapy found in God

Spirituality offers those in therapy the realization they are not alone

Even if I feel alone, I'm not alone or abandoned

Relationship with God produces security in God and allows access to strength to cope

Ultimate peace in knowing there's a reason for being and that reason is connected to God, who will not leave or forsake what $\mathrm{He}$ created

Without spirituality,

just for security. Um that's ultimately the answer, I think, in, in the Lord and the God who created them. Who is able to be for them, you know, the things that they need, you know, the things that they feel like they're lacking or maybe don't even, they haven't even put a name on it, but they know that they feel that way or feel like there's something missing. And, I think [pause] I think it just ultimately um, if I was just trying to, to simplify it, it's just realizing that I'm really not in this alone. And, even when I feel like it, because of my experiences with all the people around me, even when I feel like I'm alone that ultimately, I'm not alone. I'm not abandoned. And, I think um just in that relationship with God and in that security that people [pause] will find in the One who created them, and who loves them, and wants to be in relationship with them that they find a, I guess, a strength that they maybe never knew was available to them; you know to be able to cope. (368-382)

... Because, it, just; life is just not easy. And, even as someone who um has been walking with the Lord for most of my life, I know there are times when, it's, it's just tough. But there's an ultimate peace in knowing that [pause] I'm here for a reason, the God who has created me has promised to never leave or forsake me and that there's just a hope that no matter what comes my way, that I can live through that. Um, but yeah, again, it just seems like in for, in a lot of instances, when you put the band aid on, you may still not be answering 
therapy may act as a

band aid and leave

ultimate questions

unanswered

Deeper levels may go

unresolved

Know me and my relationship with God means knowing my ultimate hope is in God

Life circumstances created a need to therapy or assistance but trusting in spiritual foundations and knowing God will not leave or forsake you

Hope in the relationship with God produces peace, allows love to be experienced and assured of God's presence in difficult situations that ultimate question that, that person is seeking an answer for; [pause] yeah, or the ultimate need they have, that's not being met. That is, they may be trying to meet with a number of different things on a number of different levels. But they still walk away without [rubs hands together] that being resolved, kinda. Yeah, I would say that's what it is for me. It's like, it's, unless you um, unless you, for me specifically, unless you know me and know my relationship with the Lord, you wouldn't, you wouldn't' know as a therapist, that my ultimate hope is in the Lord. (382-395)

... You know it's just, I been through a lot of different experiences in my life that have driven me to therapy or to seek assistance or have created a need in my life for that but, ultimately the, the firm foundation and for me the ultimate answer is that the Lord is there and He promised He would never leave me or forsake me. And so even, you know, when you're helping me to deal with my feelings or helping me find tools to face the things that I'm dealing with on a day-to-day basis, that, my ultimate peace is just knowing that there's a Creator of this amazing universe that I look at on a day-to-day basis; Who created me, Who loves me, Who wants to have a personal relationship with me. And in that relationship, has promised to never leave me or forsake me. And, that's, that's where my hope and my peace is, 'cause in the midst of some of those 
God is real

Constancy of God

Believe in God

Believe in Jesus

Christ

Provided comfort

Spirituality can help people interact and see things in a more holistic way

What thoughts can you share

with me about spirituality?

\section{Spiritual connection}

needed to operate

Connect to a higher power

Way to see the world

Make it through tough situations

Blessing of positive things

Not necessary to actively participate in church for spiritual connection scenarios, sometimes if feels like there's no hope or peace to be found. And, it's in Him that I cling and not to this concept or not this idea, but um to this great Creator Being, Who is the source of who I am and He's the one walking with me moment-by-moment, day-by-day, when nobody else is there. (401-416)

... I guess for me I grew up in the church, so um, I think more like a religious sense, even though I know it's different for different people. Um, but for my own beliefs, I believe in God, I believe in Jesus Christ. (13-15)

... Um, I think it also provides a source of comfort, not just for me, but for other people. So regardless of their religious beliefs, I believe that spirituality can be um, I guess can really help people interact and see things in a more holistic way. Um, I just, I don't know, I just don't see how people can operate without some type of spiritual connection, at all. (22-26)

... Um, but I just look at it as a way of connecting to a higher power or um in a way to kinda see the world and make it through a lot of tough situations. But, I also see the blessings when positive things happen too. (36-39) ... But, spirituality, I don't think you have to be an active participate, participant in church in order to be spiritually connected to God. (57-58) 
Looked upon as a crutch

Particular denomination

Active in church

Pray every day

Believe in God

Trust God

God head of

household

Denomination shaped

beliefs

What factors influence your thoughts on spirituality?
Community work

Serving God

Trying to bring others

to Christ

Upbringing

Church part of family

Consistent attendance

Believed in God

valued

Stuck with what was familiar
... But, I know, I remember when I first started school, and how it was like totally separated from everything. And it was looked upon as a crutch. You know, and people saw it as, you know people's religious beliefs or spirituality was a crutch. (328-331)

... I grew up as a [denomination redacted]. Um, very active member of my church back home in [location redacted], ... but, I still pray every day, I still believe in God, still trust in God so um, you know God is the head of my household. (15-19)

... so for me you know, as a

[denomination redacted] there are certain things that I was raised to believe as a [denomination redacted]. (47-49)

... And, with being a [denomination redacted] also being able to reach out to the community, and you know serving God, and, and not just um being a mem, just someone that comes to church, but you're an active person tryin'a bring other people to Christ. (52-55)

... Um [pause] I guess I would say, my upbringing, my mother, my grandmother, like church was just a part of the family. So, like that's, that's what we did. We believed in God, it was nothing different. Um, I grew up going to church at an early age [pause] um and so, I really just, just from early on, you know. Belief in God, is what was valued in my family, and so, I just stuck with that; and, that made sense 
Experiences

solidifying beliefs

Mother connected to

God

Mother connected to

church

Connected together in

church

Feel connected to God

Mother's connection

to God during illness

Faith and connection

in God maintained

during illness

Connection to God

modeled

Active in church

Close to church

leaders

Opportunities in church to bond with mother

Leadership position

Mother engaged in similar activities to me and I felt like the experiences I've been through. I felt like there's always been something solidifying, you know, my beliefs. (62-68)

... She's very connected, she was very connected in my church too, so it's, I will say it is a little bit difficult to just talk about religion, because we were so connected at our church and now that she's not here. It's been difficult for me actually, to go to church. Um, but I still

feel that connection to God and spirituality, but it just. (129-133)

... So, um so yeah, in actuality when she was first diagnosed with cancer, her connection to God, I think is what actually strengthened my connection. Because, I felt like, if she's, she's the one with cancer; so, if she can be praising God throughout her whole experience, then I have no reason not to, you know. And so, I really feel like her um connection to God is what really brought me closer. (193-198)

... And, then also getting involved in my church was really helpful too. So, um, I'm actually pretty close to our first lady of our church. And, then our pastor too, but really the first lady. She, um implemented this aah, sister's leadership like, sister's conference. So, it's an annual bonding conference and um, we're actually going into our fourteen year. But, I'm on the executive leadership team and my mother was always an active participant too. So, that was also another way me and my 
Built real

relationships with

other women while

learning about Christ

Church people can't

do anything wrong

Attended a traditional church

Few activities for twenty somethings

Connected with

former leaders

Once a week

relationship

Distance between

leaders and participant

Attended a big church

Women's group

members were real

people

Learned a lot

mother would bond. But, it was always like a way to bond with your, um, sisters, and learn more about Christ. But, it was also real as well and I think that really helped me to connect. (202210)

... So, growing up, I always thought "church people" as like these people who were supposed to be perfect and couldn't do anything wrong, and that's just what my experience was with the old school way of, of church. 'Cause we're a pretty traditional church. (210-213)

... I felt like they didn't have a lot of things to meet the needs of twenty somethings at that time. And I, I liked the pastor and the first lady. I really connected with them. But that was just, you know, once a week on Sunday. I'm sittin', you know they're in the pulpit and I'm, you know in church; it's a pretty big church. (217221)

... So, I felt like they were real people. I guess, they are Christians, but, they also, you know they're moms um, they go through things, you know, and so I felt like I learn, learned a lot from them. (223-226)

Developed lasting relationships ... And, none of us anymore, I think are really active in [type of church group redacted]; however we are very close

Supportive relationships Pray for each other Aware of life friends. Um, and so we've, we text each other regularly, we support each other, we pray for each other, um we know what we're going through, and we 
challenges

Not judged

Teach each other

Thought behavior was

pleasing to God

Interactions increased

comfort in spirituality

God is with me, no

matter what

Inspirational songs

provided strength

Husband a Godly

person

Experiences let me

know God is real

Just a storm

Reason for the storm don't do it in such a way that um, you know you're judging anybody. So I felt like, you know, not judged. I felt like everybody was there to support each other. And just, teach each other. Like this is how God would want you to work the [undistinguishable] but, sometimes, you know, that's just now what happens [laughs]. So, and so that also, I think brought me closer to um, just feeling more comfortable in my spiritual beliefs, religious beliefs. So, God is still, I feel like God has been with me the whole way, no matter what. (226-235)

... And, it's a lot of different songs out there, I think that really had helped me um you know to feel stronger. And, then, my husband too. With him being a, I was more active in church than he was. At the same time, he grew up, all his family, you know, he even, I think said that uh, people used to tell him he needed to be a like a pastor [laughs] or something like that. So, that helps to have a husband who is also a godly person. (235-241)

... So, so, it's a lot of different things I feel like I've experienced or seen that for me is like, God is real, and this is what I believe. (242-243)

... And, even when I'm going through something, I know that things will get better or it's just a storm. And, and, and, um it may be something I don't understand at the current moment, but there's always a reason. I feel like 
Therapy helpful

What are your thoughts on seeking therapy?
Education

Experiences

Trainings

Parents modeled helping behavior

What factors influence your thoughts on therapy? there's always a reason, so. (244-247) ... I really believe that therapy can be helpful for a number of people; (76-77) ... I look at it as a collaborative process and something that can be helpful for people, whether it's individual, group, couples, family um. So yes, I think it can be very helpful thing for people. (96-98)

... Um, well as a doctoral student in counseling psychology, (76) ... I would say a lot of in in addition to like, what I've learned in school, (100) ... just experiences [laughs]. (100-101)

... so not just what I learned in school um you know, going to the trainings and things, (102-103)

... I was used to my parents helping people. (125-126) ... but both were active in like the community and helping people, so I feel like that really, you know, influenced a lot of my beliefs. (127-128) ... Yeah, so you know I'm just use to my parents helping people. (142) ... Both of them were. I feel like I grew up with parents who valued giving back; helping people (146-147)

Dad values therapy

Mom and dad

participated in therapy

... And, he values therapy and um I think he and my mom and one point did couples therapy. (158-159)

Premarital counseling ... So, I did um marriage and uh, my husband and I we had to do premarital counseling before we got married. So,

Recognize the stigma it's something that I'm use too. Also I associated to therapy know, it's still stigma for a lot of 
for people of color

Advocacy/Stigma reduction

Not separate

What, if any

are the connections

between

therapy and you? spirituality for
Therapy and

spirituality seamless

Increased comfort of integrating spirituality in therapy

Raised in the church people, um, especially people of color. (159-162)

... So, um when I have an opportunity to speak to like either youth, or adults, or even parents depending on the population I try and educate them about the usefulness of therapy. And, try and do it in a way to kinda meet them where they are and also give them a different perspective on how therapy can be used too. (162-166) ... I try and explain it to people in a way that feels safe for them. (168-169)

... But, um again I just, I, I can't separate it, you know. (253-254)

... Um, I see it more as seamless. (305)

... Um, one of the things I've noticed, just in conversation. I think more and more people are becoming comfortable, like integrating spirituality. (327-328)

... I was raised in the church, (13) ...

As I grew up in the church, (21-22)

Spirituality is a part of my being

... so it's part of my being. (13) ... It's basically my foundation. (13) ... What thoughts Spirituality is my can you share foundation with me about spirituality?
You know, hard times will come, but if you don't have that foundation, you don't know how to deal with it. (28-30)

... We were always in church, on Consistently engaged in spiritual activities
Sunday; I was superintendent of Sunday school, taught Sunday school class, sang in the choir, came back for evening service. (14-15) 
A part of upbringing

Made to go

Feel and understand what's going on and be blessed

Spirituality has a feeling or quality to it Spirituality helps me through

Feel in heart

Feel comfort; peace

Feel like prayers

heard

Spirituality is big part of life

It helps through life

Something missing in life without spirituality Spirituality found in the midst of people worshipping God for health and strength

May not survive without spirituality

Higher being
... It was just part of growing up, with my mom and grandmother. (13-16) ... Um, we didn't want to go to church all the time, but we were made to go; and now I see why. (22-23) ... Before, I was made to go. (25-26)

... You can go to church and be there; it's a building. But, to feel what's actually going on, to understand what's going on and feel like it's a blessing to you; (19-21) ... ... I learned to actually feel what spirituality was. (22) ... I feel like spirituality helps me through a lot. I know that God is listening. I just feel it. It's in my soul. I feel it in my heart. I feel comfort. I feel peace. ... And, I feel like my prayers are being heard. (4446; 47-48)

... it's big for me. (21) ... I was forced in it, but I'm glad I was because it's a part of me. It really is. (38-39) ... So yes, spirituality is big part of my life. (58)

... Because it does help us through life. Especially, when I left and went away to college. Um, I said, I'm not going to church unless I want to go. Then, I found out that there was something missing; and, that was the spirituality that came with being in the church with a group of people that worshipped God, and looked to Him for health and strength. (24-28)

... Sometimes you don't survive. (30)

... For me it is. Yeah, I feel there's a

Higher Being. (32) 
Not in control

Ordered steps and connection

Grow into spirituality

Connection

Internal place

Let things go

God hears

Bible reading

Challenges

experienced in life

God helps me through

What factors

influence your

thoughts on

spirituality?
God is in control
... I'm not in control. I feel like

Someone has ordered my steps and it's a connection for me. (32-33) ... I think that feeling of knowing that someone else is in control. Knowing that if you have something or some foundation to rely on, everything will turn out okay. (41-42)

... I think it's something that has, you have to grow into. Sometimes you don't get it right off the bat. I know I didn't. But, I stayed in it; (36-38)

... I feel a connection, I really do. (39)

... It's a place I go inside of me, to just, you know, let everything go. Let everything go. (46-47)

... I pray, a lot. And, I feel like my prayers are being heard. (47-48) ... And, reading the Bible, it helps me understand the Bible more clearly. (54)

... Mmhm, life, hard times [laughs]. (62) ... But, God has helped me through everything. My parents have been supportive. Of course, they got divorced years ago and I felt like I was cursed. I'm like no, everything's in control. I might not know what's coming next, but $\mathrm{He}$ does. (63-66)

... I've been able to go back to school

God provided support myself, get my bachelor's and my master's and I know I couldn't have

Praying to God done that without that connection. 
Praying to God, asking Him to help me through, 'cause it looked bleak. (67-70)

Foundation provided

by mother and

grandmother in

upbringing

Not alone

God knows

Family on to

something

Relied on God

Therapy not

mentioned

Just talk to God
... I was thankful. That's when I looked backed on that foundation, that my mother and grandmother raised us in. ... No, you don't have to do this alone; you do have a connection with God. He knows what you're going through; pray to Him; rely on Him. You can't handle it all. You don't have all the answers, but He does. (71-75)

... There was a big connection. Big modeling there. Like I said, my grandmother. I remember her most, my mom's mother. And then, after she passed away, the same modeling I saw in my mother, and in my dad's mother, and it just went on down the line through the generations. Like wait, they're on to something [laughs]. (8286)

... and, we relied on God for everything. (89-90)

... Um, sometimes therapy wasn't even mentioned; just pray, pray it away. That's what a lot of the older people thought. You don't need to go talk to anyone else; just talk to the Lord. (9092)

Taught to rely on God With God, therapy might not be needed

What are your Therapy not available thoughts on to Blacks
... Because, he was always taught, you know, just rely on God. So, he probably felt like he didn't need it. (98100)

..... I think the times have changed.

Back then, there wasn't a lot of 
seeking

therapy? therapy made available to us; (88-89)

Just praying

All I need is God

No desire to take medication

Cultural mistrust

Blacks do not readily

use therapy

Spirituality okay but

may need something

in conjunction

Would seek therapy

Would encourage

family and friends to

seek therapy

God works through

therapist

Shameful to seek help

beyond the church

Church didn't have

the answers

Not professionally

trained

Shame/embarrassment

Fear of taking

medications
... I don't know if he was taking his medication the way he was prescribed to take it or if he just, was praying. I hope he was praying. 'Cause that's how he was raised too, you know. (107109)

... I think at some point he probably felt like all he needed was his spirituality to get him through it, and he don't want to take the medication that was prescribed, I believed by a White doctor, you know. (111-114)

... But, I definitely feel like it's available to us, while we might not use it. It's okay to be, to have your spirituality. But, sometimes you need something coupled with that. If you need professional help, I, I would, no doubt seek it. I would encourage my family or friends, if you need help, go get the help. God works through doctors, through these practitioners, whatever. He's, if help is available. (128-133)

... But, back then, it was kinda looked at as shameful to seek, seek out help; other than the church. Many times the church didn't have the answers. I mean they weren't professionally trained in mental health. But, back then a lot of people didn't seek it because of shame, or embarrassment or taking medication they felt they didn't need. (133-137) 
Would have

spirituality to help

through therapy

Mental illness in

family

Watched how family member addressed mental health

Aware of family member's completed suicide

What factors influence your thoughts on therapy?
Know friends who have gone through something

Know friend who sought therapy

Saw therapy work for friend

Helped by friend

Encouraged by friend
... But today, I would encourage it, if I needed it; felt I needed it, I would seek help. And, I would have my spirituality to help me through that. (138-140) ... And, there's, was mental illness in my family. (92-93)

... But, he really didn't want others to know that. Just the family knew. He went to therapy, they gave him medication. I believe he started taking the medication. But not as regularly as he should have. (96-98)

... Eventually, one day he came home, put a gun to his head, and killed himself. It was a big shock to the whole family. We knew he had problems. We thought he was on his medication. Apparently, he just felt like he couldn't take it anymore. (104-107)

... I've known friends that have gone through tough times. Um, my first girlfriend went through a divorce before I did. And, she was just broken. ... And, she admitted that she had gone and sought help, professional help. (143144; 148-149)

.. And, it helped her. It pulled her out of that rut. She'd doing well now. (150151)

... And, she helped me! She was there for me. And, if she had of stayed broken, she wouldn't have been any help to me; very little. But, she was stronger by then and she was able to help me through what I needed. And she encouraged me, 'if 
to get help if needed

Relied on each other

Therapy can really help if active in attendance and taking medication

Fear of medication

Need to talk and sort things out

Coached through tough time

Shared therapy

strategies

Relationship stronger

Similar experiences

Felt comforted by

similarity

Felt understood

More than church

Can't share in church you need help; go get it. You know, you got three children, I had two. You have three. Get yourself together.' And, we're, we're, members of the same church also. So, yeah, we rely on each other. I've seen a change. It can really help, if you use it, you know the way you should. If your take your medication, go to your sessions. (153160)

... And a lot of times, people think, if you go for help, they're gonna put you on pills. Sometimes you just need to talk to somebody, professional. They need to sort things out, help you sort things out. (161-163)

... And, it was just a tough time. But she really helped me. Kinda coached me through it. And she shared everything she learned. 'You should do this. You should write down your feelings. You should do this. You should do this. And then go back and read and see where you were. See how far you've come.' (174-178)

... And it made our relationship stronger. Because some of the things she had already gone through. I shared with her. She said 'wow that happened to me too.' And you know, you're thinking you the only one. I said, man I went through that too. It was just, it was a comfort to have somebody there that could, really understood what I was going through. And encouraged me to seek the help I needed. You know, sometimes it more than church. 
Confidence in

confidentiality

Another perspective

Somewhere to vent

Professional

perspective

Relief to talk

What, if any

are the

connections

between

therapy and

spirituality for

you?
Sometimes she said 'you can't share everything with everybody in church.' Which is true. [Pause] and, you know that's the way it was. She told me, everything's confidential. Go, tell them how you feel. They'll help you sort it out. $(185-13)$

... And sometimes, we need another perspective. We just see it one way. You have, somewhere to vent and open up and get another perspective, a professional perspective; of maybe why things work the way they do. It, it gives you some relief. It gives you some relief. For me it does. (223-226)

... Just talking to others that have been there. It's tremendous, it really is [laughs]. It really is. (228-229)

Therapy connects and ... I think spirituality speaks to my helps my being to live fiber, what I'm made of. What I grew up in. My foundation, my connection with God, with a Higher Power. Therapy helps me connect that with being, living life. Putting it together, helping me make it day through, each day. (198-201)

... It gives me hope; my spirituality does. Always hope. Never give up. Keep praying. Keep connected with God. Therapy is a way to talk about how you're feeling; what's going on in your body physically. My spirituality is what I'm made of. (203-206)

Therapy helps me to ... And, my relationship with God. I function in a way that honors life know He gave me life, and aah, life to be abundant, not just a struggle every day. And to get, in order to feel abundant and whole, I had, my 
Therapy and spirituality are both valuable in maintaining the right frame of mind

Spirituality comes from Christian background

Nothing outside of belief system makes me feel spiritual

What thoughts can you share with me about spirituality?
Spirituality related to belief in Jesus Christ spirituality plays a big part. A big part, it's my connection, my relationship; and if therapy helps me hold it together, then so be it. (211-214)

... But I love being a grandmother and I want to be there for them. You know, whole! In the right frame of mind. Strong enough to be a support to them, for years to come. So, if I needed therapy, I'm gonna go get it. I don't care what the naysayers say; 'you don't need it. Just talk to your pastor.' Whatever, if I feel like I need that therapy, I going. But, I'll be in church too. $(257-261)$ ... I believe that I'm a spiritual person. Um, I believe that um, my spirituality comes from um my Christian background, my beliefs related to Christianity. And so, there's nothing outside of the, my belief system, which is in Christ, that would, would make me feel spiritual. So, I, I feel spiritual because of my belief in Jesus Christ. (13-17) ... Um, so just like I said, to me spirituality connects to Christianity, (19) ... and so there's nothing outside of Christianity that would make me feel spiritual. I feel spiritual because of my belief in Christ. (21-22)

Spirituality is being

Christ like

Connections to

everything tied to

belief system

What factors Belief in Jesus Christ influence your Christian upbringing thoughts on Pursuit of being a spirituality? better person based on
... being spiritual is also being Christ like and so therefore, my connections to everything else is tied to my belief system. (42-43)

Um, belief in Jesus Christ. Um, my Christian upbringing. Um, my aah current, um pursuit of um being a better person based on the Bible and 
tenets of the Bible

Working to be a

kinder

A person pleasing to

God

I believe in therapy

Good to talk to someone

Get another

perspective

Form thoughts about

What are your

thoughts on

seeking

therapy? the issue

Therapy useful its tenets. Um, I may have said this already, but you know, working to be a better person, to be a kinder person. $\mathrm{Um}$, to be a person who is pleasing to God. (28-31)

... So I obviously believe in therapy, fundamentally. I do believe that it's good to go and talk with someone about your, your feelings aah, your thoughts, some things that you may be experiencing. So, I definitely believe that it's good to do that. (52-55) ... Um, and I definitely believe that aah, it's good to sit down with someone to share your thoughts.

... To get um their perspective. Um, and then to help you form, aah, some opinions or some ideas and thoughts about what you're going through. (6163)

... Um, again, I do believe that, that there's a, it's useful. And, and, I do believe that people do need to be able to talk out their feelings with someone, to get a different perspective. (200-203)

... Um, and um I also think that it Therapy doesn't have to be formalized doesn't have to be formalized either. (203-204) ... [Pause] so, I definitely believe that um you know, counseling doesn't have to be or therapy doesn't have to be formal, in a formal setting; (223-225)

... I think that you know, a conversation

Conversations can be therapeutic if a real between two individuals can be

therapeutic. (203-205) ...that we as two 
dialogue takes place

between friends can

decrease the need for

therapy

Limited sharing

Receive specific

counsel during

conversation people, can, can dialogue and you know make one another feel better. (225-226)

... Um especially if, if there's, if there's really dialogue between the two. (205206)

... What I do have is, is being the counselor with her at times. (213) ... So, I don't um other than [pause] I would say other than um my daughter, aah probably is the person that I share the most personal with. (213-215)

... But, I can go to my daughter and say what I need to say; and get some spiritual counsel from her that makes me feel better. (222-223)

Needs met through conversations between individuals with shared belief systems

Conversation with friend can reduce need for formalized therapy
... Yeah, well um because if I can get; let's say it's you and I and we're friends and I can get what I need from, from you as my friend um along with my belief system, I don't wanna count that out at all because, that is my foundation, (231-233)

... but if I can, as a friend have someone who's hearing what I'm saying, understanding what I'm saying, aah to the best of her ability, and then giving me, giving me something back, that you know, encourages me or, or, or um if nothing else you know, I know what you, you know, I, what you are saying' um then that would decrease, at least for me, in my head um, the need for any kind of a formalized therapy session. (233-239) 


$\begin{array}{ll}\text { What factors } & \text { psychologist } \\ \text { influence your } & \\ \text { thoughts on } & \text { Ability to identify } \\ \text { therapy? } & \text { issue }\end{array}$

Would have talked to psychologist if available
Education

Training
Know a psychologist
Tried different things to address issue on own
... I have my, I have a master's degree in counseling. (52) ... for me um especially being in the, the counseling program, you know, you have your practicum and you have your internship that you have to do. (133134)

I have a handle on the ... Um, I have not done that personally, but um, I have thought about it. Um, I have thought about it recently, in fact. But, I think I have a handle on why aah, the issue, what the issue was, and what was causing the issue. (56-58) ... Um, in fact I actually was planning
on speaking to [name of psychologist
redacted]. And, and it was about some dreams that I'd been having. Um, and then I couldn't reach her aah for whatever reason. And then I decided that I knew what the reason was. So, um I didn't actually get that far. I would have, had I been able to reach her the day that I tried to contact her. But, since I didn't and I'm, and I'm tryin'a always figure out what is causing the, the dream issues. Aah, I did finally figure out, I think, what the issue is. (65-72)

\section{... Um, just trying different things}

before I went to bed. So, for example, um turning off the TV. Um, not going to bed with the TV on, well falling asleep with the TV on. Um, just taking some steps to make sleeping more comfortable, as opposed to, you know, letting the TV watch me sleep; and then you got your, your, you know you hearing things and you might even be seeing things too 
Prayer

Talked to husband who is a minister

Consistently prayed

Awareness about prayer and other factors that might change outcome

Low self-efficacy related to training program [laughs]. You know um that's, that's, interfering with your sleep. (74-79)

... so, it, it actually was a combination of thinking about what was going on um along with praying about what was going on and talking to my husband who is a minister, about what was going on, so. (103-105)

... um the, the dreams I've had for a long time. And I have prayed about them for a long time. Aah, but then I realized that you know, I can, I can be praying about something, (120-122) --- and maintaining bad habits on the other side. So, the praying and the maintaining of the bad habits aren't lining up so I got to change some things over here to line up with what I'm praying about and asking about. (124-126)

... Aah, but during that process, I felt that, that I personally couldn't do it. (137-138) ... So, what I realized was that for me personally that was not aah the avenue or the career choice for me; (141-142) ... But, I felt for me, it, it just wasn't for me. ... Um, I have to say, but, I didn't feel that, that I would be good at it for the client or for me. (153-155)

Personality construct would have impacted therapeutic style

What, if any Being in a relationship with someone who are the cares
... And I felt with that personality or that feeling, whatever you want to call that, maybe even a little bit of judgment, which is not really nice, but um that it wasn't for me. (147-149) ... I think it's more along the lines of, of what I've just been expressing about having a, um relationship, being in a 
between

therapy and

spirituality for Understands you you?

Shared faith

Connection with

friends to dialogue

and share relationship with someone who um

who, who cares about you. Um, who understands, pretty much who you are.

Aah, and the, the two things because, you know, my friends are gonna be, for the most part, I'm not saying I don't have friends who aren't Christians, but my, the my, my, close friends are Christians. So, um if, if I can connect, aah on a level with my, with, with my close friends um that allows us to a dialogue and share with one another um on, on any subject that we might be talking about; to me that connects them both. (244-252)

\section{Appendix I}

\begin{tabular}{|c|c|}
\hline \multicolumn{2}{|r|}{ Abstraction Table } \\
\hline Awareness and Access & $\begin{array}{l}\text { Exposure to someone else in therapy; Accessing therapy } \\
\text { normalized; Limited access to services and therapist of Color; } \\
\text { Limited access to therapy resources while growing up; Therapy not } \\
\text { discussed in Black families; No exposure to therapy; Aware of } \\
\text { chemical imbalances; Employment and volunteer work with mental } \\
\text { health agencies; Lack of information and understanding about } \\
\text { therapy; Training and studying of psychological concepts; Early } \\
\text { desire to help others; Encouraged by school counselor to pursue } \\
\text { career in counseling; Mom and dad participated in therapy; Know } \\
\text { friend who sought therapy; Saw therapy work for friend; Education }\end{array}$ \\
\hline $\begin{array}{l}\text { Connection between } \\
\text { therapy and spirituality }\end{array}$ & $\begin{array}{l}\text { Therapy and spirituality lightly connected; Therapy not seen as } \\
\text { separate from spirituality; Intertwined Spiritual concepts can be } \\
\text { used in therapy; Spiritual principles in used therapy provides }\end{array}$ \\
\hline
\end{tabular}


Effects of slavery

Exposed to therapy in church

God is enough

God Provides

Informal therapy

Levels of therapy and spirituality techniques and practical applications; Therapy connects and helps my being to live; Therapy connects the physical with the spiritual

Cultural mistrust; Effects of slavery; Generational scars; Betrayal produces lack of trust; Black people bombard by many things which can create bondage

Free access to therapy; Supported by therapist on staff at church; Recognized need for support in church; Church proactive regarding therapy; Church has counseling center; Open conversations in church; Therapeutic practices modeled in church

Godly Family; Seek God first; God is first in our lives; Spirituality is a choice; Therapy is benefited by spirituality, but spirituality is not benefited; God is complete; God created the world; Principles found in therapy are not new to God, we're just putting labels on things He is already aware of; Trust God; God head of household; God is in control; All I need is God; With God, therapy might not be needed

Therapy not needed because God provides all; Church provides what is needed to address concerns; God's provision is through a spiritual connection; Taught God provides; God's provision is for what is needed; God reveals what needs to be done; Sense of being cared for; A lot of things are based and rooted in God as the source; God provided support

Talked to elder and pastor of church; Profound advice; Desire to talk through feelings; Alternate support provided; Alternate support provided; Friends who are psychologist; Neutral person to discuss things with; Unbiased view of situations in life; Relied on each other; Even though it wasn't therapy, the experience felt similar; Coached through tough time; Shared therapy strategies; Therapy doesn't have to be formalized; Conversations can be therapeutic if a real dialogue takes place

Levels of operation; Different levels of therapy; A different level of support is needed; Therapy is not spiritual; Levels of support; Don't access therapy first; Prayer more spiritual than therapy; Build upon spiritual principles and practice through therapy; Spirituality as the foundation of therapy reinforces the application of spiritual principles practiced in therapy; May stop at prayer; 


\begin{tabular}{|c|c|}
\hline & $\begin{array}{l}\text { Therapy may provide a different benefit; Deeper levels may go } \\
\text { unresolved; Church didn't have the answers; Not separate; Therapy } \\
\text { and spirituality seamless; Increased comfort of integrating } \\
\text { spirituality in therapy }\end{array}$ \\
\hline $\begin{array}{l}\text { Life is hard, but I'm } \\
\text { resilient }\end{array}$ & $\begin{array}{l}\text { Resilience; Unresolved trauma or pain; Impact of childhood } \\
\text { experiences not understood until later in life; Traumatic } \\
\text { experiences; You'll get over it; Personal experiences and } \\
\text { background as an adult; Childhood experiences prevail; Different } \\
\text { experiences serve as basis for therapy; Experience of dealing with } \\
\text { different things in life; Life is not easy; it's tough; Make it through } \\
\text { tough situations; Experiences solidified beliefs; Experiences let me } \\
\text { know God is real; Let things go; I have a handle on the issue }\end{array}$ \\
\hline Privacy & $\begin{array}{l}\text { Privacy issues; Learned early to keep quiet; Issues stifled or } \\
\text { covered up; Desired to share but couldn't; Can't share in church' } \\
\text { Confidence in confidentiality; Limited sharing }\end{array}$ \\
\hline $\begin{array}{l}\text { Relationship with God } \\
\text { does not exclude therapy }\end{array}$ & $\begin{array}{l}\text { Therapy that provides a foundation in God is good; Comfortable } \\
\text { with Christian based therapy; Witnessed positive results of } \\
\text { Christian based therapy; God's leading may lead to therapy; } \\
\text { Therapy is a way that God provides help; Open to what and how } \\
\text { God provides; Take advantage of what God provides; Recognized } \\
\text { relationship with God does not exclude therapy; Spirituality and } \\
\text { therapy help with living and life; Licensed clinicians on staff; } \\
\text { Church supported therapy; Church practices shaped understanding } \\
\text { of therapy and modeled help seeking }\end{array}$ \\
\hline Relationships & $\begin{array}{l}\text { Godly role models; Friendship influenced the pursuit of God and } \\
\text { spiritual experiences; Peers and friends acted as sounding board; } \\
\text { God placed stepmother to be a constant source of support; Friend } \\
\text { helped to lay spiritual foundation; God put people in my life; Godly } \\
\text { role models; Support outside of family or origin to pursue dreams; } \\
\text { Mentored by spiritual people; Spiritual mothers who guided and } \\
\text { mentored; Faith connected to family; Faith connected to family; } \\
\text { Responses to difficult circumstances modeled in family; } \\
\text { Understanding of God grows over time and through different } \\
\text { experiences; How God revealed Himself to the Jews; Influenced by } \\
\text { church members, friends, and other adults; Mother connected to } \\
\text { God; Mother connected to church; Connected together in church; } \\
\text { Feel connected to God; Experiences and relationships related to } \\
\text { therapy; Know me and my relationship with God means knowing }\end{array}$ \\
\hline
\end{tabular}


Shame/Stigma

Spirituality

Therapy as a resource my ultimate hope is in God; Relationship with God modeled in family; Being in a relationship with someone who cares;

Connection with friends to dialogue and share

Shame; Afraid of child being labeled so did not follow through with suggestion; Timing determines pursuing therapy; Stigma in family; Stigma in church; Exposed to the perspective of older family members who believe therapy is quackery and prayer is sufficient for any concern; Negative stigma within certain cultures; Negative experiences of therapy may skew perspective; Fear of being view incapable of taking care of self; Recognize the stigma associated to therapy for people of color; Advocacy/Stigma reduction; No desire to take medication; Shameful to seek help beyond the church; Shame/embarrassment; Fear of taking medications

Bible reveals God's plan for us; Inner man; Spirituality is connecting with God; Spirituality is our being; Spirituality is connection between individual and God; Spirituality impacts wellbeing of the whole person; Feel and understand what's going on and be blessed; Internal place; Spirituality is being Christ like; Connections to everything tied to belief system; Looked upon as a crutch; Surrounded by spirituality in the Black community; Consistently attended church born and raised in; Spiritual practices; Scriptures, the Bible; Increased knowledge of a relationship with Christ; Exposure to different belief systems; Prayer shared in a community; Spirituality grounded in what you do based upon what you believe; Openness related to spirituality is a lifestyle starting with home of origin; Church an escape from home; Helps us function the way God intended; Faith grew out of what taught as a child; Consistently chose; Many unaware of the impact of spiritual factors on life; Spirituality helps me through; Nothing outside of belief system makes me feel spiritual; Various experiences over the years shape understanding of spirituality

Therapy great; Everybody needs therapy; Therapy helps to define where you need to be; Therapy like medicine; Would seek if felt it was needed; Therapy used for crisis, as well as, preventatively; Appreciate what therapy has to offer; Therapy helpful; Would encourage family and friends to seek therapy; Therapy helps me to function in a way that honors life; Good to talk to someone; Get another perspective; Therapy useful 
Therapy a temporary fix; Therapy needs to connect with Christianity; Without spirituality, therapy may be superficial and Therapy is a temporary fix not address the root of what's going on for the individual; Without spirituality, therapy may act as a band aid and leave ultimate questions unanswered

Groundwork laid; Non-toxic environment; Influence of home of origin and upbringing; Brought up in church; Raised in Christian Upbringing family; Upbringing; Witness to individuals being helped; Taught to believe in God; Growing up in church; Belief in God valued; Stuck with what was familiar; A part of upbringing; Made to go to church; Christian upbringing

Spirituality offers those in therapy the realization they are not alone; Even if I feel alone, I'm not alone; Life circumstances

You are not alone created a need for therapy or assistance but trusting in spiritual foundations and knowing God will not leave or forsake you; Constancy of God; Feel in heart; Feel like prayers heard 